Portland State University

PDXScholar

$11-2018$

\title{
Incorporate Emerging Travel Modes in the Regional Strategic Planning Model (RSPM) Tool
}

\author{
Liming Wang \\ Portland State University, limwang@pdx.edu \\ Joseph Broach \\ Portland State University, jbroach@pdx.edu \\ Huajie Yang \\ Portland State University, huajie@pdx.edu
}

Follow this and additional works at: https://pdxscholar.library.pdx.edu/trec_reports

Part of the Transportation Commons, Urban Studies Commons, and the Urban Studies and Planning Commons

Let us know how access to this document benefits you.

\begin{abstract}
Recommended Citation
Wang, Liming, Joseph Broach, and Huajie Yang. Incorporate Emerging Travel Modes in the Regional Strategic Planning Model (RSPM) Tool. NITC-RR-881. Portland, OR: Transportation Research and Education Center (TREC), 2018. https://doi.org/10.15760/trec.209
\end{abstract}

This Report is brought to you for free and open access. It has been accepted for inclusion in TREC Final Reports by an authorized administrator of PDXScholar. Please contact us if we can make this document more accessible: pdxscholar@pdx.edu. 
FINAL REPORT

Incorporate Emerging Travel Modes in the Regional Strategic Planning Model (RSPM) Tool

NITC-RR-881 November 2018

NITC is a U.S. Department of Transportation national university transportation center.

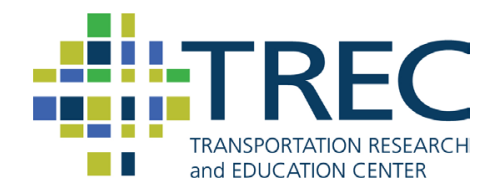




\title{
INCORPORATE EMERGING TRAVEL MODES IN THE REGIONAL STRATEGIC PLANNING MODEL (RSPM) TOOL
}

\author{
Final Report \\ NITC-RR-881 \\ by \\ Liming Wang \\ Joseph Broach \\ Huajie Yang \\ Portland State University
}

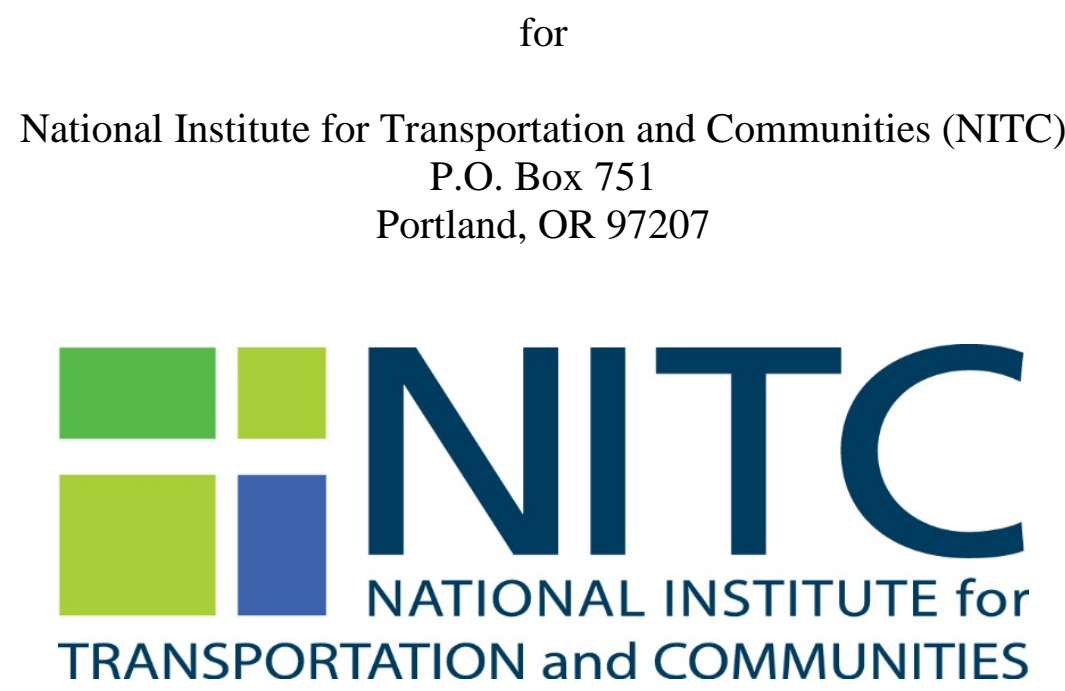

November 2018 


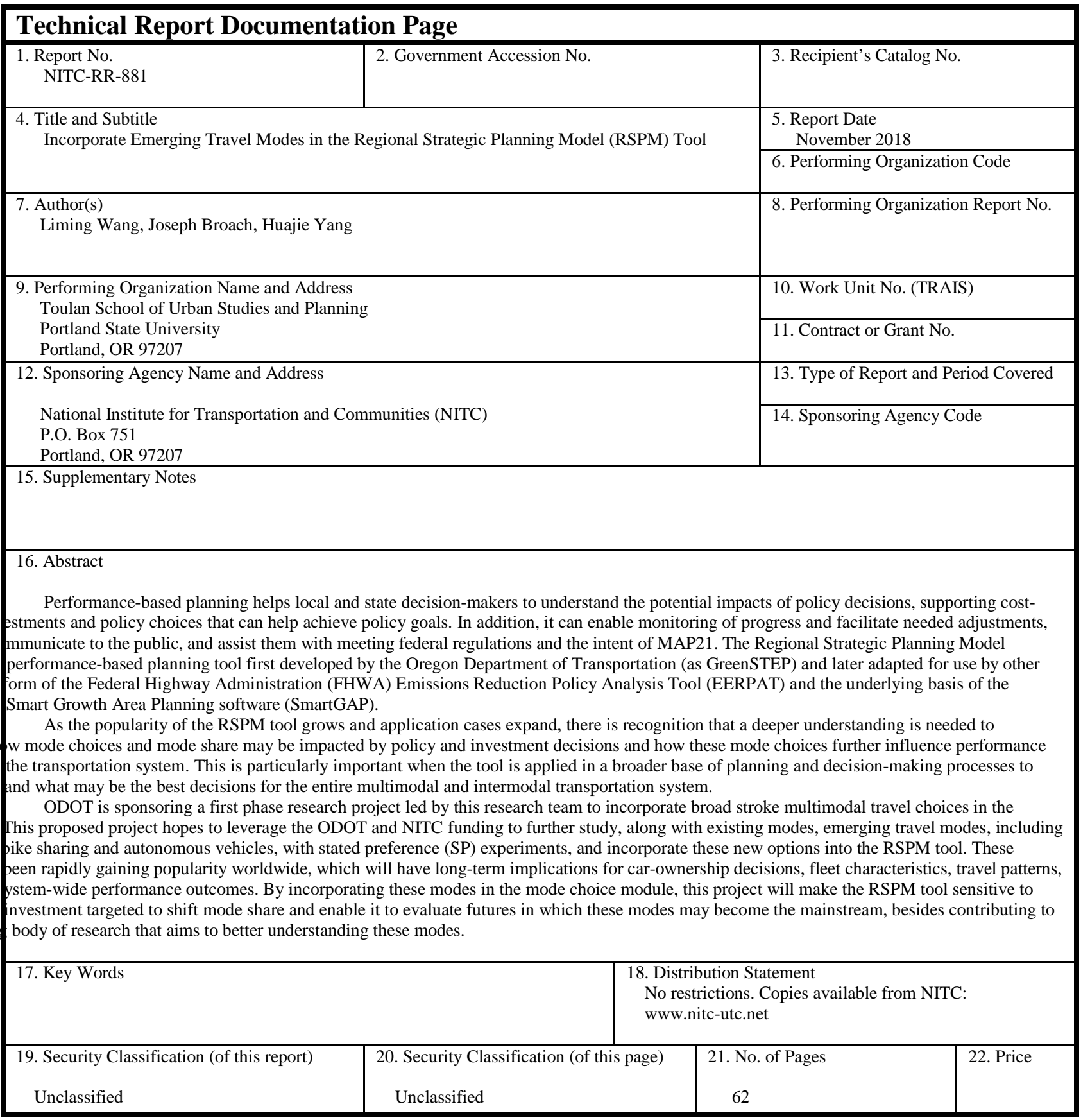




\section{ACKNOWLEDGEMENTS}

The investigators of the project would like to acknowledge support from the National Institute for Transportation and Communities (NITC) under grant number (881) and the Oregon Department of Transportation under grant number SPR-788.

\section{DISCLAIMER}

The contents of this report reflect the views of the authors, who are solely responsible for the facts and the accuracy of the material and information presented herein. This document is disseminated under the sponsorship of the U.S. Department of Transportation University Transportation Centers Program and Oregon DOT in the interest of information exchange. The U.S. Government and Oregon DOT assumes no liability for the contents or use thereof. The contents do not necessarily reflect the official views of the U.S. Government and Oregon DOT. This report does not constitute a standard, specification, or regulation.

\section{RECOMMENDED CITATION}

Wang, Liming, Joseph Broach, and Huajie Yang. Incorporate Emerging Travel Modes in the Regional Strategic Planning Model (RSPM) Tool. NITC-RR-881. Portland, OR: Transportation Research and Education Center (TREC), 2018. 


\subsection{TABLE OF CONTENTS}

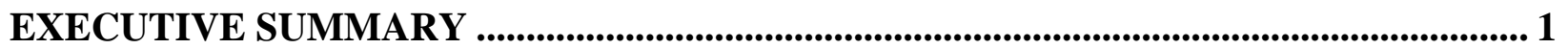

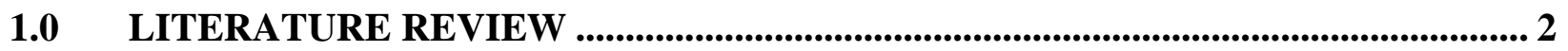

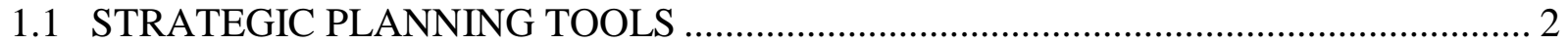

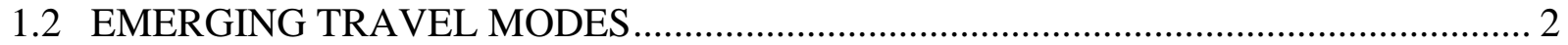

1.2.1 Car and Bicycle Share Systems ....................................................................... 2

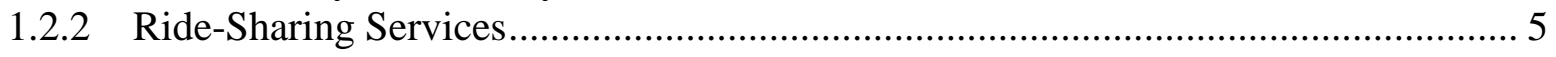

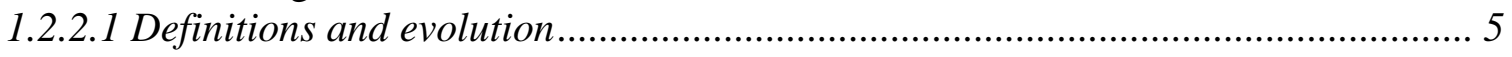

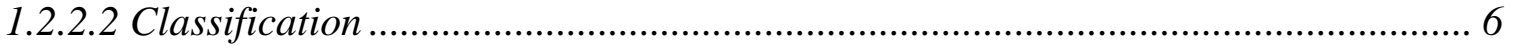

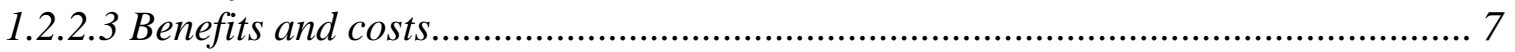

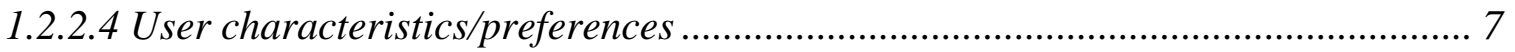

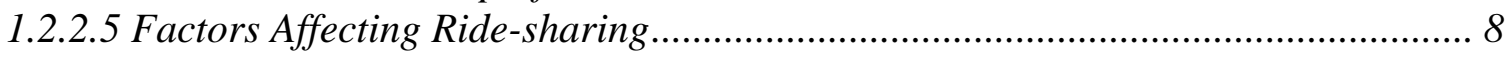

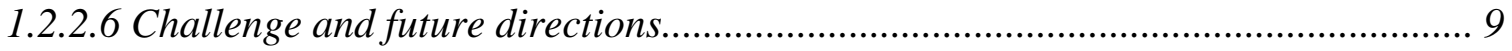

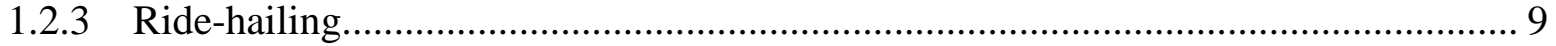

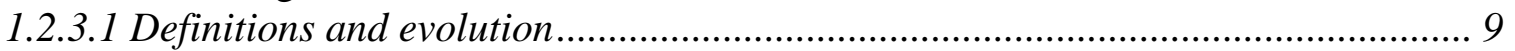

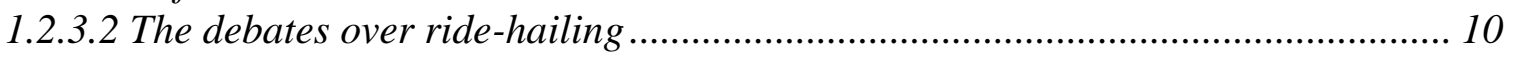

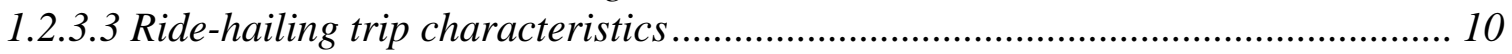

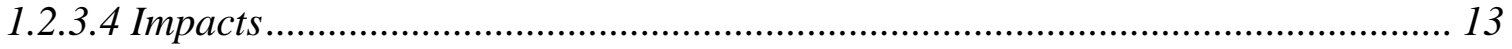

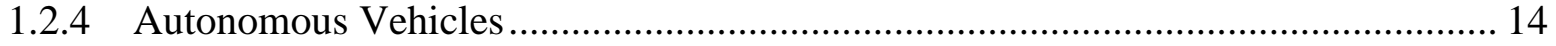

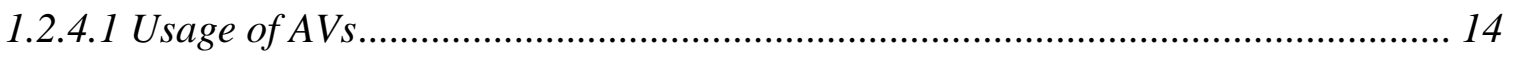

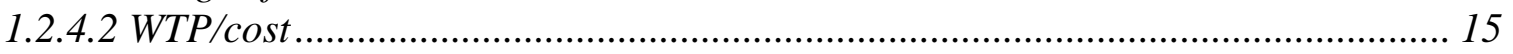

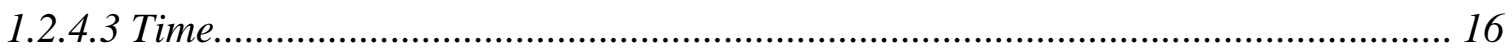

1.2.4.4 The Role of Socio-demographic Characteristics, Attitude, and Trip Attributes... 17

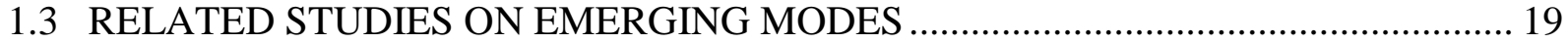

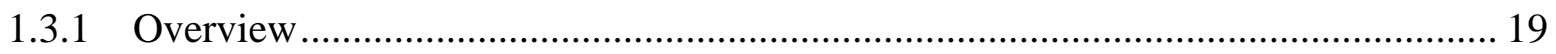

1.3.2 Modeling Approaches ............................................................................... 20

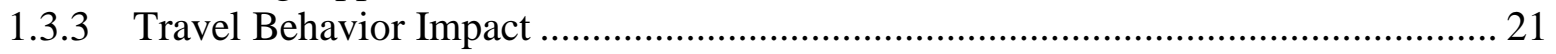

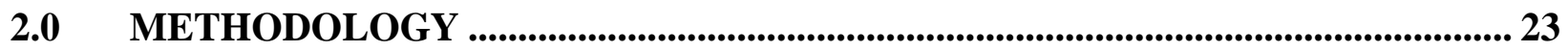

2.1 STATED PREFERENCE APPROACH.............................................................. 23

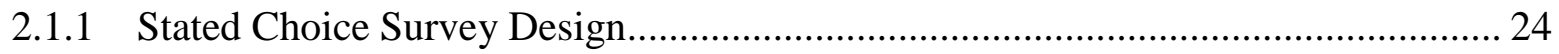

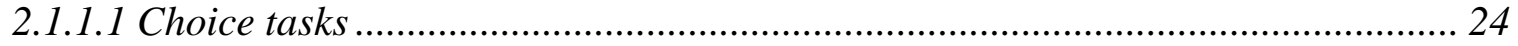

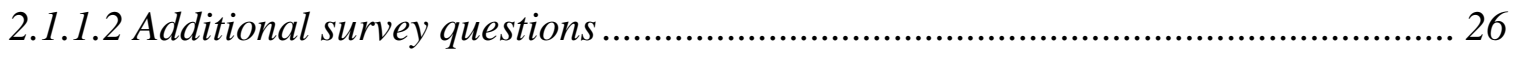

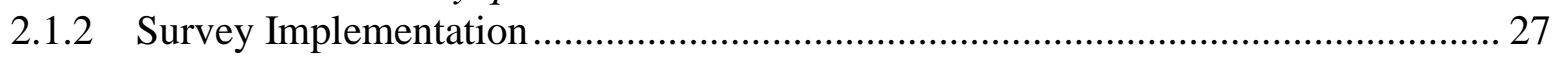

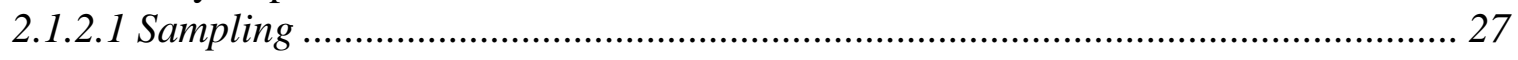

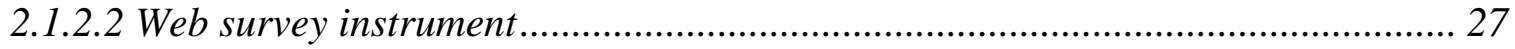

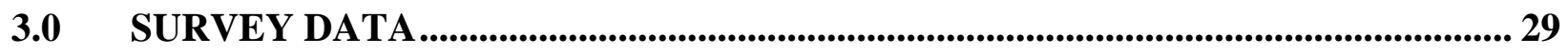

3.1 SOCIO-DEMOGRAPHIC CHARACTERISTICS …................................................ 29

3.2 DESCRIPTIVE STATISTICS OF REVEALED PREFERENCE (RP) DATA............... 41

3.3 DESCRIPTIVE STATISTICS OF STATED PREFERENCE (SP) CHOICE

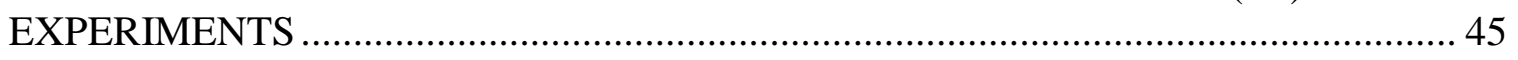

4.0 MODELING THE STATED PREFERENCE CHOICE EXPERIMENTS............. 49

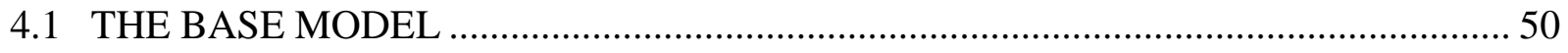

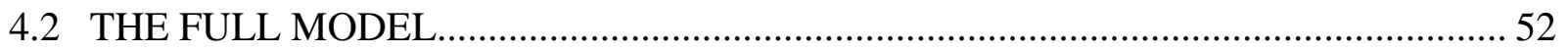




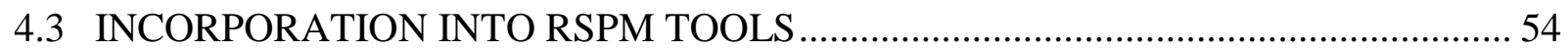

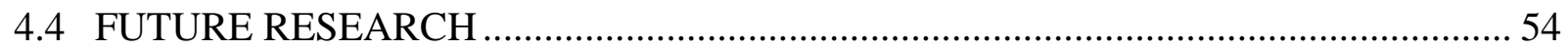

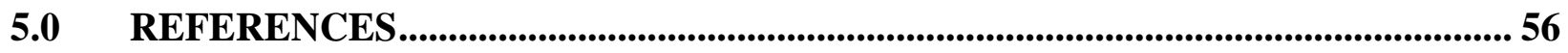

\section{LIST OF TABLES}

Table 1.1: Cost estimates of floating car-sharing services ........................................................... 3

Table 1.2: Cost estimates of public bicycle sharing ………....................................................... 4

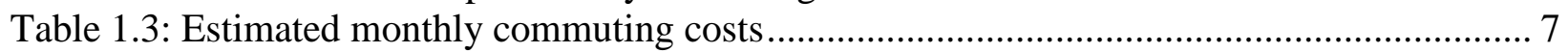

Table 1.4: Cost estimates of ride hailing services............................................................................ 12

Table 1.5: Cost estimates of shared autonomous vehicles (SAVs) and ride sharing autonomous

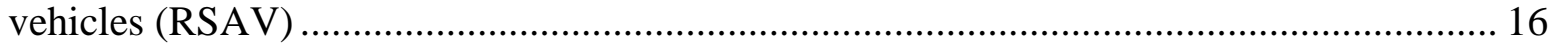

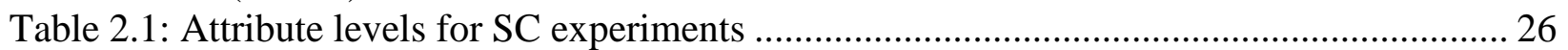

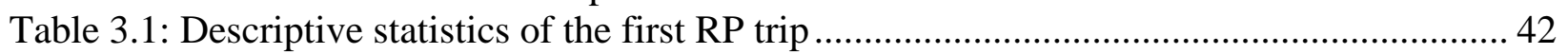

Table 3.2: Descriptive statistics of the second RP trip ………....................................................... 42

Table 3.3: Mode share of RP trips by trip purpose ...................................................................... 43

Table 3.4: Mode share of SP choice experiments by trip purpose................................................ 47

Table 4.1: Model specification of the base model ........................................................................ 51

Table 4.2: Value of time and willingness to pay derived from the base model............................. 52

Table 4.3: Model specification of the full model........................................................................... 52

Table 4.4: Value of time and willingness to pay derived from the full model ............................... 54

Table 4.5: Value of time and willingness to pay derived from the full model for employed

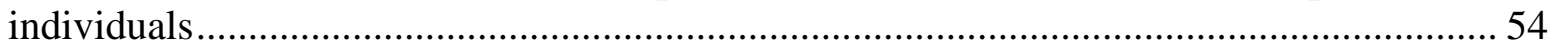

\section{LIST OF FIGURES}

Figure 2.1: Emerging mode alternatives .............................................................................. 25

Figure 2.2: Sample choice task from (a) web and (b) mobile survey. Current option was walking,

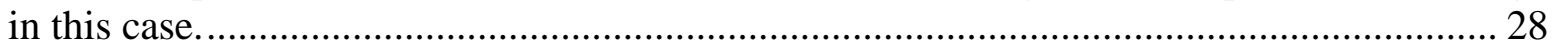

Figure 3.1: Number of survey respondents by UZA................................................................ 29

Figure 3.2: Number of survey respondents by household income................................................ 30

Figure 3.3: Status of owning/renting home................................................................................ 31

Figure 3.4: Distribution of household size of participants........................................................... 32

Figure 3.5: Age distribution of survey respondents by gender ........................................................ 33

Figure 3.6: Race/Ethnic characteristics of survey respondents ...................................................... 34

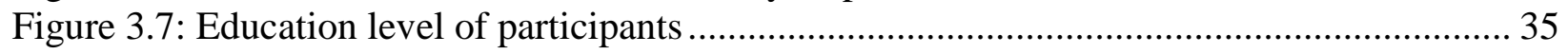

Figure 3.8: Hours worked per week by number of jobs ................................................................. 36

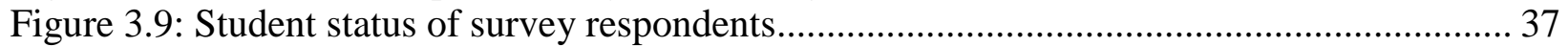

Figure 3.10: Mode and technology availability of participants .................................................... 38

Figure 3.11: Number of participants by who pays for parking pass .............................................. 39

Figure 3.12: Number of participants by who pays for transit pass ................................................. 40

Figure 3.13: Self-report health condition................................................................................ 41 
Figure 3.14: Frequency by mode and purpose of the first recalled trip ..................................... 42

Figure 3.15: Frequency by mode of the second recalled trip................................................... 43

Figure 3.16: Calculated average in-vehicle speed (miles/hour) of the first recalled trip by mode44

Figure 3.17: Calculated average in-vehicle speed (miles/hour) of the second recalled trip by

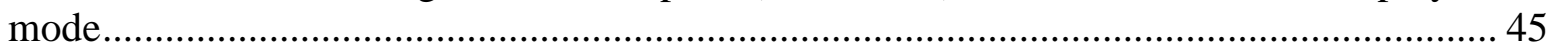

Figure 3.18: Share of SP mode by mode used for the recalled trips by trip purpose .................. 47 


\section{EXECUTIVE SUMMARY}

In recent years, a set of new travel modes - including car sharing, bike sharing, ride-hailing, and autonomous vehicles - are emerging as both policy and travel options throughout the U.S. These emerging modes are only just beginning to be considered in travel modeling applications, and our understanding of their likely impacts on travel behavior is limited. Given the innate uncertainties in the evolution of these emerging modes, modeling applications need to consider these questions when evaluating effects of policy scenarios. Strategic planning models facilitate the consideration of these uncertainties and enable rapid evaluation of technology and policy scenarios by focusing on their first-order effects. Regional Strategic Planning Models (RSPM) are examples of such planning tools, initially developed by the Oregon Department of Transportation (ODOT) and later modified for adoption by other states and authorities. The goal of this paper is to first enhance and then apply RSPM to consider the effects of emerging modes.

Using data from a nationwide U.S. survey with stated choice experiments that include both conventional and emerging mode options, we develop stated preference utility models to understand the changes in travel behavior. We then implement our estimated models for RSPM to enable it to simulate scenarios with different market penetration of emerging modes. We consider both how existing strategies may be impacted by emerging modes, as well as potential strategies that seek to harness these new travel options to meet performance goals.

Incorporating emerging modes in an existing strategic planning tool allows us to understand and evaluate scenarios in which these modes may become the mainstream, besides contributing to the emerging body of research that aims to better understand these modes. New technologies and travel options present both policy opportunities and challenges for planners and decisionmakers. Strategic models are a promising arena for initial applications that include these new alternatives. 


\subsection{LITERATURE REVIEW}

\subsection{STRATEGIC PLANNING TOOLS}

The Regional Strategic Planning Model (RSPM) is a performance-based planning tool first developed by the Oregon Department of Transportation (ODOT) as GreenSTEP, a primary tool for analyzing state-wide greenhouse gas emission scenarios. GreenSTEP has been adapted by the FHWA as the Emissions Reduction Policy Analysis Tool (ERPAT) to "assist state transportation agencies with analyzing greenhouse gas reduction scenarios and alternatives for use in the transportation planning process, the development of state climate action plans, scenario planning exercises, and to measure the reduction potential of various transportation strategies to meet state greenhouse gas reduction goals and targets” (FHWA, 2015). GreenSTEP was also adapted as the underlying basis of the SHRP2 C16 Smart Growth Area Planning software (SmartGAP), a tool for evaluating the impacts of various regional smart growth strategies on travel demand (Outwater et al., 2014). In 2010, GreenSTEP won a national award from the American Association of State Highway Transportation Officials (AASHTO). The RSPM tool is a version of GreenSTEP re-envisioned for use at the metropolitan level. Current work is underway in a partnership between FHWA and ODOT to create a common framework for the GreenSTEP family of models that are open, modular, scalable and accessible.

Compared with other sketch planning tools, the RSPM tool operates at the county or metropolitan planning organization level and with model coefficients estimated from data with national coverage, such as the National Household Travel Survey (NHTS). It can work as a policy evaluation tool for areas without travel demand models or emission modeling experience, or as a quick policy screening tool for areas that do use more complex models. It is capable of evaluating effects of land use policies, demographics, vehicle fleet characteristics, and a large set of policies in transportation supply and pricing.

As the popularity of the RSPM tool grows and application cases expand, there is recognition that a deeper understanding is needed to determine how mode choices and mode share may be impacted by policy and investment decisions and how these mode choices further influence performance outcomes of the transportation system. ODOT is sponsoring a first-phase research project led by this research team to incorporate broad stroke multimodal travel choices, including driving, transit and non-motorized mode, in the RSPM tool.

\subsection{EMERGING TRAVEL MODES}

\subsubsection{Car and Bicycle Share Systems}

Car sharing, as considered in this research, refers to systems that allow a traveler to check out an available car from a public parking space or other designated location, drive to their destination, and leave the car in any allowable parking space nearby. This operating model is referred to as "free-floating" car sharing, as opposed to those requiring a user to return the car to the same location where they picked it up or to some other fixed station location. Typically, the services 
charge per minute and require the user to have a valid driver's license, download a smartphone app and perhaps become a member for some nominal fee. Examples in the U.S. are car2go and ReachNow. At the time of this research, we identified seven U.S. cities with car2go and three with ReachNow (Table 1.1).

Shaheen, Chan and Micheaux (2015) provide a recent review of car sharing in the Americas. Current research on these emerging travel modes has largely focused on documenting the characteristics of the shared mode and its users. For example, Burkhardt and Millard-Ball (2006) surveyed the user characteristics of fixed-station car sharing programs across North America. Wielinski et al. (2015) looked into the user characteristics of free-floating car sharing in Montreal and found that women were more likely to become users, and that trip distances and durations were much shorter than traditional car sharing.

Table 1.1: Cost estimates of floating car-sharing services

\begin{tabular}{|c|c|c|c|}
\hline Service & City & Cost (\$/mi) & $\begin{array}{l}\text { Notes (peak/off-peak, surge/normal, } \\
\text { etc.) }\end{array}$ \\
\hline car2go & Portland/Seattle & $\begin{array}{l}\text { Smart Fortwo }{ }^{1}: 0.35 / \text { minute, } \\
\text { \$15/hr,\$59/day } \\
\text { GLA/CLA }{ }^{2} \text { \$0.45/minute, } \\
\text { \$19/hr, \$79/day }\end{array}$ & Per trip driver protection fee: $\$ 1$ \\
\hline car2go & Austin & $\begin{array}{l}\text { Smart Fortwo: 0.41/minute, } \\
\text { \$15/hr,\$59/day } \\
\text { GLA/CLA: \$0.47/minute, } \\
\text { \$19/hr, \$79/day }\end{array}$ & Per trip driver protection fee: $\$ 1+$ taxes. \\
\hline car2go & Columbus & $\begin{array}{l}\text { Smart Fortwo: \$0.41/minute, } \\
\text { \$13/1-hour package, } \\
\text { \$29/3-hour package, } \\
\text { \$49/6-hour package, } \\
\text { \$69/1-day package, \$99/2-day } \\
\text { package }\end{array}$ & Per trip driver protection fee: $\$ 1+$ taxes. \\
\hline car2go & Denver & $\begin{array}{l}\text { GLA/CLA: \$19/1-hour package, } \\
\text { \$39/3-hour package, } \\
\text { \$59/6-hour package, } \\
\text { \$89/1-day package, \$169/2-day } \\
\text { package }\end{array}$ & Per trip driver protection fee: $\$ 1+$ taxes. \\
\hline car2go & New York City & Smart Fortwo: \$0.41/minute, & Per trip driver protection fee: $\$ 1+$ taxes. \\
\hline car2go & Washington & $\begin{array}{l}\text { Smart Fortwo: \$0.41/minute } \\
\text { GLA/CLA: \$19/1-hour package, }\end{array}$ & Per trip driver protection fee: $\$ 1+$ taxes. \\
\hline ReachNow & Seattle/Portland & $\begin{array}{l}\text { Per minute } \\
\$ 0.41 / \text { minute when driving }\end{array}$ & \\
\hline ReachNow & Brooklyn & $\begin{array}{l}\text { Per minute } \\
\$ 0.41 / \text { minute when driving }\end{array}$ & \\
\hline
\end{tabular}

${ }^{1}$ Smart Fortwo refers to a two-seat vehicle

${ }^{2}$ GLA/CLA refers to a more conventional five-seat Mercedes-Benz vehicle

Public bike-share systems (BSS) refer here to those allowing members or walk-up users to check out a bike at one place and return it to another place near their destination. Traditionally, these 
systems have relied on fixed-station locations where the bicycles are docked and undocked to check in and out, but advances in GPS technology have permitted “dockless” BSS that allow operation without fixed stations (or with a mix of stations and dockless operation). As of mid2017, over 150 bike-share systems were either operating or due to launch in the U.S. (McNeil et al., 2018), and that number has likely grown even larger as dockless providers enter new and existing markets. Our own scan at the outset of this project found that 39 of the top 50 U.S. cities had public bike-share systems.

Similar to the car-sharing literature, existing research has focused mainly on operational and user characteristics of bike share. Fishman, Washington and Haworth (2013) and Fishman (2016) provide recent reviews. Noted are numerous studies supporting the notion that bike-share users are more likely to be higher income, more educated and to be employed than the general population (Fishman et al., 2013). Another common finding is that bike share is used most commonly as a substitute for public transit or walking, though in some locations $20 \%$ or more of bike-share trips substitute for car travel (Fishman, 2016).

Unlike free-floating car share, bike-share systems have traditionally operated largely on membership models, where a certain amount of riding is included at no additional charge. This makes direct cost comparisons with other mode options difficult. We reviewed a number of systems that priced rides by the minute or by the trip to inform our survey design, and the results are presented in Table 1.2.

Table 1.2: Cost estimates of public bicycle sharing

\begin{tabular}{|c|c|c|c|c|}
\hline Source & Service & City & Cost & $\begin{array}{l}\text { Notes (peak/off- } \\
\text { peak, } \\
\text { surge/normal, } \\
\text { etc.) }\end{array}$ \\
\hline https://www.biketownpdx.com/ & Biketown & $\begin{array}{l}\text { Portland, } \\
\text { OR }\end{array}$ & $\$ 0.08 / \mathrm{min}$ & $\begin{array}{l}\text { After one-time } \\
\$ 5 \text { signup fee }\end{array}$ \\
\hline https://www.capitalbikeshare.com/ & $\begin{array}{l}\text { Capital } \\
\text { Bikeshare }\end{array}$ & $\begin{array}{l}\text { Washington } \\
\text { DC }\end{array}$ & \$2/trip & Up to 30 mins \\
\hline https://www.citibikenyc.com/ & CitiBike & New York & N/A & $\begin{array}{l}\text { Pass options } \\
\text { only }\end{array}$ \\
\hline https://www.divvybikes.com/pricing & Divvy & Chicago & \$3/trip & Up to 30 mins \\
\hline https://www.bluebikes.com/ & BLUEbikes & Boston & $\$ 2.50 /$ trip & \\
\hline https://bikeshare.metro.net/ & $\begin{array}{l}\text { Metro Bike } \\
\text { Share }\end{array}$ & $\begin{array}{l}\text { Los } \\
\text { Angeles }\end{array}$ & \$3.50/trip & Up to 30 mins \\
\hline https://www.ofo.com/us/en & $\begin{array}{l}\text { Ofo Bike } \\
\text { Share }\end{array}$ & $\begin{array}{l}\text { Seattle } \\
\text { (\&others) }\end{array}$ & $\begin{array}{l}\text { \$1/hr } \\
(\$ 0.0167 / \mathrm{min})\end{array}$ & \\
\hline https://www.limebike.com/help & LimeBike & $\begin{array}{l}\text { Seattle } \\
\text { (\&others) }\end{array}$ & $\begin{array}{l}\$ 1 / \mathrm{half} \mathrm{hr} \\
(\$ 0.0333 / \mathrm{min})\end{array}$ & \\
\hline $\begin{array}{l}\text { http://seattlerefined.com/lifestyle/limebike-vs- } \\
\text { spin-which-one-is-the-better-bike-share }\end{array}$ & Spin & $\begin{array}{l}\text { Seattle } \\
\text { (\&others) }\end{array}$ & $\begin{array}{l}\text { \$1/half hr } \\
(\$ 0.0333 / \mathrm{min})\end{array}$ & \\
\hline $\begin{array}{l}\text { https://houston.bcycle.com/top-nav- } \\
\text { pages/rates-membership/rates2 }\end{array}$ & $\begin{array}{l}\text { Houston } \\
\text { Bcycle }\end{array}$ & Houston & $\begin{array}{l}\$ 3 / 30 \mathrm{mins} \\
(\$ 0.033 / \mathrm{min})\end{array}$ & \\
\hline
\end{tabular}




\subsubsection{Ride-Sharing Services}

\subsubsection{Definitions and evolution}

Neoh et al. (2017) define ride-sharing as two or more persons who are not household members travel in the same private vehicle. Ride-sharing groups are at least two participants who have joint trips in one vehicle. Carpooling and vanpooling are typical forms of ride-sharing. Carpooling participants share a private automobile, and vanpooling participants share a ride in a van. Ride-sharing is not limited to these two forms. There are also other forms, such as casual carpooling. Ride-sharing is not intended to gain financial profit, which is quite different from existing taxis and ride-hailing services. The payment of ride-sharing only covers part of driving costs.

Ride-sharing is classified based on its characteristics. Chan and Shaheen (2012) propose a ridesharing classification scheme based on how ride-sharing appears today and the relationship between ride-sharing participants. According to their classification scheme, there are three types of ride-sharing: acquaintance-based ride-sharing, organization-based ride-sharing and ad-hoc ride-sharing. The participants of acquaintance-based ride-sharing are typically family members, friends and coworkers. The participants of organized-based ride-sharing are members of a ridesharing service provider. The ad-hoc" ride-sharing is casual carpooling, which does not require a relationship between participants. Furuhata et al. (2013) classify ride-sharing into organized ridesharing and unorganized ride-sharing. In their classification, unorganized ride-sharing includes acquaintance-based ride-sharing and ad-hoc ride-sharing. Organized ride-sharing is the same as organized-based ride-sharing. For organized ride-sharing, there are two types of service provider: service operators and matching agencies. Matching agencies do not own their own vehicles and drivers, while they only match drivers and passengers. Service operators use vehicles and drivers and provide service to passengers, such as vanpooling and airport shuttle.

A comprehensive overview of the evolution of ride-sharing is essential to understand ridesharing. The earliest form of ride-sharing, "car clubs" or "car sharing," began in the 1940s. Such ride-sharing is supported by the government to conserve fuel during World War II. Based on an overview of ride-sharing's history, Chan and Shaheen (2012) classify ride-sharing into five key phases. The first phase is called car sharing clubs (1942-45). The objective of car-sharing clubs is to conserve rubber during World War II. The matching between riders and drivers is through a bulletin board at work. Phase two lasted from the late 1960s to 1980. In the late 1960s, ridesharing reappeared. Due to the energy crisis and the Arab oil embargo during the 1970s, ridesharing developed significantly. In this period, vanpooling, HOV lanes and governmentsponsored commuter ride-sharing demonstration projects, as well as other strategies, contributed to the rapid growth of ride-sharing. Phase three was from 1980 to 1997. The objective of ridesharing became improving congestion and air quality. The availability of telephone and internet facilitated the matching between drivers and passengers. During this phase, the competitiveness of ride-sharing decreased because of the low price of gasoline. Phase four was between 1999 and 2004. The objective of ride-sharing during this period focused on traffic congestion mitigation. The "critical mass" was still a big issue for most ride-sharing systems, thus the most efforts of the ride-sharing system were spent on encouraging ride-sharing among commuters. The internet played a more important role in ride matching. Some online ride-sharing "platforms" appeared during this period. Before 1999, the website pages mainly provided contact information. The 
next phase was from 2004 to the present, the period when the internet, mobile phones, social networking and ride-sharing were integrated. Most of the ride matching process was completed on websites through a ride-sharing software platform. Drivers and passengers get real-time detailed information, which facilitates ride-sharing. Such dynamic or real-time ride-sharing systems automatically match drivers and passengers in very short time (Agatz et al., 2011).

\subsubsection{Classification}

Furuhata et al. (2013) use two taxonomic criteria, primary search criteria and target market, to classify ride-sharing matching agencies. The primary search criteria refer to the information used for matching drivers and passengers. The target markets refer to the market segmentation based on demand types of ride-sharing participants. Based on the taxonomic criteria, they classify 39 matching agencies investigated into six classes: dynamic real-time ride-sharing, carpooling, long-distance ride-match, one-shot ride-match, bulletin-board, and flexible carpooling.

Dynamic real-time ride-sharing is the most recent class. With the proliferation of the internet and smart phone, this type of ride-sharing becomes increasingly important. It matches drivers and passengers, and automatically specifies pick-up and drop-off locations in a very short time or even en route. At the same time, matching agencies propose a cost for all participants.

The second type of ride-sharing is carpooling. Carpooling mainly serves commuters who have close origin-destination (OD) pair, and start and end times of their work. Typically, the vehicle used for ride-sharing is a private vehicle of one participant.

The third type is long-distance ride-match. Typically, participants of this type of ride-sharing have more flexibility for schedules than those of the above two types of ride-sharing. Some matching agencies provide existing travel lists for users, then users can select a preferred departure time among the travel lists.

One-shot ride-match combines the characteristics of carpooling and long-distance ride-sharing. Matching agencies provide several ride-matching methods for users according to trip types. These matching methods are similar to those used for long-distance, ride-matching and carpooling ride-sharing. Besides OD pair and time, matching agencies also provide lists, keywords, and route as search criteria.

Bulletin-board ride-sharing matches drivers and passengers via notice board. Ride-sharing offers and requests are listed by matching agencies. The matching between drivers and passengers are based on keywords/list. Typically, drivers and passengers decide the ride-sharing conditions together.

Flexible carpooling refers to ride-sharing that is formed through coordination on the spot. Flexible carpooling does not need match agencies. The pick-up/drop-off location and time are predetermined and known by potential users. A representative example is people sharing a vehicle to use HOV lanes. Typically, such ride-sharing is based on a first come, first serve strategy. 


\subsubsection{Benefits and costs}

Benefits include reducing vehicle trips and, consequently, decreasing traffic congestion and pollution emission and providing an alternative mode choice for people who do not own a vehicle or cannot drive. Ride-sharing provides time savings if the trip uses HOV lanes.

Ride-sharing includes carpooling and vanpooling. Generally, the vehicles used for carpooling are private automobiles, while the vehicles used for vanpooling are rented vans. Participants of ridesharing share operating costs. The incremental costs of ride-sharing are relatively low because it uses empty vehicle seats. Because ride-sharing does not need a paid driver and backhauls, the costs per vehicle-mile tend to be lower than transit. Due to its characteristics, ride-sharing is a cost-efficient mode. Table 1.3 shows the cost of driving alone and ride-sharing.

Table 1.3: Estimated monthly commuting costs

\begin{tabular}{l|l|l|l}
\hline Round-trip miles & Drive alone & Three-rider carpool & 10-rider vanpool \\
\hline 30 & $\$ 193$ & $\$ 64$ & $\$ 31$ \\
\hline 40 & $\$ 257$ & $\$ 86$ & $\$ 37$ \\
\hline 50 & $\$ 321$ & $\$ 107$ & $\$ 43$ \\
\hline 60 & $\$ 386$ & $\$ 129$ & $\$ 50$ \\
\hline 70 & $\$ 450$ & $\$ 150$ & $\$ 56$ \\
\hline 80 & $\$ 514$ & $\$ 171$ & $\$ 63$ \\
\hline
\end{tabular}

Source: Ride-sharing, Carpooling, and Vanpooling TDM Encyclopedia, Victoria Transport Policy Institute, 2017

Wambalaba et al. (2004) summarized average operating costs for vanpooling, and they found the operating costs range from $\$ 1,000$ to $\$ 1,250$ per month. Giuliano et al. (1995) investigated one ride-match project in Los Angeles. They found that the setup and marketing of this project needs $\$ 150,000$ (U.S. dollars in 1995), and the operating cost for each user was \$3. Other potential costs include, but are not limited to, schedule constraints for matching riders, privacy exposure, and additional travel distance and time for picking up riders.

Some researchers investigate the elasticity of vanpooling ridership with respect to fees. The elasticity is between $-2.6 \%$ to $-14.8 \%$ (Concas et al., 2005). This means if there is a $\$ 1$ increase (or decrease) in vanpool fares, there will be a $2.6 \%$ to $14.8 \%$ increase (or decrease) in the probability of choosing vanpool. York and Fabricatore (2003) found that a $10 \%$ increase in vanpool fares will lead to a $15 \%$ decrease in ridership.

In the long run, ride-sharing may incur urban sprawl because people can afford long-distance commutes with ride-sharing. Besides, ride-sharing is supposed to compete with public transit, decreasing transit ridership.

\subsubsection{User characteristics/preferences}

Some studies investigate the characteristics of ride-sharing participants. Results indicate that socio-demographic factors do not strongly influence ride-sharing participation (Canning et al., 2010). However, income and education status are positively related to ride-sharing participation 
(Ferguson, 1995). These are attributed to individual car ownership. Younger people are more likely to take ride-sharing as a travel mode than older people (Gärling et al., 2000). After controlling for socio-economic factors, immigrants are more likely to adopt ride-sharing than non-immigrants in the USA (Cline et al., 2009). Men are more likely to take ride-sharing than women (Ferguson, 1995), while some recent studies do not agree on this (DeLoach \& Tiemann, 2012). Neoh et al. (2017) conduct meta-analysis of a large body of literature, and find that women are more likely to carpool than men.

\subsubsection{Factors Affecting Ride-sharing}

When public transportation is not available, carpooling is important and attractive (Eriksson et al., 2008). Existing literature does not have consistent conclusions about whether longer-distance trips encourage ride-sharing (Neoh et al., 2017). Some studies claim that ride-sharing trips are more likely to have longer distances than SOV trips (Ferguson, 1997), while other studies argue that detour for pick-up and drop-off lead to an increase in trip distance (Shoup, 1997).

Ride-sharing projects are supposed to be quite effective in relatively low-density areas with low level of transit service. Organizations, commercial companies, local and regional government, and employers are all willing to implement ride-sharing projects. The wider area the ride-sharing serves, the larger the pool of ride-sharing participants will be.

The psychological factors are supposed to be more important than socio-demographic factors (Gardner \& Abraham, 2007). If commuters perceive ride-sharing as convenient, they are more willing to take ride-sharing as a travel mode (Gardner \& Abraham, 2007). In general, privacy and comfort are supposed to be the determinants of transport choices. People who value privacy are less likely to take ride-sharing with others (Correia \& Viegas, 2011). Besides, people need to feel in control of their ride-sharing trip; otherwise they are not willing to participate ride-sharing (Ozanne \& Mollenkopf, 1999). The desire to socialize contributes to the people's decisions to participate in ride-sharing (Morency, 2007). Participants of ride-sharing take races and ethnicities (these are related to cultural background) into consideration, indicating similarities in values are helpful to form ride-sharing (Charles \& Kline, 2006).

HOV facilities, financial subsidies, parking management, and marketing are all likely to improve the effectiveness of ride-sharing programs. If parking pricing is implemented, ride-sharing programs can bring about $5 \%-15 \%$ and up to $20 \%$ or more reduction in daily vehicle commute trips to worksites (Ewing, 1993).

For encouraging ride-sharing, punishment policies, such as extra parking charges for SOVs, are found to be more influential than reward policies, such as reserved parking (Hwang \& Giuliano, 1990; Jacobson \& King, 2009). However, the punishment policies are more practical for implementation than rewards policies.

The workplace is supposed to be the proper place to form ride-sharing programs. Collura (1994) proposes three advantages of the workplace: employers and employees are willing to relieve parking demand; potential participants are available; and employers can organize ride-sharing. Because large employers have large numbers of employees, they are more easily able to find potential ride-sharing participants (Teal, 1987). Furthermore, these coworkers have similar 
schedules (Buliung et al., 2010), which is considered an important prerequisite for ride-sharing. Among situational factors, Neoh et al. (2017) find the employer has the largest positive effect on increasing the likelihood of carpooling, while travel costs, fixed work schedule and living in an urban area only have a moderate effect on encouraging ride-sharing.

To improve the attractiveness of ride-sharing, some workplaces pay ride-sharing participants' travel expenses if ride-sharing drivers leave before the predetermined time. Results of studies indicate that this strategy contributes to an increase in ride-sharing (Giuliano et al., 1993; Menczer, 2007).

Some empirical studies identify effective policies for encouraging ride-sharing. Transportation policies that make commuters realize the cost of SOV driving are effective to attract them to participate in ride-sharing (Meyer, 1999). Cash incentives are more attractive in encouraging ride-sharing than parking discounts (Canning et al., 2010). Because HOV lanes only save a small amount of travel time, they are not effective to attract ride-sharing participants (Kwon \& Varaiya, 2008). Neoh et al. (2017) find that reserved parking and HOV lanes encourage the propensity of ride-sharing.

These findings are helpful for policymakers to allocate efforts efficiently by concentrating on factors that maximize effects.

\subsubsection{Challenge and future directions}

Based on the analysis of previous and present ride-sharing programs, Chan \& Shaheen (2012) posit that technology, causal carpooling and public policy are likely to affect ride-sharing. Technology will be the main impetus in the future. Advancement in technologies will improve the interoperability among numerous ride-sharing databases. This will expand the pool of potential ride-sharing participants and consequently improve the effectiveness of ride-sharing programs. Besides, technology will achieve the seamless connection between ride-sharing and other transportation modes, such as car sharing, transit. Casual ride-sharing is likely to be the major type of ride-sharing, because it does not need prearrangement. Supportive public policies, especially TDM policies, are critical for the effectiveness of ride-sharing programs.

\subsubsection{Ride-hailing}

\subsubsection{Definitions and evolution}

Ride-hailing refers to app-based, on-demand ride services. Besides ride-hailing, there are other commonly used names, including transportation network companies (TNCs), on-demand rides, parataxis, and ridesourcing. Ride-hailing trips are typically real-time and demand-responsive trips. Ride-hailing companies, such as Lyft and Uber, develop smart phone apps whereby passengers can request a ride in real time. The locations and destinations of passengers are communicated to nearby drivers who typically do not have commercial licenses. As long as a driver accepts the ride request, the passenger can view the real-time location of the vehicle and 
estimated arrival time. After the driver picks up the passenger, the app provides GPS-enabled navigation for driving to the destination. The payment is charged to the passenger's credit card. The driver keeps a major portion of the fare and the ride-hailing companies keep the rest. The app provides a rating system for both drivers and passengers after the ride is completed.

The ride-hailing originates from ride-sharing and it has traits of traditional taxi services (Shaheen, Chan \& Rayle, 2017). Similar to ride-sharing, ride-hailing allows unrelated passengers to share a ride. However, drivers of ride-hailing do not have a joint trip with passengers, and their motivation is making a profit. In some ways, ride-hailing is similar to taxi, which offers a ride for a fare. Different from taxi, ride-hailing services dynamically match passengers and drivers with a smart phone and dynamic matching algorithm. In many cities, ride-hailing services are not subject to taxi regulations which determine supply, fares and other service standards. Further, the evolvement of transportation modes makes the distinctions between these modes more blurred. Ride-hailing companies have provided services, such as Uber Pool and Lyft Line, which allow unrelated passenger to share a ride. These services resemble ride-sharing. Besides, taxi companies have provided an app-based service known as e-hail.

Different from such emerging modes as bike sharing and carsharing, the academic literature on ridesourcing is relatively limited because of its short history and lack of open data (Henao, 2017).

\subsubsection{The debates over ride-hailing}

There are numerous debates about ride-hailing services. Opponents criticize that ride-hailing services compete with transit, cause public safety issues and increase extra traffic volume. However, advocators state that ride-hailing services provide more mobility. For city governments, there is an urgent need for appropriate regulatory and public policy responses to ride-hailing services. There have been clashes between ride-hailing companies and city halls (Flegenheimer \& Fitzsimmons, 2015).

\subsubsection{Ride-hailing trip characteristics}

A comprehensive understanding of ride-hailing trips is crucial for transportation planning and regulation. Although open data on ride-hailing services are limited, some studies examine the characteristics of ride-hailing trips through conducting surveys or acquiring data via a Freedom of Information Act request.

Henao (2017) creates a unique dataset through becoming a driver for Uber and Lyft. The dataset includes travel attributes and passenger information. He estimates the ride-hailing time and distance efficiency. For time efficiency, time with the rider accounts for $39.2 \%$ of overall time. For distance efficiency, distance with the rider accounts for $59.2 \%$ of overall distance. Ridehailing trips take approximately six minutes for boarding after the driver accepts a request, and the median distance and travel time for passengers is about 11.5 minutes and 3.6 miles. The average speed is 28.8 miles per hour. 
Two media reports analyze Uber usage data acquired via a Freedom of Information Act request (Bialik et al, 2015; Fischer-Baum \& Bialik, 2015). They compare general travel cost (using basic assumptions) of public transit, Uber, and owning a car, and find that the combination of Uber with high use (around 65\% to 85\%) and public transportation can be significantly cheaper than car ownership. The combination of high use of public transit and some Uber rides is much more affordable for lots of people than Uber alone or owning a vehicle. Henao (2017) estimates the earnings of ride-hailing drivers. The gross earning is $\$ 15.69 / \mathrm{hr}$. After accounting for driving expenses, the average net earnings equal $\$ 7.94 / \mathrm{hr}$. This provides information about costs of ridehailing from the perspective of drivers.

Henao (2017) reviews literature on ride-hailing and argues that the users of ride-hailing are different from the overall population in characteristics of travel behavior, socio-economics, and demographics. Users tend to be younger, and have higher income and education level than the general population (Bialik et al., 2015; Fischer-Baum \& Bialik, 2015; Dawes, 2016; Shirgaokar, 2017). They prefer living in denser areas with convenient transit accessibility. For travel behavior, they have lower car ownership and higher level of bike ownership and transit pass than the overall population. The non-auto modes, including bike, walking and transit, account for larger shares than the general population. However, these findings are at an aggregate level, and there is limited research investigating the impacts of ride-hailing services on travel behavior at individual level. Silver and Fischer-Baum (2015) analyze pick-up rates at the census tract level and they find lower incomes experienced fewer pick-ups.

Shirgaokar (2017) conducts an exploratory study to examine the gender-specific barriers to using ride-hailing services with a mixed method of in-person interviews and gender-separated focus groups. Results indicate that there are mainly three barriers to using ride-hailing services: mistrust with online financial transactions, trust and risk averseness, and ambiguity about ridehailing services.

Dawes (2016) conducts an online survey about attitudes toward ride-hailing services and differentiates respondents by users and non-users. There are 394 completed questionnaires from 15 metropolitan statistical areas in the U.S. For trip purposes. The results of the survey indicate that riders mostly use ride-hailing services for typical purposes, such as avoiding driving because of drinking and from/to the airport. Ride-hailing services provide a supplement to regular trips, such as commuting to work or school, instead of an alternative mode. Some respondents state that they will use ride-hailing services less because the ride-hailing companies do not treat drivers as employee. Besides, there are a small percentage of respondents who do not use ridehailing services because of ethical opposition. 
Table 1.4: Cost estimates of ride hailing services ${ }^{1}$

\begin{tabular}{|c|c|c|c|c|}
\hline Source & Service & City & $\begin{array}{l}\text { Cost } \\
(\$ / \mathrm{mi})\end{array}$ & $\begin{array}{l}\text { Notes (peak/off-peak, } \\
\text { surge/normal, etc.) }\end{array}$ \\
\hline www.lyft.com/cities/portland-or & Lyft & Portland, OR & 1.21 & $\begin{array}{l}+0.20 / \mathrm{min}+\$ 3.65 \\
\text { other fees per trip }\end{array}$ \\
\hline https://www.lyft.com/cities/new-york-city-ny & Lyft & $\begin{array}{l}\text { New York } \\
\text { City, NY }\end{array}$ & 1.58 & $\begin{array}{l}+0.32 / \mathrm{min}+\$ 2.29 \\
\text { other fees per trip }\end{array}$ \\
\hline https://www.lyft.com/cities/los-angeles-ca & Lyft & $\begin{array}{l}\text { Los Angeles, } \\
\text { CA }\end{array}$ & 0.96 & $\begin{array}{l}+0.15 / \text { min }+\$ 2.1 \text { other } \\
\text { fees per trip }\end{array}$ \\
\hline https://www.lyft.com/cities/atlanta-ga & Lyft & Atlanta, GA & 0.81 & $\begin{array}{l}+0.12 / \min +\$ 3.25 \\
\text { other fees per trip }\end{array}$ \\
\hline https://www.lyft.com/cities/denver-co & Lyft & Denver, CO & 1.00 & $\begin{array}{l}+0.13 / \min +\$ 3.25 \\
\text { other fees per trip }\end{array}$ \\
\hline https://www.lyft.com/cities/st-louis-mo & Lyft & St. Louis, MO & 1.26 & $\begin{array}{l}0.20 / \mathrm{min}+\$ 4.05 \text { other } \\
\text { fees per trip }\end{array}$ \\
\hline https://www.lyft.com/cities/cincinnati-oh & Lyft & $\begin{array}{l}\text { Cincinnati, } \\
\mathrm{OH}\end{array}$ & 0.86 & $\begin{array}{l}0.15 / \mathrm{min}+\$ 3.30 \text { other } \\
\text { fees per trip }\end{array}$ \\
\hline https://www.lyft.com/cities/las-vegas-nv & Lyft & $\begin{array}{l}\text { Las Vegas, } \\
\text { NV }\end{array}$ & 0.96 & $\begin{array}{l}0.15 / \mathrm{min}+\$ 3.75 \text { other } \\
\text { fees per trip }\end{array}$ \\
\hline $\begin{array}{l}\text { https://www.lyft.com/cities/virginia-beach- } \\
\text { hampton-roads-va }\end{array}$ & Lyft & $\begin{array}{l}\text { Virginia } \\
\text { Beach, VA }\end{array}$ & 0.84 & $\begin{array}{l}0.15 / \mathrm{min}+\$ 3.55 \text { other } \\
\text { fees per trip }\end{array}$ \\
\hline https://www.lyft.com/cities/milwaukee-wi & Lyft & $\begin{array}{l}\text { Milwaukee, } \\
\text { WI }\end{array}$ & 1.16 & $\begin{array}{l}0.20 / \mathrm{min}+\$ 3.00 \text { other } \\
\text { fees per trip }\end{array}$ \\
\hline https://www.lyft.com/cities/salt-lake-city-ut & Lyft & $\begin{array}{l}\text { Salt Lake } \\
\text { City, UT }\end{array}$ & 0.95 & $\begin{array}{l}0.11 / \mathrm{min}+\$ 2.7 \text { other } \\
\text { fees per trip }\end{array}$ \\
\hline http://uberestimate.com/prices/Portland/ & Uber & Portland, OR & 1.21 & $\begin{array}{l}0.20 / \mathrm{min}+\$ 3.15 \text { other } \\
\text { fees per trip }\end{array}$ \\
\hline http://uberestimate.com/prices/New-York-City/ & Uber & $\begin{array}{l}\text { New York } \\
\text { City, NY }\end{array}$ & 1.75 & $\begin{array}{l}0.35 / \mathrm{min}+\$ 2.55 \text { other } \\
\text { fees per trip }\end{array}$ \\
\hline http://uberestimate.com/prices/Los-Angeles/ & Uber & $\begin{array}{l}\text { Los Angeles, } \\
\text { CA }\end{array}$ & 0.96 & $\begin{array}{l}0.15+\$ 2.10 \text { other fees } \\
\text { per trip }\end{array}$ \\
\hline http://uberestimate.com/prices/Atlanta/ & Uber & Atlanta, GA & 0.81 & $\begin{array}{l}0.12 / \mathrm{min}+\$ 3.25 \text { other } \\
\text { fees per trip }\end{array}$ \\
\hline http://uberestimate.com/prices/Denver/ & Uber & Denver, CO & 1.10 & $\begin{array}{l}0.16 / \mathrm{min}+\$ 2.95 \text { other } \\
\text { fees per trip }\end{array}$ \\
\hline http://uberestimate.com/prices/St-Louis/ & Uber & St. Louis, MO & 1.26 & $\begin{array}{l}0.20 / \mathrm{min}+\$ 4.05 \text { other } \\
\text { fees per trip }\end{array}$ \\
\hline http://uberestimate.com/prices/Cincinnati/ & Uber & $\begin{array}{l}\text { Cincinnati, } \\
\text { OH }\end{array}$ & 0.86 & $\begin{array}{l}0.15 / \mathrm{min}+\$ 3.30 \text { other } \\
\text { fees per trip }\end{array}$ \\
\hline http://uberestimate.com/prices/Las-Vegas/ & Uber & $\begin{array}{l}\text { Las Vegas, } \\
\text { NV }\end{array}$ & 0.96 & $\begin{array}{l}0.15 / \mathrm{min}+\$ 3.75 \text { other } \\
\text { fees per trip }\end{array}$ \\
\hline http://uberestimate.com/prices/Virginia-Beach/ & Uber & $\begin{array}{l}\text { Virginia } \\
\text { Beach, VA }\end{array}$ & 0.84 & $\begin{array}{l}0.15 / \mathrm{min}+\$ 3.55 \text { other } \\
\text { fees per trip }\end{array}$ \\
\hline http://uberestimate.com/prices/Milwaukee/ & Uber & $\begin{array}{l}\text { Milwaukee, } \\
\text { WI }\end{array}$ & 1.16 & $\begin{array}{l}0.20 / \mathrm{min}+\$ 3.00 \text { other } \\
\text { fees per trip }\end{array}$ \\
\hline http://uberestimate.com/prices/Salt-Lake-City/ & Uber & $\begin{array}{l}\text { Salt Lake } \\
\text { City, UT }\end{array}$ & 0.95 & $\begin{array}{l}0.11 / \mathrm{min}+\$ 2.70 \text { other } \\
\text { fees per trip }\end{array}$ \\
\hline
\end{tabular}

\footnotetext{
${ }^{1}$ With UberPool, both passenger and driver know the exact fare only after the trip, which can come as a surprise to the rider. Regular UberPool users even reported that the final amount tends to be more expensive than an UberX ride. Uber notes that this is a rare possibility and that UberPool rides will usually be $20 \%-70 \%$ less than UberX rides. The algorithm for matching riders and drivers also differs between these ride-sharing services. When booking a Lyft Line ride, the rider must wait for about a minute or two while the app searches for another booking that might
} 


\subsubsection{Impacts}

Ride-hailing services are supposed to lead to comprehensive impacts on urban transportation system. In this report, the impacts of ride-hailing services are classified into three categories: induced travel, vehicle ownership and driving frequency, and relationship between ride-hailing and transit.

There is a small impact of ride-hailing on induced travel. Shaheen et al. (2017) conduct a survey on ride-hailing in San Francisco. They ask the question: "How would you have made this trip if Uber/Lyft/Sidecar were not available?” Result shows that $92 \%$ of users still would have made the trip, indicating $8 \%$ trips are induced travel. There are approximately one-third of users who would have taken transit for the trips. There are 3\% of respondents who have ever used ridehailing instead of driving after drinking alcohol. However, the survey only covers ride-hailing users and does not provide characteristics of potential ride-hailing users or people who do not ever use ride-hailing services. Henao (2017) creates a unique dataset through becoming a driver for Uber and Lyft. He finds that there are $12.2 \%$ of passengers who would not have traveled if ride-hailing services were not available. If the results of his study can apply to the entire country, ride-hailing services increase approximately 5.5 billion extra miles per year. He also examines the impacts of ride-hailing services on travel behavior based on the modality styles of passengers and trip purposes. For typical drivers, they mostly use ride-hailing for to/from airport, social trips, when out of town, drinking/avoid drinking and parking. For typical non-drivers, they usually use ride-hailing services for work and school trips when transit services are not available.

Ride-hailing potentially affects vehicle miles and vehicle ownership. Given that ride-hailing is relatively new and vehicle ownership is a long-term decision, there is little strong evidence about the impact of ride-hailing on vehicle ownership. Shaheen et al. (2017) find that $40 \%$ of respondents drive less after they use ride-hailing in their survey. But this survey is not representative since they only collect respondents in "hot spots" in San Francisco. Besides, ridehailing services even reduce parking demand. Henao (2017) finds that parking makes passengers use ride-hailing services instead of driving.

Ride-hailing services are expected to complement transit instead of compete with it. Shaheen et al. (2017) find there are 4\% of ride-hailing trips made to access transit stations. Empirically, results indicate that Uber pick-up rates are high in areas with high transit accessibility (Bialik et al., 2015; Fischer-Baum \& Bialik, 2015). They posit that Uber is attractive for customers who want to save time or have productive time (work or relax in the vehicle), and it will also attract more customers who want to save money if Uber decreases travel costs. Rayle et al. (2016) conduct an intercept survey of ride-hailing users in San Francisco. The participants of this survey

\footnotetext{
be going in a similar direction. If no matches are found, the rider will still pay the reduced fare even if they ride alone (link).. Express Pool passengers will be asked to wait a minute or two longer than usual to be matched with a driver. The idea is that during this additional time, Uber's algorithm is blasting through hundreds of different drivers, routes, pickup and dropoff locations, and additional riders looking for the optimal match. After the match, riders will be directed to walk a few extra blocks to their pickup location, where, if Uber's algorithm worked the way its supposed to, they'll hopefully meet one or two additional riders who've also been matched with the same driver. [...] At the end of the ride, passengers will be dropped off within walking distance to their final destination. And their reward for all this extra waiting and walking? Dirt-cheap fares, up to 50 percent cheaper than UberPool and 75 percent less expensive than UberX (link).
} 
think ride-hailing services both substitute for and complement transit, walking and biking. Murphy (2016) investigated the relationship between shared modes, including carsharing, bike sharing and ride-hailing services with transit. Results indicate that shared modes complement transit, and that the more frequently people use shared modes, the more likely they use transit and reduce transportation costs and car ownership.

Competing with taxis, ride-hailing has some advantages. Ride-hailing services have shorter wait times than typical taxi services (Rayle et al., 2016; Shaheen et al., 2017). Bialik et al. (2015) use data from Uber and they find that it serves a larger area than taxis in New York. Fischer-Baum and Bialik (2015) state that Uber takes rides away from taxis in New York.

\subsubsection{Autonomous Vehicles}

Autonomous vehicle refers to a type of motorized vehicle that uses computerization to operate on public roadways without requiring a driver or operator. While challenges to implementation remain, AVs may become widely available as early as 2022-2025 (Fagnant \& Kockelman, 2015). Compared with other recent technological changes such as hybrid and electric vehicles, AVs have the potential to spark transportation behavior, system, and market changes on a much larger scale. In addition to potential safety and operations improvements from eliminating the limitations of human drivers, researchers have suggested that AVs are likely to accelerate existing trends in vehicle and ride-sharing (Fagnant \& Kockelman, 2015). AVs also open the door to a complete re-thinking of vehicle interiors as mobile workspaces or entertainment centers (Fagnant \& Kockelman, 2015). Each of these potential changes may significantly affect car ownership, travel choices, and even location and land-use decisions.

\subsubsection{Usage of AVs}

Some studies focus on forecasting the adoption of AVs. Zmud et al. (2016) conducted an online Stated Preference (SP) survey and face-to-face interview in the Austin, TX, region, and applied a car technology acceptance model to examine adoption and use of self-driving vehicles. There were $52 \%$ of respondents who indicated they would use self-driving cars. Bansal and Kockelman (2017) developed a simulation-based fleet evolution framework to forecast long-term adoption of connected autonomous vehicle (CAV) technologies in the United States. They estimated Americans' preference for CAV technologies and their decisions about vehicle transaction with a U.S.-wide survey, then they used these estimations to forecast long-term adoption of CAV technologies in different scenarios. The adoption rates of different levels of automation technologies largely depended on willingness-to-pay (WTP) increment rate and automation technologies price reduction rate. The share of level 4 AV (the highest level of AV) will reach up to $87.2 \%$ in scenario with a $10 \%$ reduction rate of AV price and a $10 \%$ rise in WTP values. This study assumes the reduction rate of AV price and growth rate of WTP values is constant over time, but these rates will change over time.

Some studies examine the usage of shared autonomous vehicles (SAVs). Schweizer and Meggs (2013) used a direct demand stated preference method to estimate the mode share of personal 
rapid transit (PRT). PRT is a new public transport mode, which is operated on separated guideways with small automated vehicles. Their model indicates the mode share of car and motorcycle would become less than $15 \%$ in the majority of 10 surveyed cities, and PRT would be the dominant mode after citywide PRT service was provided. Levine et al. (2013) explored how automated driverless community transit and urban-design improvement in pedestrian and bicycling facilities might address the last-mile issue. They conducted a stated preference survey in four neighborhoods in metropolitan Chicago. Results indicated that the automated driverless community transit would increase Chicago Transportation Authority share from 50\% to 67\% and reduce automobile share from $36 \%$ to $22 \%$. They find complementary policies, such as increasing parking prices, would be conducive to increasing transit share.

\subsubsection{WTP/cost}

Travel cost is a critical determinant of the use of AVs. Operating costs of AVs are still somewhat uncertain (Table 1.5), but Litman (2014) noted that they seem likely to fall somewhere between non-AV car sharing (\$0.60-1.00 per mile) and conventional taxis ( $\$ 2.00-\$ 3.00$ per mile). A privately owned vehicle driven 10,000 miles per year has a per-mile cost of about 60 cents per mile (Litman, 2014). 
Table 1.5: Cost estimates of shared autonomous vehicles (SAVs) and ride sharing autonomous vehicles (RSAV)

\begin{tabular}{|c|c|c|c|}
\hline Source & $\begin{array}{l}\text { AV } \\
\text { Cost } \\
(\$ / m i)\end{array}$ & $\begin{array}{l}\text { Driving } \\
(\$ / \mathrm{mi})\end{array}$ & AV/Driving Type (context) \\
\hline $\begin{array}{l}\text { Burns et al. } \\
(2013)\end{array}$ & 0.15 & $0.59-0.75$ & $\begin{array}{l}\text { SAV (small to medium-sized town); } 0.59 \text { is } 15,000 \mathrm{mi} / \mathrm{yr} \& 0.75 \text { is } \\
10,000 \mathrm{mi} / \mathrm{yr} \text { (Ann Arbor, MI case study) }\end{array}$ \\
\hline $\begin{array}{l}\text { Fagnant \& } \\
\text { Kockelman } \\
\text { (2014) }\end{array}$ & 1.00 & $0.51-0.77$ & $\begin{array}{l}\text { SAV (fare including normal profit); typical annual ownership and } \\
\text { operating costs range from } \$ 6,000 \text { to } \$ 13,000 \text { depending on vehicle } \\
\text { model and mileage (AAA, 2012), } 0.51 \text { is } 20,000 \mathrm{mi} / \mathrm{yr} \& 0.77 \text { is for } \\
10,000 \mathrm{mi} / \mathrm{yr}\end{array}$ \\
\hline Litman (2014) & $\begin{array}{l}1.00- \\
2.00\end{array}$ & 0.2 & $\begin{array}{l}\text { SAV; } \$ 4,000 \text { annually in fixed expenses plus } \$ 0.20 \text { per mile in } \\
\text { operating costs. }\end{array}$ \\
\hline Johnson (2015) & 0.44 & 0.66 & $\begin{array}{l}\text { SAV (fare including normal profit); traditional vehicle operating cost } \\
\text { per mile }\end{array}$ \\
\hline Johnson (2015) & 0.16 & 0.66 & RSAV (fare including normal profit) \\
\hline $\begin{array}{l}\text { Stephens et al. } \\
\text { (2016) }\end{array}$ & $\begin{array}{l}0.20- \\
0.30\end{array}$ & 0.65 & RSAV \\
\hline $\begin{array}{l}\text { Johnson \& } \\
\text { Walker (2016) }\end{array}$ & 0.30 & 0.65 & RSAV \\
\hline $\begin{array}{l}\text { Bösch et al. } \\
\text { (2017) }\end{array}$ & $0.63^{2}$ & 0.77 & SAV (urban) \\
\hline $\begin{array}{l}\text { Bösch et al. } \\
\text { (2017) }\end{array}$ & $0.44^{1}$ & 0.77 & RSAV (urban) \\
\hline $\begin{array}{l}\text { Bösch et al. } \\
(2017)\end{array}$ & $0.47^{1}$ & 0.77 & SAV (suburban/exurban) \\
\hline $\begin{array}{l}\text { Bösch et al. } \\
(2017)\end{array}$ & $0.29^{1}$ & 0.77 & RSAV (suburban/exurban) \\
\hline
\end{tabular}

Some studies found the majority of respondents did not want to pay extra for AV technology (J.D. Power, 2015; Schoettle \& Sivak, 2014). J.D. Power (2015) found only 24\% of respondents have the intent to pay $\$ 3,000$ for an autonomous driving model in their next vehicle. Bansal and Kockelman (2017) developed a simulation-based fleet evolution framework to forecast long-term adoption of CAV technologies based in the USA. Their forecast largely depended on WTP increment rate and automation technologies price reduction rate. They argued that the changes in price and WTP would affect the adoption of AVs.

\subsubsection{Time}

Travel time and waiting time are critical determinants of the use of SAVs (Krueger, Rashidi, \& Rose, 2016). Different from the existing travel modes, AVs are supposed to enable productive use of travel. Singleton (2018) argued that the AVs would reduce value-of-time (VOT) and such reduction would be smaller than anticipated because AV users felt more like car passengers than train riders, thus activity participation would be limited. He posited that reduced stresses of driving and commuting burdens would contribute to the reduction in VOT. Krueger et al. (2016) estimated VOT with a mixed logit model. According to the final model, the value of in-vehicle

\footnotetext{
2 Assuming $1 \mathrm{CHF}=1 \mathrm{USD}$, private car cost estimated at $\$ 0.81 / \mathrm{mi}$ in same settings
} 
time is 0.78 Australian Dollar (AUD) $3 /$ minute for SAV without dynamic ride-sharing (DRS), and 1.06 AUD/minute for SAV with DRS. The value of waiting time is $0.05 \mathrm{AUD} / \mathrm{minute} \mathrm{SAV}$ without DRS, and 0.10 AUD/minute for SAV with DRS. Because the marginal WTP estimates of SAV with DRS are larger than those of SAV without DRS, they argued that they are two distinct modes.

\subsubsection{The Role of Socio-demographic Characteristics, Attitude, and Trip Attributes}

The relationship between sociodemographic variables and the adoption and use of AVs is uncertain, because the existing studies found conflicting results. Younger respondents were more likely to accept and use AVs (J.D. Power, 2017). Krueger et al. (2016) found that respondents aged between 24 and 29 were more likely to adopt SAV with DRS. Sommer (2013) found younger individuals had greater preference for full self-driving vehicles than older. On the other hand, Kyriakidis et al. (2015) found insignificant relationship between age and opinion about AVS.

From the theoretical perspective, individuals who are unable or unwilling to drive vehicles or individuals who have no access to private vehicles are potential users (Anderson et al., 2014). For example, SAVs are supposed to be an age-appropriate travel mode for elderly travelers because they do not have to drive themselves and do not have to own private vehicles. Krueger et al. (2016) found that individuals between 65 and 84 had no preference for SAV modes, and Haustein's (2012) empirical studies found that the travel behaviors of elderly travelers are heterogeneous.

Kyriakidis et al. (2015) found that there was significant association between willingness to pay for self-driving technology and income. Similarly, Howard and Dai (2014) also found income was associated with acceptance of self-driving technology. Zmud et al. (2016) found individuals with less than $\$ 25,000$ household income tended to be unlikely to use (56\%), and individuals with $\$ 25,000$ - \$50,000 household income tended to be more likely to use AVs (54\%).

Zmud et al. (2016) found male travelers had higher propensity to be extremely likely to use AVs than female travelers. They also found no association between educational attainment and intent to use. Current car ownership was not associated with intent to use AVs, but individuals who owned a vehicle with some self-driving features would be more likely to use AVs.

Perceived safety and trust were found to be influential factors. The data privacy, software hacking, and issues of control affected whether individuals trust self-driving or not (Howard \& Dai, 2014; Kyriakidis et al., 2015), but the trust decreased though AV technologies became closer to reality (J.D. Power, 2017). Zmud et al. (2016) found data privacy concern deterred intention to use AVs.

\footnotetext{
${ }^{3} 1$ Australian Dollar $=0.72$ USD
} 
Perceived safety depended on the performance of AVs in mixed traffic and driving performance relative to human drivers (Schoettle \& Sivak, 2014). J.D. Power (2017) found individuals would accept AVs only when they got firsthand experience and total understanding.

Among respondents of surveys conducted in Austin, TX, the reasons for being unlikely to use AVs for regular use included lack of trust in the technology (40\%), safety (24\%), cost (20\%) and insurance/liability (1\%) (Zmud et al., 2016). Zmud et al. (2016) also found positive attitudes towards AVs was associated with higher level of intent to use AVs. They found individuals who exhibited high intention to use AVs were those who think a self-driving vehicle would decrease accident risk, using AVs would be fun and using AVs would be easy.

Several studies explored how attitudinal factors affect the adoption of emerging modes (Burkhardt \& Millard-Ball, 2006; Schaefers, 2013). They found innovativeness, proenvironmental considerations, thriftiness, and convenience were important motivations for carsharing users, which were also potential motivations for SAVs.

The attributes of a reference trip affect respondents' selection of modes in choice scenarios. Krueger et al. (2016) found SAVs were less likely to be selected when the purpose of the reference is a medical or dental appointment. The option SAV without DRS was more likely to be selected when respondents traveled by car as the driver on the reference trip; the option SAV with DRS is more likely to be selected when respondents traveled by car as a passenger on the reference trip. Respondents who traveled by public transit were more likely to select SAV without DRS.

Some studies identified modality styles through clustering travelers' frequencies of use of travel modes. Krueger et al. (2016) found respondents with multimodal patterns had higher propensity to select SAV options. For example, individuals who were carsharing users are more likely to choose the option SAV with DRS. Some studies also corroborated that carsharing users were more inclined to exhibit multimodal patterns (Kopp, Gerike \& Axhausen, 2015; Schaefers, 2013).

Levine et al. (2013) found complementary policies, such as increasing parking price, would be conducive to improve the effect of automated driverless community transit on mode choice.

Of most interest to the present study are individual travel behavior impacts of AVs. Of course, some people might choose to own an AV despite the much higher expected purchase cost, but they are not the focus here. Researchers have identified a number of likely impacts on travel choices (Fagnant \& Kockelman, 2015). These include:

- increased demand due to reduced travel effort

- increased demand due to reduced time, fuel, and parking costs

- increased non-driver mobility

- mode shift to shared vehicle and shared ride services due to decreased coordination and operating costs 
Litman (2014) suggested that certain attributes of AVs might moderate demand for AV travel especially for shared vehicles - due to differences in privacy, control, status, and, potentially, comfort.

There have been a few studies that investigate this issue, but the majority of studies are based on logic or assumptions instead of on verified evidence supported by observations or experience. For example, Zmud et al. (2016) conducted qualitative and face-to-face interviews with people who were likely to use AVs to capture the impacts of AVs on travel behavior. They found that the majority of respondents who indicated willingness to use self-driving vehicles reported that using self-driving would not affect residential location choice (80\%), annual VMT (66\%) and auto ownership (55\%). There is little empirical evidence on the impact of AVs on travel behavior. Besides, the public does not completely understand the opportunities and challenges of AVs, thus analysis based on surveys and assumptions might not totally represent the impact of AVs.

Existing studies provide direction for potential impacts, though there is no empirical evidence. Related to stages of AVs, Milakis et al. (2017) classified the impacts of AVs as first-order, second-order and third-order impacts. The first-order impacts refer to impacts on traffic, travel cost, and travel choice. The second-order impacts include impacts on vehicle ownership and sharing, location choices and land use, and transport infrastructure. The third-order impacts refer to impacts on energy consumption, air pollution, safety, social equity, economy, and public health. They found the impacts on fuel efficiency, emissions, road capacity, and accident risk would be beneficial, and the magnitude of these impacts depends on the adoption and use level of AVs. However, they argued that AVs would lead to more and longer trips and thus caused additional travel demand. They posited that other third-order impacts on safety, economy, public health and social equity were not clear yet. Fraedrich et al. (2018) conducted a comprehensive literature review, and performed quantitative online survey and qualitative interviews with representatives of urban transport planning authorities in Germany. The results indicated that AVs might be not compatible with objectives of transportation planning, such as promoting active and public transportation and reducing driving. They also argued the impacts of AVs largely depends on how AVs would be used.

\subsection{RELATED STUDIES ON EMERGING MODES}

\subsubsection{Overview}

Studies about emerging modes are conducted in the large cities located in Europe, the United States, Australia and China. The direction of findings are consistent among studies conducted in different countries, while estimations or magnitudes are varied, possibly due to local heterogeneous attributes. The focus of studies also varies by study area to some degree. Those studies conducted in China focus on bike sharing. Studies conducted in Europe and the United States focus on car sharing, ride-hailing and AVs. 
The Stated Preference survey is commonly used in studies examining emerging modes, because most studies on emerging modes explore the hypothetical or speculative nature of emerging modes and scenarios that do not exist yet. The SP surveys are based on revealed preference trip. The SP surveys usually include two parts. The first part collects sociodemographic characteristics, travel patterns, and mobility characteristics, as well as other necessary information. The second part of the survey includes one or a few stated choice experiments. Every stated choice experiment generally consists of two important steps. The first step of the experiment asks respondents to recall a recent trip. This trip is called a reference trip. Respondents provide detailed trips attributes, such as purpose, time, distance, mode and cost as well as other necessary attributes. The second step of the experiment provides choice tasks for respondents. In each choice task, there are several mobility options, and respondents are asked to select one of these mobility options for the reference trip. The sample size of surveys depends on the survey design and purposes of the research.

\subsubsection{Modeling Approaches}

There are a variety of modeling approaches used in existing studies about emerging modes. Discrete choice modeling approaches are widely used in studies examining mode choices. The discrete choice models are grounded on random utility theory, and the forms of discrete choice models are based on the data and purpose of the studies. The binomial logit (BL) model is used to examine mode choice between two alternatives. Cartenì et al. (2016) estimated a BL model to examine choice between private car and carsharing service and the likelihood to choose EVs for a carsharing service. When the number of alternatives is more than two, a multinomial logit (MNL) model is used. De Luca \& Di Pace (2015) estimated multinomial logit, hierarchical logit (HL), cross-nested logit (CNL), and mixed multinomial logit (MMNL) models based on different assumptions about joint probability distribution for random residual. In the MNL model, the random residuals are assumed to be identically distributed (iid). The MMNL model is quite flexible, because the decision-maker's taste is allowed to randomly distribute, and the MMNL model does not require independence of irrelevant alternatives and restrict substitution patterns.

Some studies used approaches to explore how travelers switch between the usually chosen transport mode and hypothetical or speculative mode options. De Luca \& Di Pace (2015) compared three modeling approaches, including a conditional switching model, unconditional switching model, and holding model. These approaches were specified with different modeling solutions, including homoscedastic, heteroscedastic, and cross-correlated closed-form solution, based on the behavior paradigm of the utility theory. Similarly, Zacharias and Li (2016) estimated a conditional logistic regression to examine respondents' mode preference with an increase in travel distance and a progressive rise in subway ticket fare.

Besides regression approaches, some models are developed to forecast the usage of emerging modes. Bansal and Kockelman (2017) developed a simulation-based fleet evolution framework to forecast long-term adoption of connected autonomous vehicle (CAV) technologies in America. The adoption rates of different levels of automation technologies largely depended on WTP increment rate and automation technologies price reduction rate. The share of level $4 \mathrm{AV}$ 
(the highest level of AV) will reach up to $87.2 \%$ under a scenario with a $10 \%$ reduction rate in AV price and a 10\% rise in WTP values. Because AV and SAV are not available yet on the market, Zmud et al. (2016) used a car technology acceptance model to investigate the adoption and use of self-driving vehicles. The car technology acceptance model provides a theoretical framework for acceptance and use of self-driving vehicles.

\subsubsection{Travel Behavior Impact}

The emerging modes provide more options for travelers and exert impacts on travel behavior. There is no study that examines the syngeneic effect of emerging modes on travel behavior, but the comprehensive literature on emerging modes provides insights on travel behavior impacts. Though the direction and magnitude of overall travel behavior impacts are not easy to forecast, some specific impacts are relatively certain. First, emerging modes provide mobility for people who would not make the trip if the emerging modes are not available. For example, if one has access to a carsharing program, he can drive a car even though he does not own a vehicle. AVs do not even require individuals' ability to drive a vehicle. Second, the costs of emerging modes are relatively lower than existing modes that provide similar travel services. For instance, the costs of ride-hailing services are much lower than conventional taxis. Some studies investigate ride-hailing services in San Francisco.

The emerging modes are supposed to affect vehicle trips, but the overall magnitude and direction are uncertain. Ride-sharing is supposed to reduce vehicle trips, because two or more travelers share a ride in one vehicle. Ride-hailing is supposed to lead to induced travel. Shaheen et al. (2017) found that $8 \%$ of ride-hailing trips were induced travel. Given the relatively low mode share of ride-hailing, the impact of ride-hailing services on induced travel is not large. However, the magnitude of induced travel is large when the time and distance efficiency of ride-hailing are taken into consideration. For ride-hailing services, time with rider accounts for $39.2 \%$ of overall driving time, and distance with rider accounts for $59.2 \%$ of overall driving distance (Henao, 2017). AVs are supposed to lead to more and longer trips and thus caused additional travel demand and negative environmental effects (Fraedrich et al., 2018).

The interaction between emerging modes and existing modes are also uncertain. Because ridesharing does not need a paid driver and backhauls, the cost per vehicle tends to be lower than transit. Thus, ride-sharing is expected to compete with public transit and reduce transit ridership. Ride-hailing services are found to both complement with and compete with transit.

Ride-hailing services are expected to complement transit instead of compete with it. Shaheen et al. (2017) find there are 4\% of ride-hailing trips made to access transit stations. Rayle et al. (2016) conduct an intercept survey of ride-hailing users in San Francisco. The participants of this survey think ride-hailing services both substitute for and complement transit. Empirically, results indicate that Uber pick-up rates are high in areas with high transit accessibility (Bialik et al., 2015; Fischer-Baum \& Bialik, 2015). There is much more uncertainty for the impact of AVs on travel behavior, because the empirical evidences of AVs usage are not available yet. Fraedrich et al. (2018) conducted a comprehensive literature review, and performed quantitative online survey and qualitative interviews with representatives of urban transport planning authorities in 
Germany. The results indicated that AVs might be not be compatible with objectives of transportation planning, such as promoting active and public transportation and reducing driving. They also argued the impacts of AVs largely depend on how AVs would be used. AVs even provide a new transit option: personal rapid transit (PRT), which is a new public transport mode that is operated on separated guideways with small automated vehicles. Some studies regard the shared autonomous vehicles (SAVs) as part of the public transit system.

The emerging modes generate new opportunities and challenges for transportation planning, and it has become more and more important to explore how to efficiently incorporate emerging modes into existing transportation systems. The adoption of emerging modes is expected to largely increase in the future. Empirical studies indicate that users of emerging modes tend to be younger than the overall population (Bialik et al., 2015; Dawes, 2016; Gärling et al., 2000; Krueger et al., 2016). In the future, it can be predicted that the mode share of emerging modes will continue growing because young people have a high propensity to adopt emerging modes. The different usage of emerging modes seems to bring about various implications; thus planners should have a clear idea with regard to the impacts of emerging modes to properly deal with the opportunities and challenges in the future. 


\subsection{METHODOLOGY}

\subsection{STATED PREFERENCE APPROACH}

Travel behavior research can be divided into two types: revealed and stated preference. Revealed preference (RP) research uses actual (i.e., revealed) behavior to examine the attractiveness of different types of transportation facilities. Data are collected through surveys and/or passive means, such as global positioning system (GPS) units. With stated preference (SP) research, the researcher asks a person what travel behavior they would prefer, potentially, in a hypothetical setting. In other words, their preference is stated and not revealed through actual behavior.

Some of the limitations of RP research can be addressed through SP techniques. This allows researchers to understand people's preferences for options they may not have been exposed to, or to understand the preferences of individuals who do not currently use certain modes. The simplest type of SP research asks people to rate or rank a mode or indicate whether having such a mode would encourage them to use it. Some of the studies looking into emerging travel modes use these simple SP techniques (for example, Ciari and Axhuasen, 2012; Eiró and Martínez, 2014; Akar and Clifton, 2009).

Most of the methods are based on some form of SP survey data. Frequently, this involves describing to participants the characteristics of different travel modes, and asking the participants either to select which mode they would choose or else to rate all modes in a particular travel situation. To achieve the most valid results, the researcher tries to place the decision-maker in a realistic mindset to compare a number of alternatives, each described in terms of their attributes. This approach is particularly useful when the researcher wishes to examine options that the respondents may not have seen before, such as autonomous vehicles, or alternatives that are relatively novel and not yet as widely available or used as more traditional options, such as car share, ride hail, and bike share.

In a stated choice (SC) experiment, participants are presented with a scenario and asked to choose among two or more choice alternatives. Each alternative has a set of attributes of interest that are bundled into a "card." Each card reflects a different combination of attributes and may include both text and imagery to describe the context and convey alternative characteristics such as costs, travel time, etc. Respondents are asked to choose their preference between a pair or set of cards, each with a unique combination of attributes and levels. The comparison of cards is called a task, and in any given experiment respondents can be asked to engage in a number of tasks. For different types of trips, SC surveys can test individuals' tradeoffs between attributes across different attributes using the same mode (costs, travel time) as well the tradeoffs between attributes across different modes (e.g., car sharing vs. bike sharing).

SC experiments may be entirely hypothetical, or they may include information from revealed behavior provided by participants. Participant-specific information may be used to tailor the 
experiment in hopes of injecting a greater dose of realism into the choice task. This revealed information may enter the choice task directly (e.g., posing a choice between a participant's current travel mode and hypothetical alternatives), indirectly (e.g., using location or trip details to adjust options or attribute levels for added realism), or both.

For the purpose of this project, since not all the emerging modes are available to most participants in the data we plan to use, especially for the autonomous vehicle mode, we chose to use SP techniques and SC experiments to estimate participants' willingness to accept tradeoffs between attributes as well as across different modes. For increased realism, we used revealed information about participants' current travel and options to tailor the choice tasks, as explained in detail in the SC survey design description.

\subsubsection{Stated Choice Survey Design}

The stated choice experiment was designed to understand the various tradeoffs that respondents make when choosing a mode for a particular trip under a given set of conditions. Modes included participants' current travel mode (which included both conventional and emerging modes) as well as emerging alternative modes: autonomous vehicle (AV), ride hailing, floating car share, and bike share. Trip types were elicited from actual travel and included both work (commuting) and non-work travel such as shopping, social activities, personal business, etc. Alternative mode attributes of the trip included: travel time (broken down into in-vehicle, walk access/egress, and waiting time), out-of-pocket cost, and, for certain modes, whether or not the ride was shared with another party.

The SC experiment was designed and pre-tested with collaborators of this project before actual participants were recruited. Because of our desire to test a number of emerging mode alternatives and to tailor the choice tasks on an individual basis, a full factorial design (all possible combinations of choices and attributes) was not possible. Instead, we opted for a fractional factorial design executed by randomizing alternatives and attribute levels subject to certain bounds established by design and by revealed information. The survey questionnaire was be designed to incorporate the SC experiments as well as a number of questions about the respondent, their attitudes and preferences, and their patterns of existing travel behavior.

\subsubsection{Choice tasks}

Each respondent was asked to complete two SC experiments, each consisting of five choice tasks. The trip context for each experiment was established by asking respondents to recall a recent trip from their home to another location. Participants who worked outside their home were first prompted to recall their most recent trip from home to work, while others were first asked to recall any recent trip. Everyone was then asked to recall a trip to a different destination for the second experiment.

Within each experiment, each task asked respondents to compare their current mode and its attributes against a pair of emerging mode alternatives. At the beginning of each experiment, a brief description of each emerging mode was provided to familiarize them. It was further asked that respondents consider that all other conditions (e.g., number traveling with them) were the same as their recent trip and also that the emerging modes were "widely available and well- 
proven at the time [they] would be making the choice.” This was done to focus the choice decision on differences in attributes (that we could control) and mitigate the effects of uncontrolled influences (e.g., perceived reliability or availability of different technologies).

For each choice task, one self-driving (AV) and one non-AV alternative were chosen at random, subject to availability constraints (Figure 2.1). Self-driving modes consisted of shared vehicle (traveler does not own the vehicle but has exclusive use of it for the trip) and shared ride options. Other modes included floating car share, public bike share, and ride-hail services (again, both shared vehicle and shared ride). Self-driving modes were always available, since they do not require anything from participants beyond payment and were not expected to be used for current travel by participants. Car share was available only to licensed drivers. Bike share was available to those physically able to bike for trips of not more than five miles. If one of the emerging modes was the same as that used on the actual trip, it was not presented as an additional alternative.

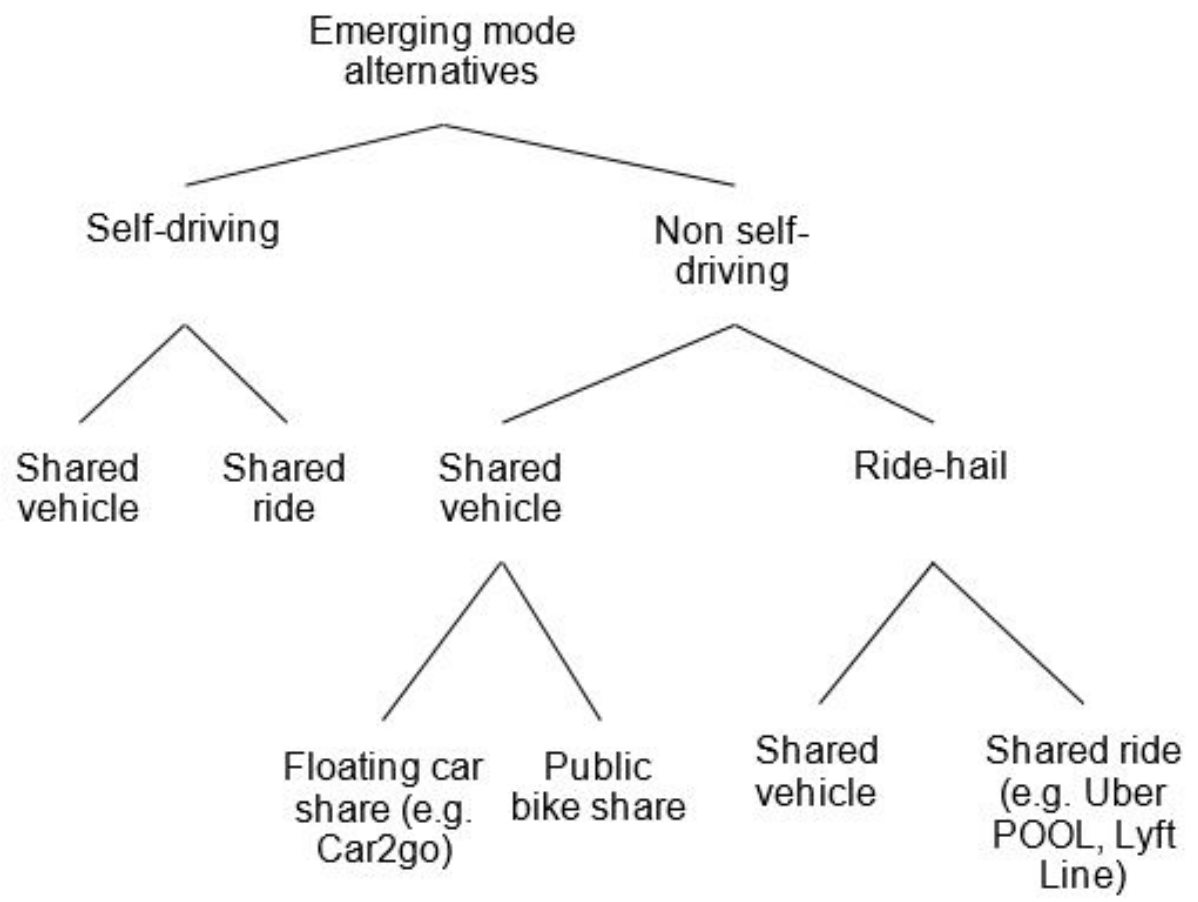

Figure 2.1: Emerging mode alternatives

Attributes of the revealed (actual) mode were fixed to the respondent-supplied values. Attribute levels of the emerging mode alternatives were set at random based on a combination of revealed trip characteristics, respondent location, and defined attribute ranges based on our review of estimated costs (self-driving modes) or currently offered services (other modes). Realistically, auto-based modes will all be subject to the same traffic congestion and speed limits; therefore, we set in-vehicle time of these modes to match revealed drive time, where available. When not available (e.g., respondent used transit or other non-auto mode), we used an estimate of drive time specific to the respondents' trip distance and trip purpose (work or non-work) derived from NHTS (2009) data and controlling for fixed effects across different cities. Full estimation results of our travel time model are provided as an appendix. The city-specific intercepts (i.e., the part of 
travel time not related to distance) were used as an estimate of the walk access to car share time in different locations (e.g., due to differences in competition for parking by city). Rather than try to estimate the driving time impact of shared ride services (i.e., when additional passengers might be picked up along the way), we chose to reflect this additional uncertainty in terms of higher waiting time levels. Similarly, rather than distinguish between station-based (docked) and dockless bike share explicitly, we elected to capture the difference in terms of walking time to access a bike.

In survey testing, multiple respondents felt the lowest estimates of self-driving costs (\$0.075\$0.15 per mile) seemed unrealistically low, perhaps reflecting that most estimates have assumed marginal cost pricing when in reality perfect competition is unlikely. In response, we shifted the costs of AV options slightly upward for the final survey by eliminating the lowest level. Table 2.1 provides the SC experiment attribute levels from which a random choice was made for each choice task mode "card."

Table 2.1: Attribute levels for SC experiments

\begin{tabular}{|c|c|c|c|c|c|c|}
\hline \multirow[b]{2}{*}{ Attribute } & \multicolumn{2}{|c|}{ Self-driving alternatives } & \multicolumn{4}{|c|}{ Non-self-driving alternatives } \\
\hline & Self-driving & $\begin{array}{l}\text { Self-driving } \\
\text { (shared ride) }\end{array}$ & Ride-hail & $\begin{array}{c}\text { Ride-hail } \\
\text { (shared ride) }\end{array}$ & Car Share & Bike Share \\
\hline $\begin{array}{l}\text { In-vehicle } \\
\text { travel time } \\
\text { (mins) }\end{array}$ & \multicolumn{5}{|c|}{ revealed driving time or NHTS estimate } & $\begin{array}{l}\text { revealed } \\
\text { distance at } \\
\text { assumed } 10 \\
\mathrm{mi} / \mathrm{hr}\end{array}$ \\
\hline $\begin{array}{l}\text { Out of } \\
\text { pocket cost } \\
(\$)\end{array}$ & $\begin{array}{c}{[0.30,0.60} \\
1.00,1.50 \\
2.00] / \text { mile }\end{array}$ & $\begin{array}{l}{[0.5,0.65} \\
0.8] * \text { Self- } \\
\text { driving cost }\end{array}$ & $\begin{array}{c}{[0.80,1.20,1.50]} \\
/ \mathrm{mi}+[0.10,0.20 \\
0.30] / \mathrm{min}+ \\
{[2.00,2.50,3.00,} \\
3.50,4.00]^{1}\end{array}$ & $\begin{array}{l}{[0.5,0.65,0.8]} \\
* \text { Ride-hail cost }\end{array}$ & $\begin{array}{c}{[0.35,0.40} \\
0.45,0.50] \\
/ \min +1.00\end{array}$ & $\begin{array}{c}\text { [1.00, 2.00, } \\
3.00] \text { /trip }\end{array}$ \\
\hline $\begin{array}{l}\text { Walk time } \\
\text { (mins) }\end{array}$ & \multicolumn{4}{|c|}{0} & $\begin{array}{l}\text { NHTS city- } \\
\text { specific } \\
\text { model } \\
\text { estimate }\end{array}$ & {$[0,5,10]$} \\
\hline $\begin{array}{l}\text { Wait time } \\
\text { (mins) }\end{array}$ & {$[2,5,10]$} & {$[2,10,15]$} & {$[0,5,10]$} & {$[0,10,15]$} & \multicolumn{2}{|l|}{0} \\
\hline
\end{tabular}

Note: time values presented were rounded to nearest integer; money rounded to nearest \$0.05

\subsubsection{Additional survey questions}

In addition to survey items already described to support the SC experiment, we also asked additional questions about socio-demographics, current travel patterns, and attitudes toward travel and technology. Attitudinal questions were derived from several sources: previous work by project collaborators, a subset of the Media and Technology Usage and Attitudes Scale (MTUAS) (Rosen et al., 2013), and a recent poll on attitudes toward self-driving technology (Pew, 2017). The complete survey questionnaire is provided as an appendix.

While we did not ask specifically about respondents' comfort with either ride-hail drivers or AVs, the experimental design allows us to infer that information from subsequent choice modeling since, controlling for other attributes, the only difference between ride-hail and AV options in our experiment is the presence of a driver. 


\subsubsection{Survey Implementation}

\subsubsection{Sampling}

We defined our sampling frame as all adults with internet access in the largest 50 U.S. cities. We considered that these are the areas where emerging modes are already available (car share, bike share, ride-hail) or likely to be available sooner (AV). Those without internet access or in smaller markets were viewed as less likely to be early adopters of emerging modes, and perhaps less likely to meaningfully consider them as viable options in choice experiments.

We used two methods for the recruitment of participants: Amazon Mechanical Turk (MTurk) and InfoUSA email lists. MTurk is a program through which participants can choose to complete an online task (such as our web survey) for a fixed amount of compensation. In either case, participants were invited at random and opted in after learning about the research project and survey. MTurk participants were screened by an initial zip code question to ensure they lived within a target city, while InfoUSA invitees were pre-screened by ZIP Code. MTurk participants were offered $\$ 2$ to complete the survey. Email participants were offered entry into a drawing for an Amazon gift card (\$50 or \$250). Unfortunately, our email campaign was not successful in recruiting participants ( $<1 \%$ response rate), and so the results are almost entirely based on the MTurk sample. We can only speculate that the lack of response to our email campaign was due to ever-more complex email filtering tools and perhaps general fatigue for email offers and solicitations. Although past research has indicated that email recruitment can be nearly as effective as postal mail campaigns, our experience suggests this may no longer be the case.

\subsubsection{Web survey instrument}

We implemented the survey using a combination of Qualtrics survey software and a custom Python web service we developed to handle the SC experiment logic. Initial revealed information provided by respondents was sent via Qualtrics to the Python web service before each experiment to evaluate our alternative availability conditions and randomly select alternatives and attribute levels for each of the five choice tasks per experiment. Before launching the live survey, we tested our web service's ability to handle a "worst case" situation of thousands of respondents taking the survey at the same time. No technical issues were noted during deployment.

We considered several variations of choice task presentation, including graphical depictions of emerging mode options. In the end, we chose to use a simple text-based "card" style for two reasons: 1) to ensure focus on the attributes of various modes than reactions to a certain depiction of, for instance, a self-driving vehicle, and 2) to ensure that the card display would appear equivalently across web browsers and mobile phone platforms. An example choice task presentation is shown in Figure 2.2. A respondent would have already been provided with instructions and a brief description of the emerging mode options. Alternatives (including the current revealed option) were presented in random order for each task. 
If the following options were available, how would you have made this trip?

Current Option

$\$ 2.00$ out of pocket

30 minutes total

(including 0 minutes walking

and 0 minutes waiting)
Self-driving car shared with unknown passenger $\$ 1.50$ out of pocket 40 minutes total (including 0 minutes walking and 10 minutes waiting)
Bike share bike $\$ 2.00$ out of pocket

35 minutes total (including 5 minutes walking and 0 minutes waiting)

(a)

\begin{tabular}{|l|}
\hline $0 \%$ \\
If the following options were \\
available, how would you have \\
made this trip? \\
Current Option \\
$\$ 2.00$ out of pocket \\
30 minutes total \\
(including 0 minutes walking \\
and 0 minutes waiting) \\
Self-driving car shared with \\
unknown passenger \\
$\$ 1.50$ out of pocket \\
40 minutes total \\
(including 0 minutes walking \\
and 10 minutes waiting) \\
\end{tabular}

(b)

Figure 2.2: Sample choice task from (a) web and (b) mobile survey. Current option was walking, in this case. 


\subsection{SURVEY DATA}

There are 1,117 survey participants. Figure 3.1 shows the number of survey participants by urbanized areas (UZAs). The geographic distribution generally corresponds to the population size of UZAs, indicating the survey is largely representative, even though for this study we were not specifically aiming for a representative sample.

\subsection{SOCIO-DEMOGRAPHIC CHARACTERISTICS}

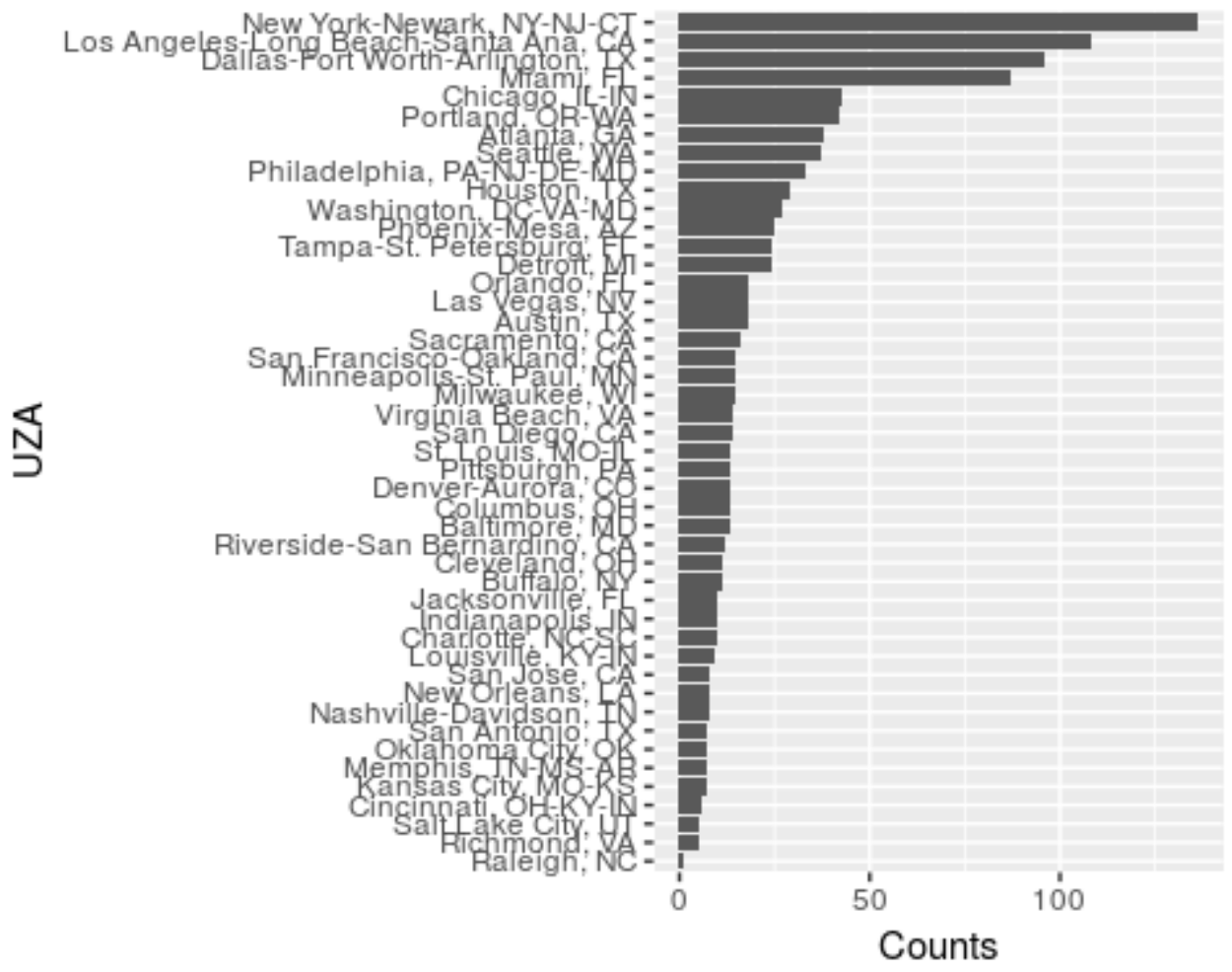

Figure 3.1: Number of survey respondents by UZA 
Figure 3.2 shows the household income distribution. There are the most participants in the household income bracket of $\$ 45,000-\$ 59,999$, followed by $\$ 60,000-\$ 74,999$ and $\$ 75,000$ $\$ 99,999$. The median household income of the survey respondents falls in the bracket of $\$ 45,000-\$ 59,999$, which is in line with the 2017 median household income in the U.S. reported by the Census Bureau.

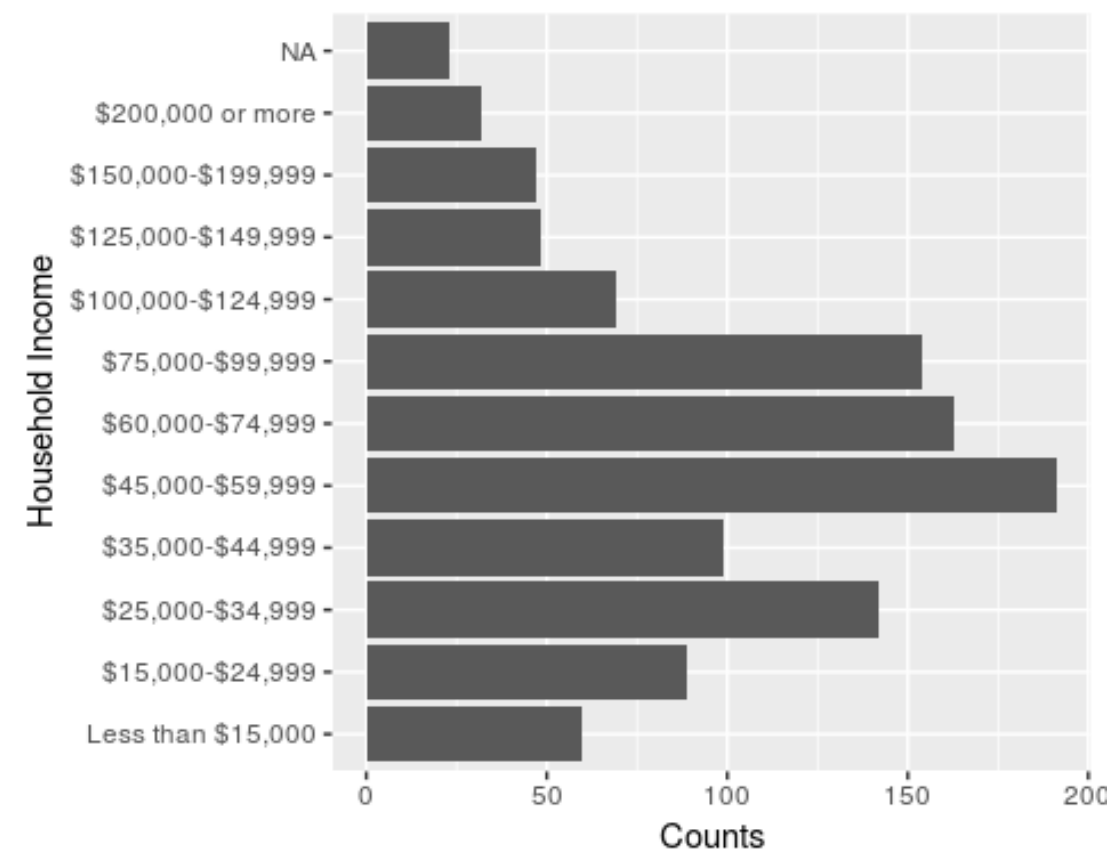

Figure 3.2: Number of survey respondents by household income 
Figure 3.3 shows that there are more participants owning their home than those renting, and these two living situations make up the majority of participants.

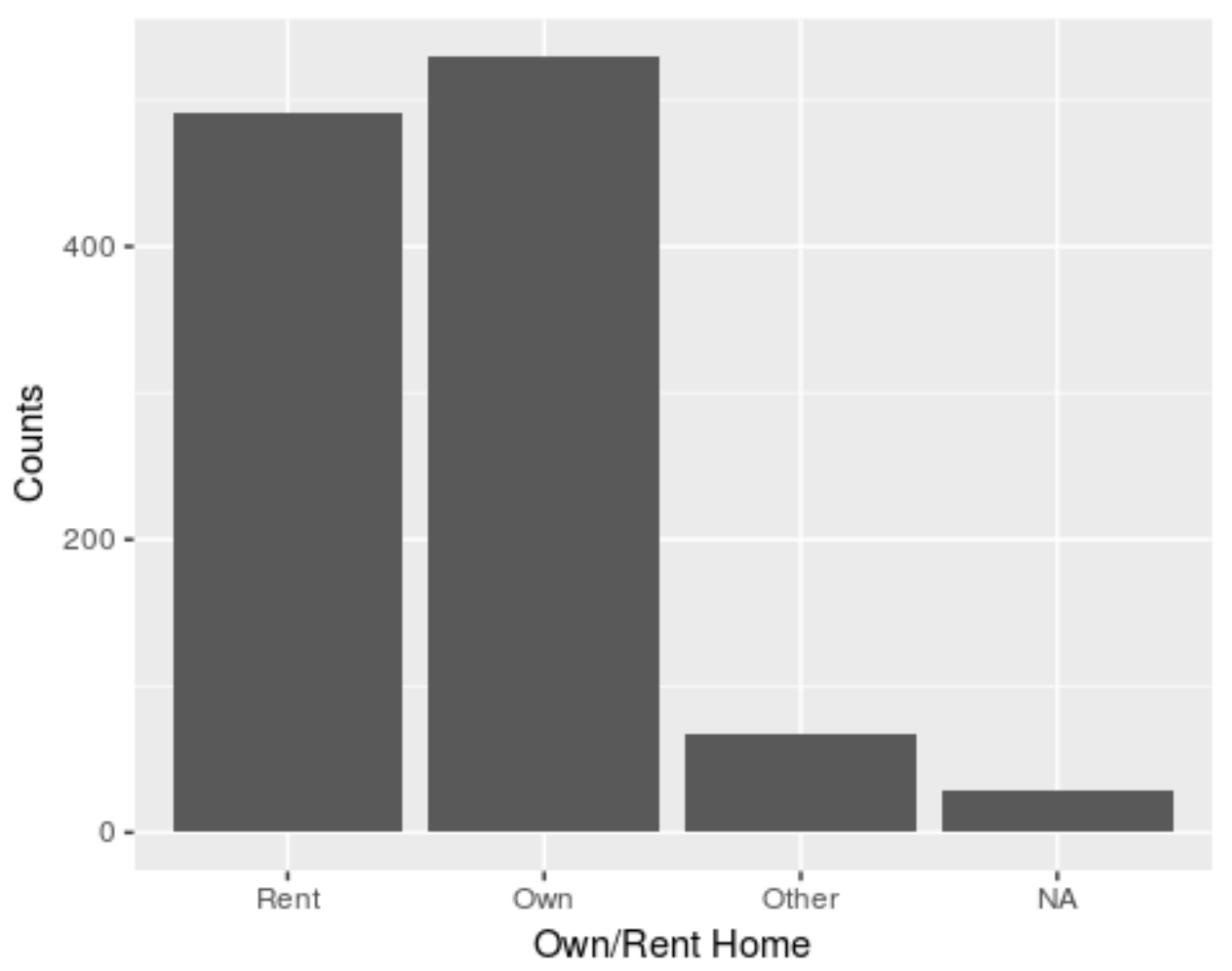

Figure 3.3: Status of owning/renting home 
Figure 3.4 presents the number of participants by their household size. The mean and median of household size is 2.88 and 3.00, respectively.

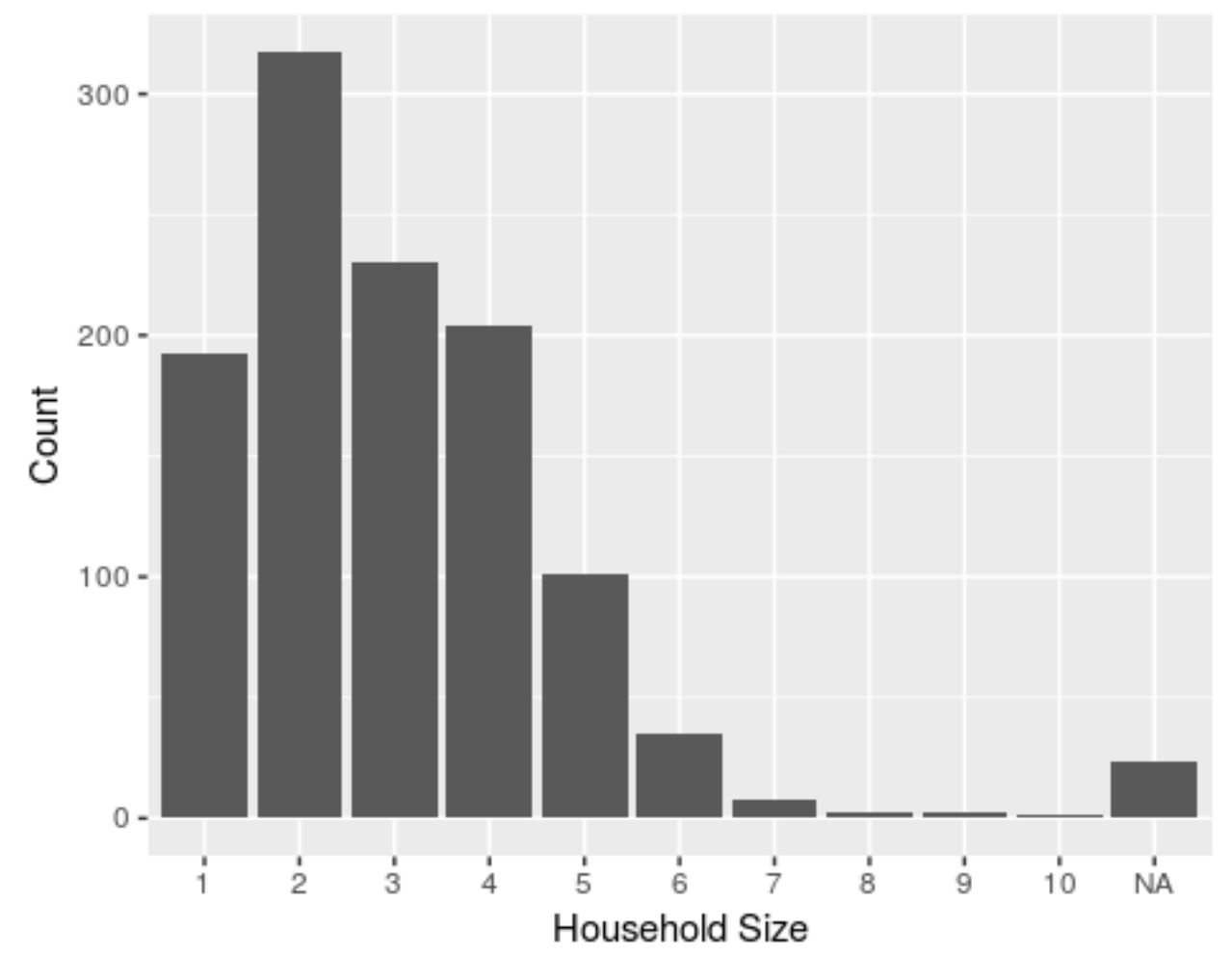

Figure 3.4: Distribution of household size of participants 
As Figure 3.5 shows, the majority of the participants are under the age of 40 . The participants are younger than the overall population. There are also more male than female participants.

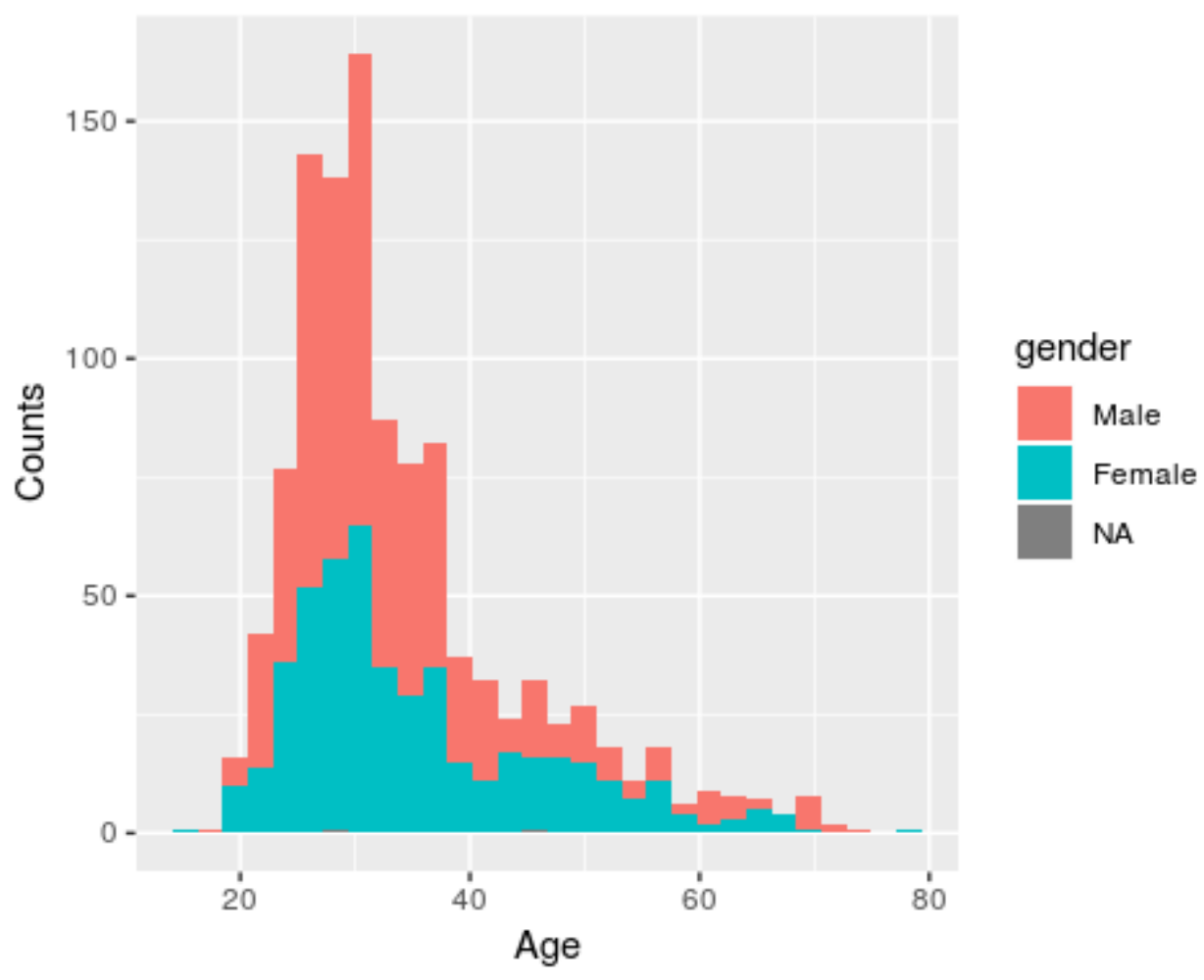

Figure 3.5: Age distribution of survey respondents by gender 
Figure 3.6 shows the race distribution of the participants. The majority of participants are White, followed by Black, Native American, Asian, and Hispanic or Latino origin. These five race/ethnic categories account for more than $90 \%$ of participants. Note that the respondents are allowed to choose multiple races in the survey.

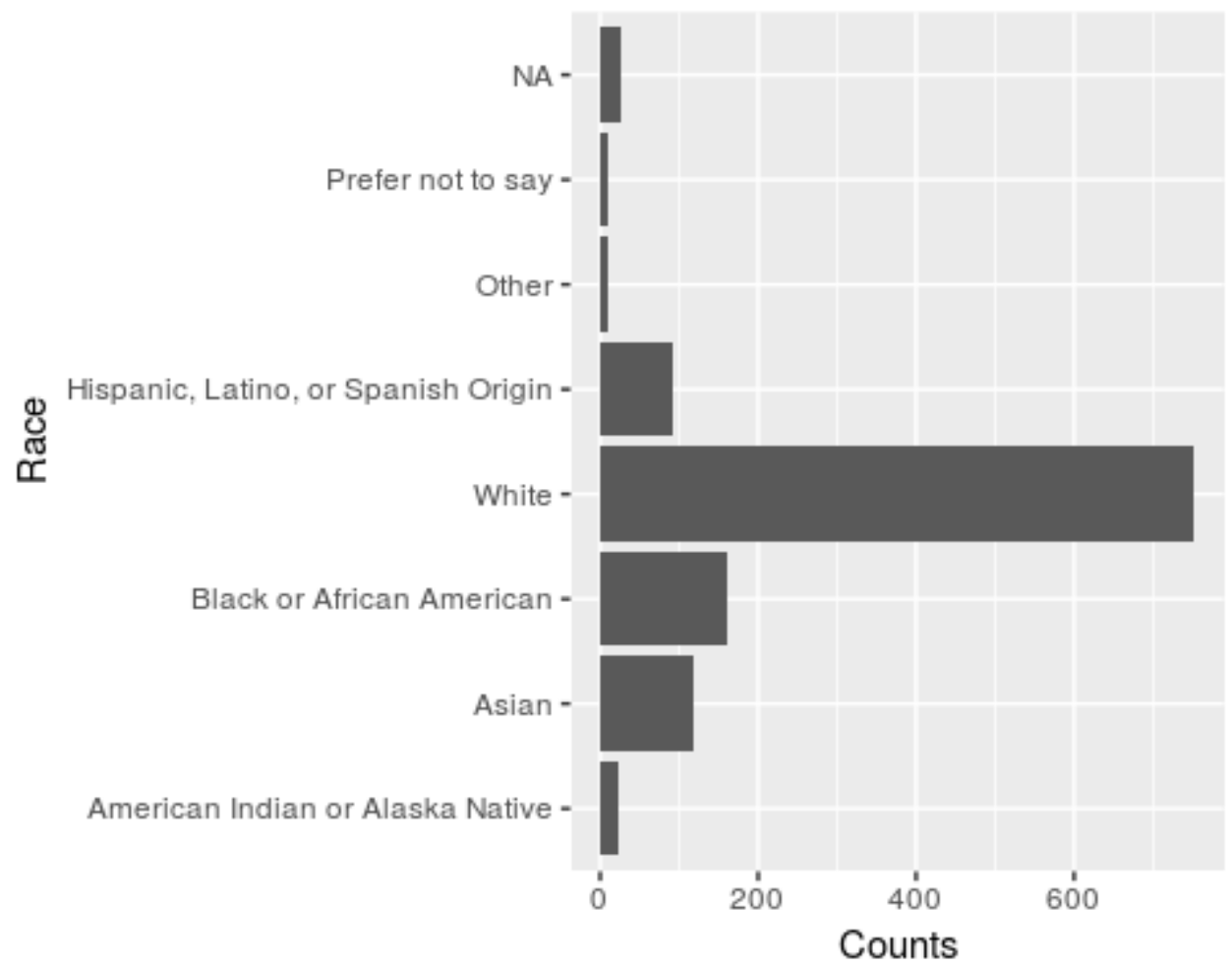

Figure 3.6: Race/Ethnic characteristics of survey respondents 
Figure 3.7 presents the education level of the participants. More than half of the participants have a bachelor's degree or higher level of education. This is in accord with the characteristics of emerging modes users, who tend to have higher education levels than the overall population.

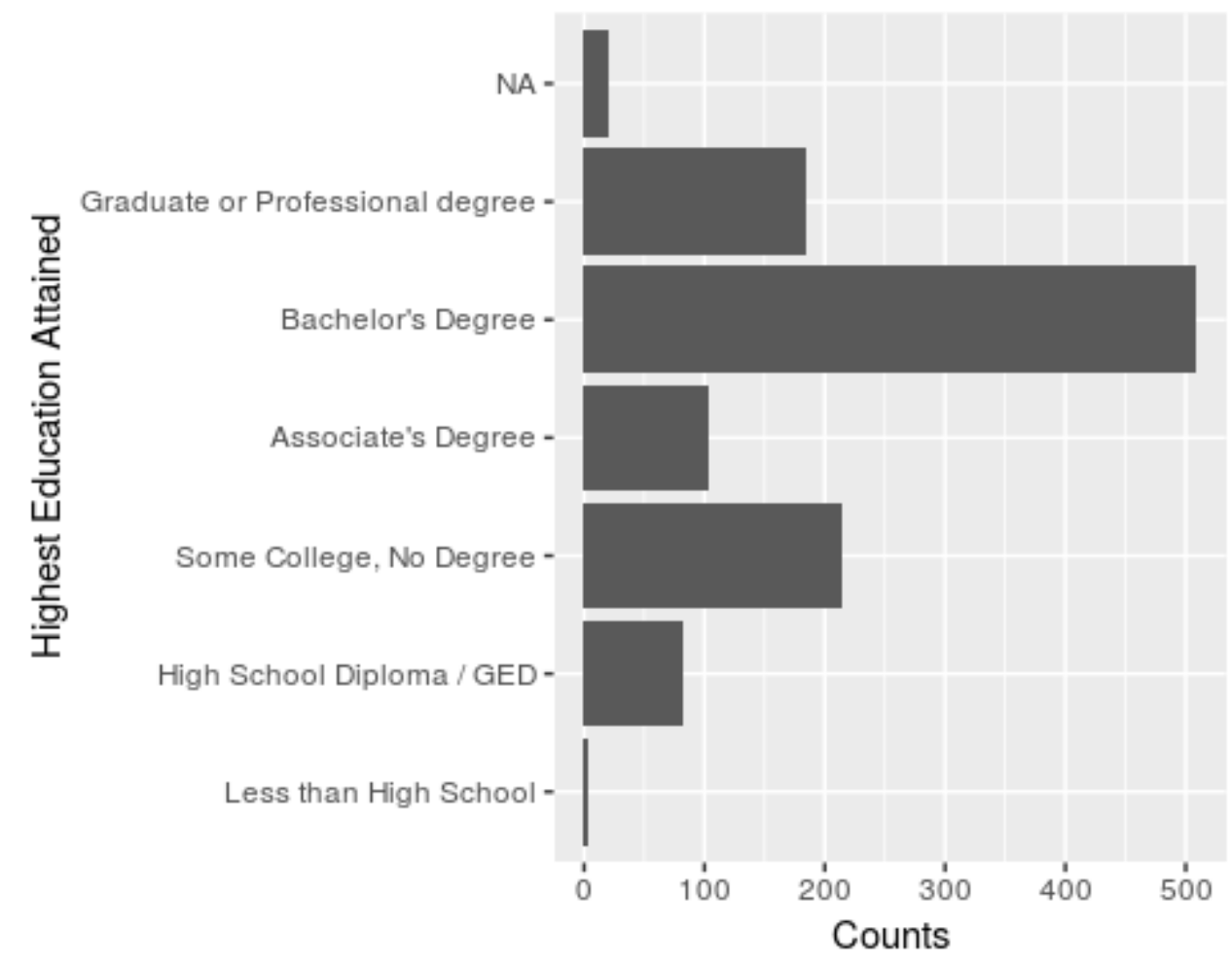

Figure 3.7: Education level of participants 
Figure 3.8 shows participants' hours worked per week by number of jobs. The majority of participants work for more than 35 hours per week, and some of these participants have two jobs. There is also a substantial proportion of the participants who work for less than 35 hours per week.

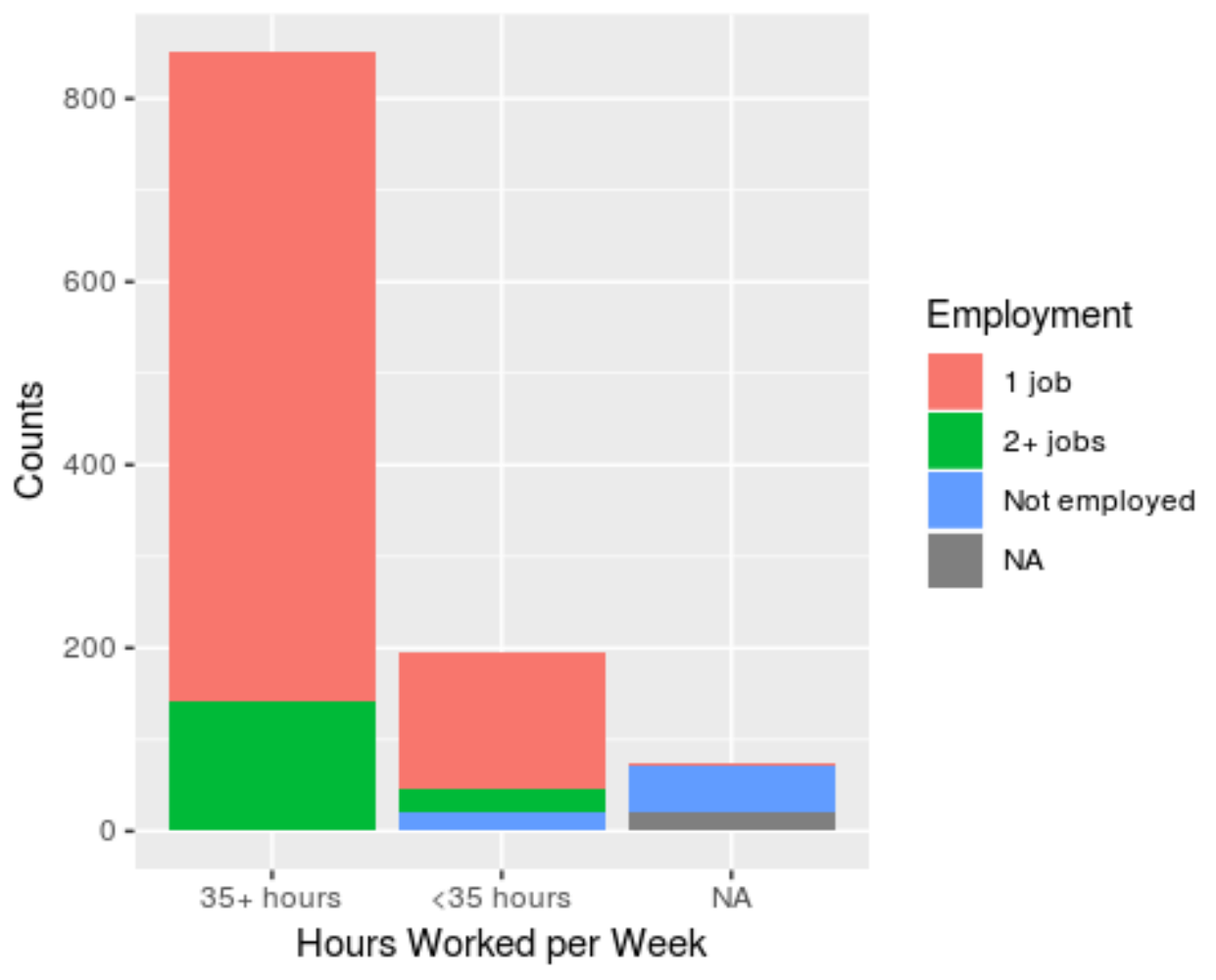

Figure 3.8: Hours worked per week by number of jobs 
As Figure 3.9 shows, students, either full-time or part-time, account for a large proportion of the participants. Students may be more willing to use emerging modes and take surveys online.

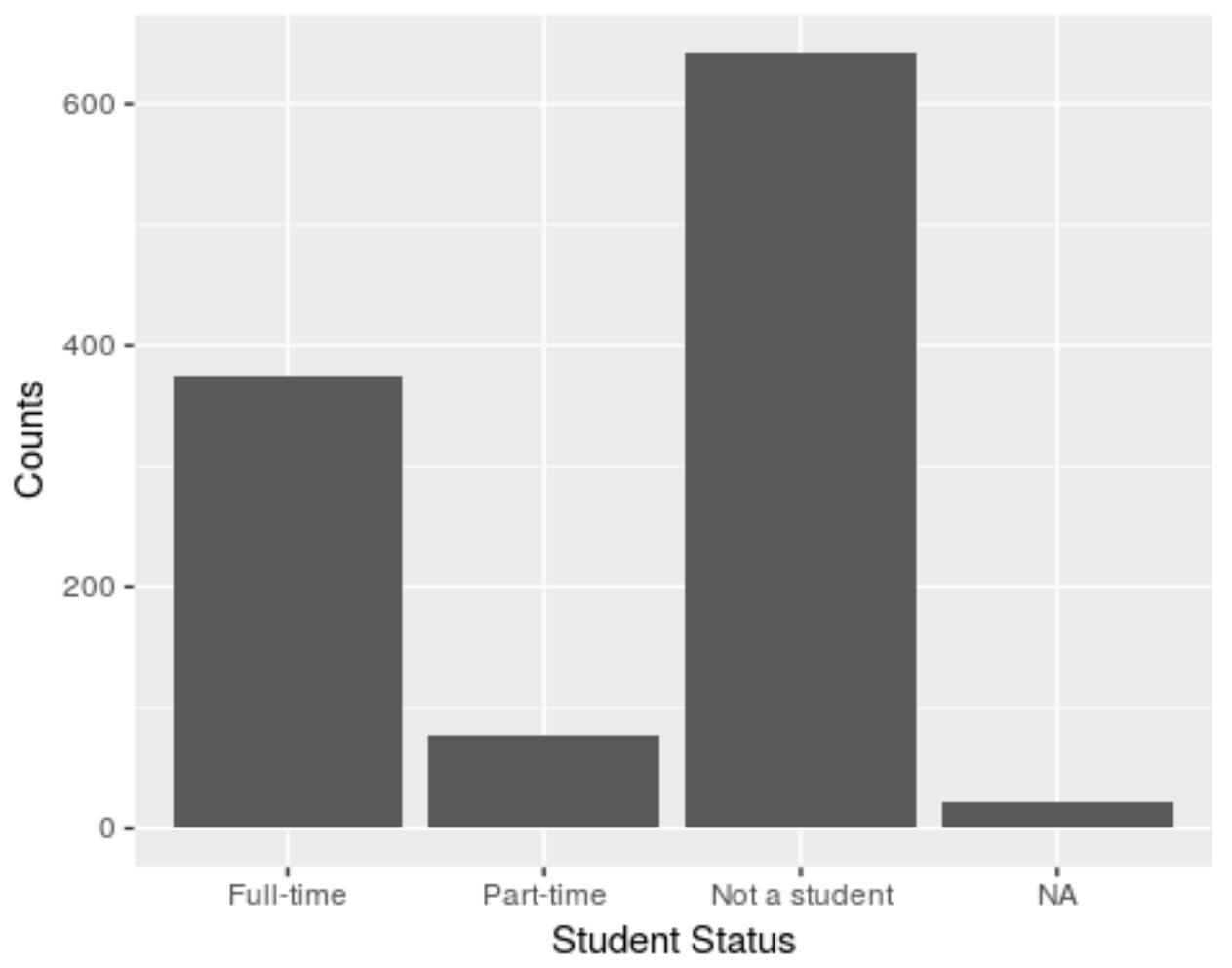

Figure 3.9: Student status of survey respondents 
Figure 3.10 presents the availability of travel modes and technologies of the participants. Stable internet, debit card, credit card, and smart phone are available to the majority of the participants. These technologies are necessary for utilizing emerging modes, especially ride-hailing services. The number of participants who have an active ride-hailing account is relatively small (much smaller than those who have internet, debit card, credit card, and smart phone). A car is available to most participants, as the revealed preference data show that driving is still the dominant travel mode for most people. The number of participants who have a parking pass is smaller than those who possess a transit pass. The number of participants who are members of a car-sharing program is tiny, which is similar to those who have a bike-share membership. The number of participants who have a working bicycle is much larger than those who are members of a bikesharing program. This is expected because car sharing and bike sharing are not yet as widely available in America as other options.

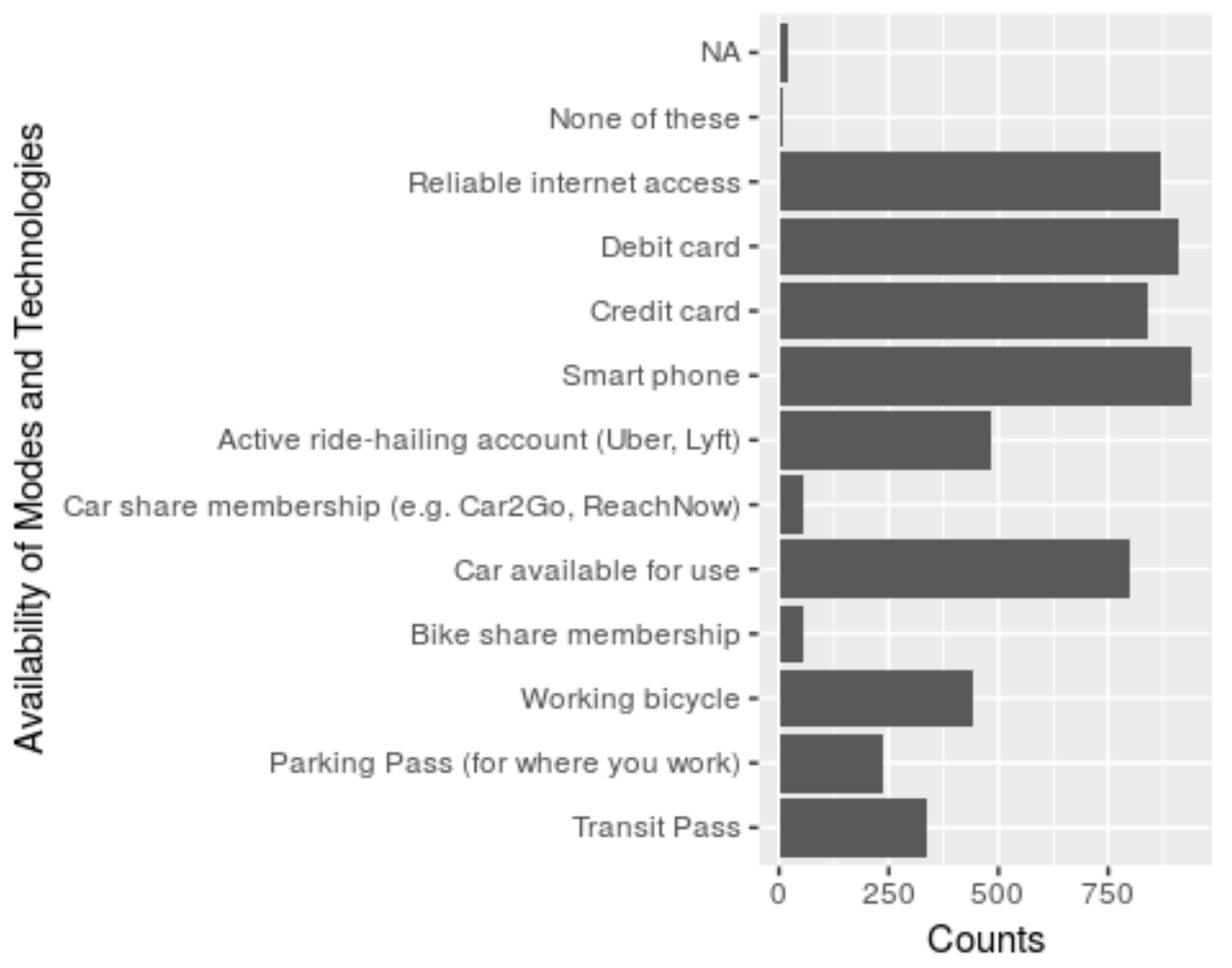

Figure 3.10: Mode and technology availability of participants 
Figure 3.11 presents who pays for a parking pass. The majority of participants do not indicate who pays for their parking pass, as most probably do not own a parking pass. Among those who provide the information, the majority of the parking passes are paid by their employers, either in full or partly.

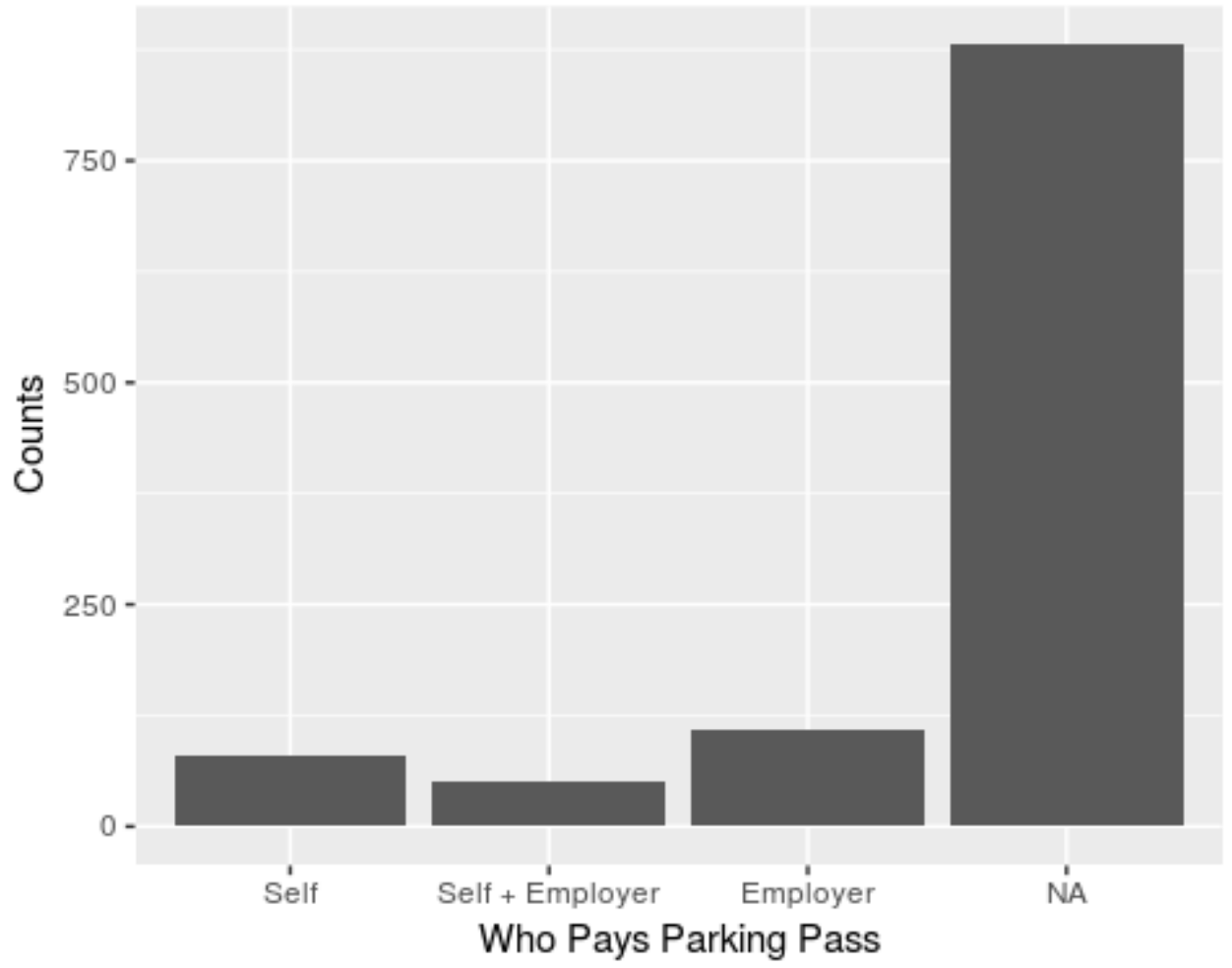

Figure 3.11: Number of participants by who pays for parking pass 
Figure 3.12 shows who pays for transit (self, employer, or each paying a part) among those having a pass. The majority of the participants do not indicate who pays for their transit pass. Among those who provided the information, the majority of the transit passes are paid for by the participants themselves and only a small proportion of their transit passes are paid for by their employers.

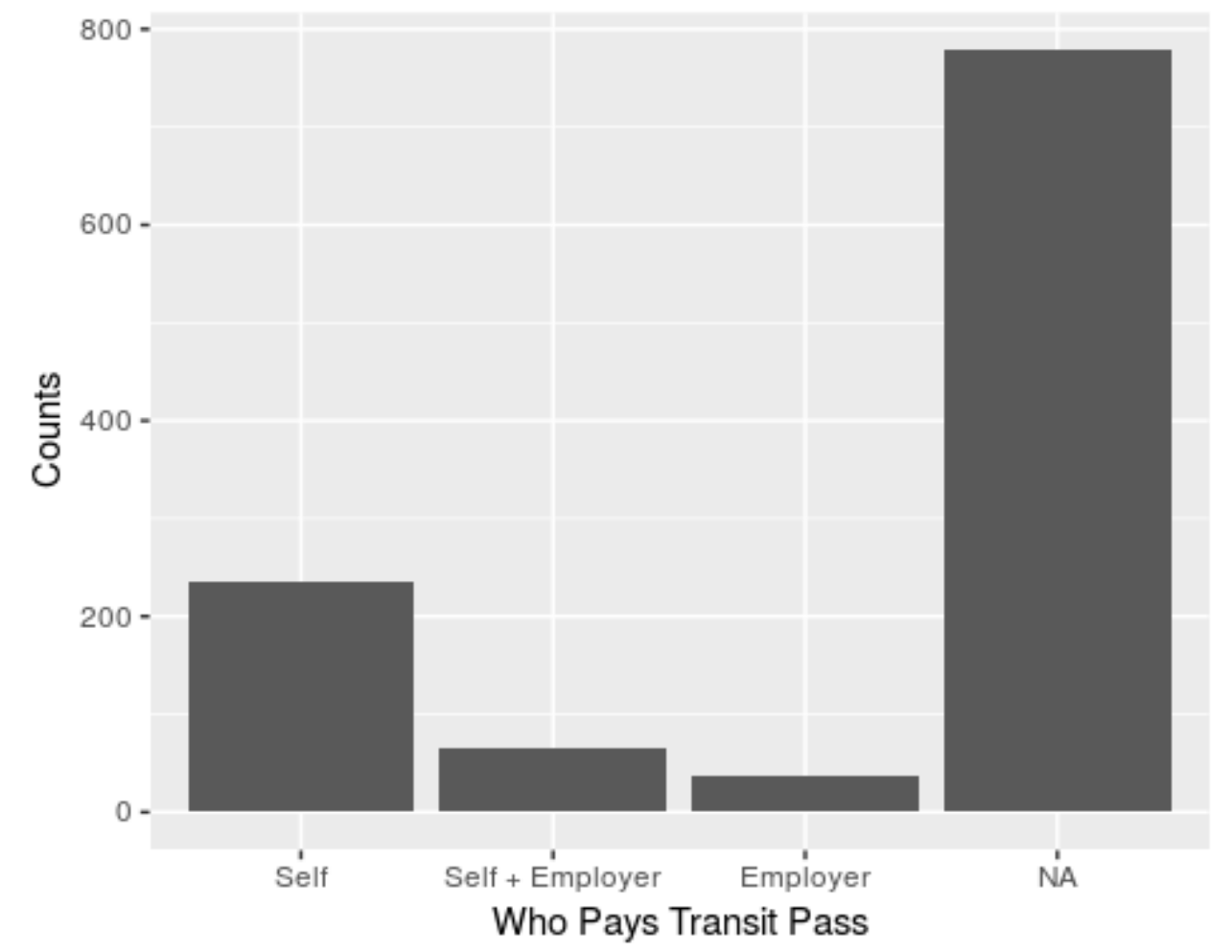

Figure 3.12: Number of participants by who pays for transit pass 
Figure 3.13 shows the survey participants who self-report good health, with participants claiming Excellent, Very Good, Good, or Fair Health making up more than 95\%. The health condition question is included in the survey because it may influence the respondents' capability of utilizing certain modes, in particular, biking.

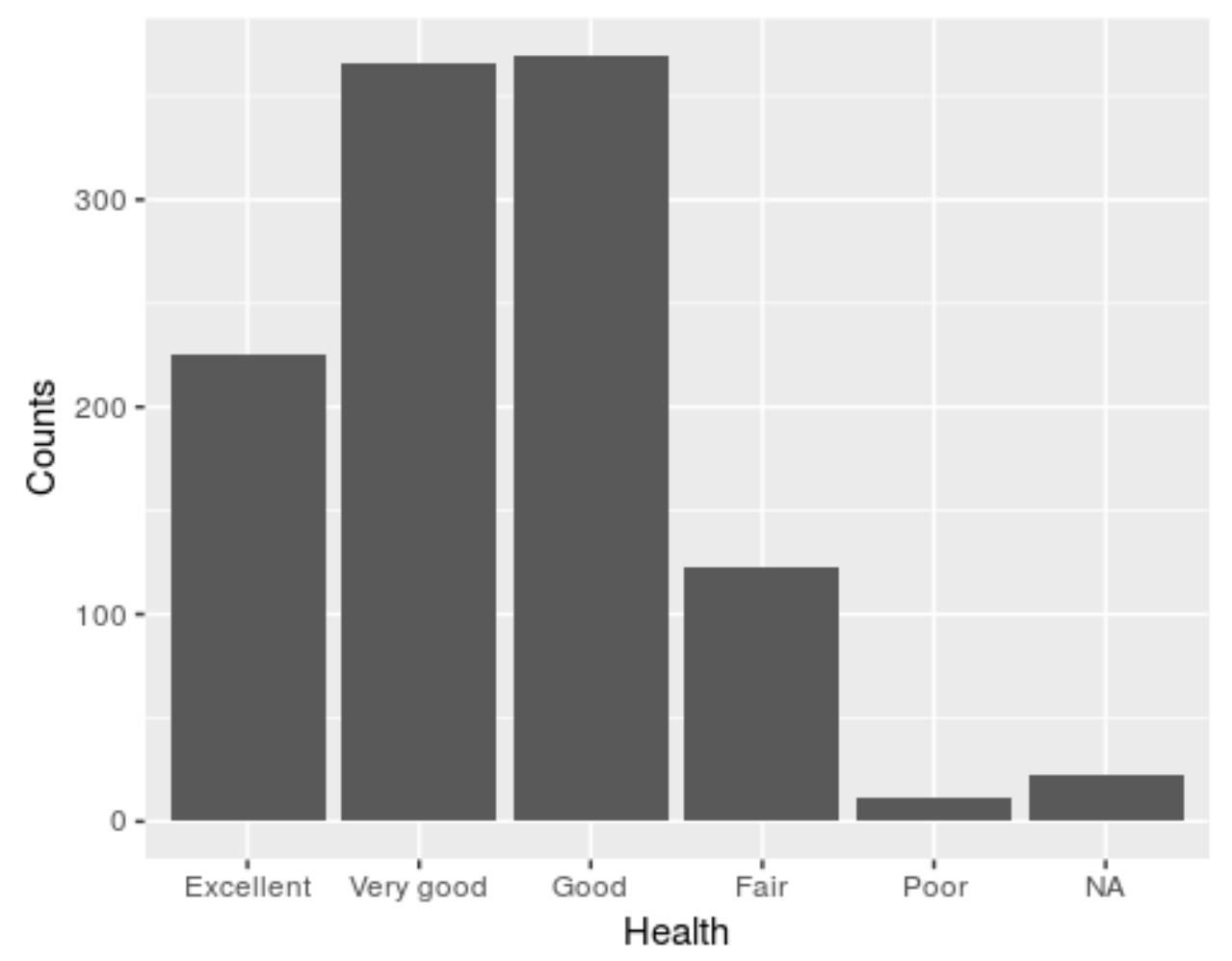

Figure 3.13: Self-report health condition

\subsection{DESCRIPTIVE STATISTICS OF REVEALED PREFERENCE (RP) DATA}

In the survey, respondents are asked to recall two recent trips, and, correspondingly, two hypothetical scenarios for stated preference (SP) experiments are pivoted from the attributes of these two reference trips. The summary statistics of the first recalled (revealed reference) trips are shown in Table 3.1. Figure 3.14 shows the frequency by modes and trip purposes for the first recalled trip. For the first trip, participants were asked to recall their most recent trip from home to work, if they reported a workplace outside the home. 
Table 3.1: Descriptive statistics of the first RP trip

\begin{tabular}{l|r|r|r|r|r}
\hline & min & max & Median & mean & std.dev \\
\hline cost & 0.0 & 150 & 0 & 4.83 & 13.33 \\
\hline dist & 0.1 & 150 & 10 & 12.33 & 11.89 \\
\hline totmins & 3.0 & 174 & 31 & 39.03 & 27.04 \\
\hline walk & 0.0 & 120 & 3 & 8.02 & 14.17 \\
\hline wait & 0.0 & 73 & 3 & 5.65 & 7.91 \\
\hline ivmins & 3.0 & 125 & 20 & 25.36 & 16.24 \\
\hline ivspeed & 0.6 & 78 & 28 & 29.65 & 17.41 \\
\hline
\end{tabular}

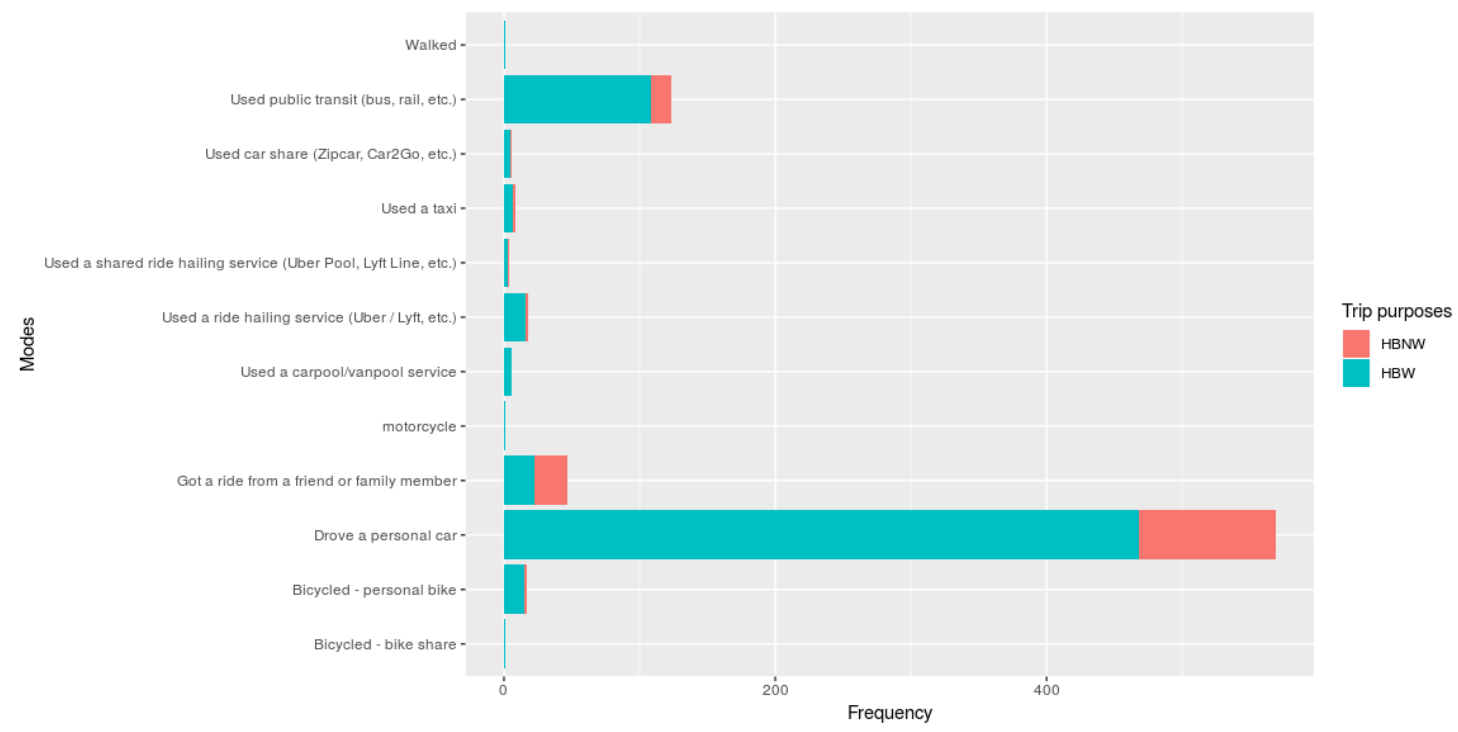

Figure 3.14: Frequency by mode and purpose of the first recalled trip

The summary statistics of the second recalled (revealed reference) trips are shown in Table 3.2, while Figure 3.15 shows the frequency by mode and purpose. The second recalled trips are all home-based non-work (HBNW) trips.

Table 3.2: Descriptive statistics of the second RP trip

\begin{tabular}{l|r|r|r|r|r}
\hline & min & max & median & mean & std.dev \\
\hline cost & 0.00 & 250 & 0 & 5.43 & 16.01 \\
\hline dist & 0.15 & 200 & 6 & 11.02 & 15.53 \\
\hline totmins & 2.00 & 177 & 22 & 31.10 & 27.50 \\
\hline walk & 0.00 & 120 & 1 & 4.83 & 10.75 \\
\hline wait & 0.00 & 50 & 0 & 4.35 & 7.25 \\
\hline ivmins & 2.00 & 160 & 15 & 21.92 & 20.41 \\
\hline ivspeed & 0.60 & 75 & 27 & 29.70 & 17.42 \\
\hline
\end{tabular}




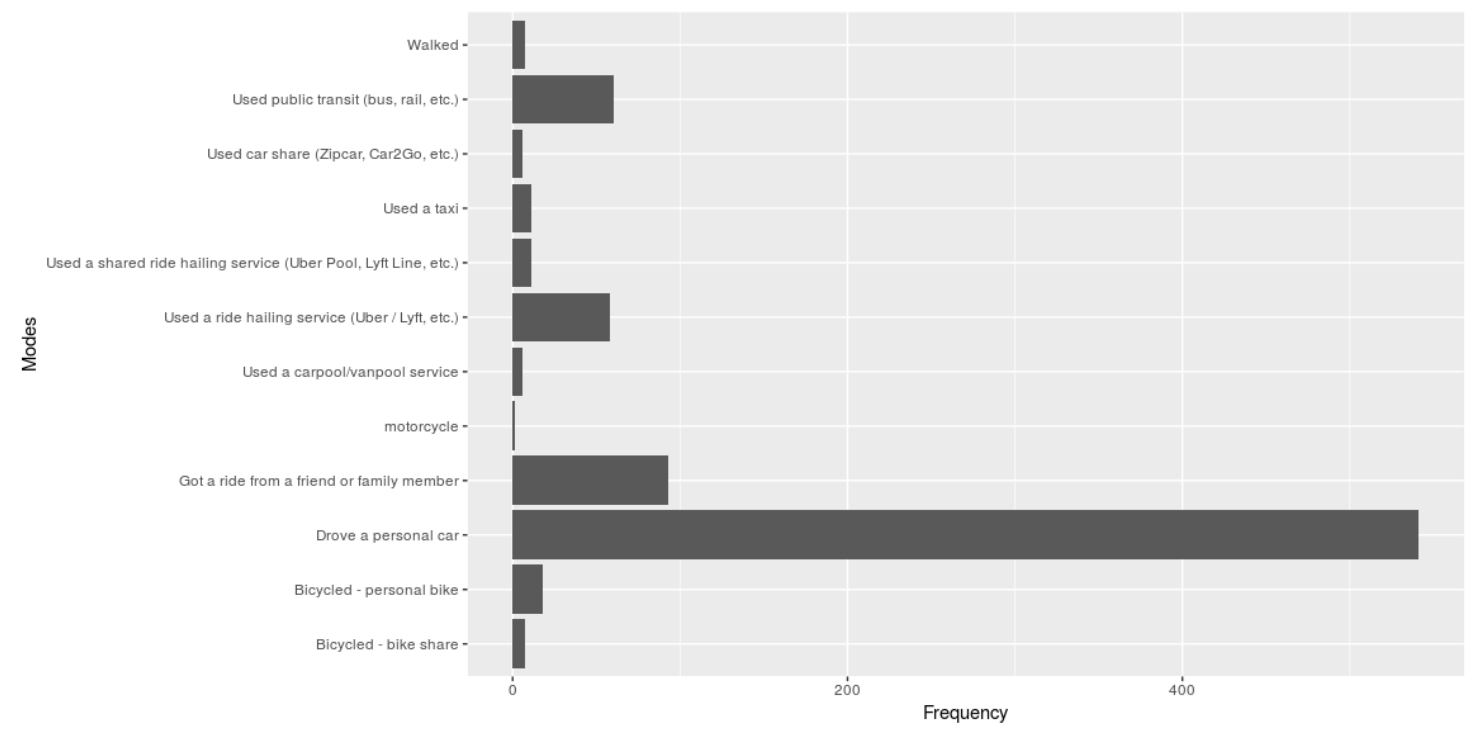

Figure 3.15: Frequency by mode of the second recalled trip

Table 3.3 shows the mode share of RP trips by trip purpose. The driving mode is the dominant mode for both HBW and HBNW trips. The emerging modes, such as ride-hailing, bike sharing, and car sharing, are used by some respondents for their recalled trips, but their mode share is very small.

Table 3.3: Mode share of RP trips by trip purpose

\begin{tabular}{l|l|r|c}
$\begin{array}{c}\text { Trip } \\
\text { Purpose }\end{array}$ & \multicolumn{1}{c|}{ Mode } & $\mathbf{n}$ & $\mathbf{\%}$ \\
\hline HBNW & Drove a personal car & 642 & 0.664 \\
\hline HBNW & Got a ride from a friend or family member & 118 & 0.122 \\
\hline HBNW & Used public transit (bus, rail, etc.) & 75 & 0.078 \\
\hline HBNW & Used a ride hailing service (Uber / Lyft, etc.) & 60 & 0.062 \\
\hline HBNW & Bicycled - personal bike & 20 & 0.021 \\
\hline HBNW & Used a shared ride hailing service (Uber Pool, Lyft Line, etc.) & 12 & 0.012 \\
\hline HBNW & Used a taxi & 12 & 0.012 \\
\hline HBNW & Bicycled - bike share & 7 & 0.007 \\
\hline HBNW & Used car share (Zipcar, Car2Go, etc.) & 7 & 0.007 \\
\hline HBNW & Walked & 7 & 0.007 \\
\hline HBNW & Used a carpool/vanpool service & 6 & 0.006 \\
\hline HBNW & motorcycle & 1 & 0.001 \\
\hline HBW & Drove a personal car & 468 & 0.717 \\
\hline HBW & Used public transit (bus, rail, etc.) & 108 & 0.165 \\
\hline HBW & Got a ride from a friend or family member & 22 & 0.034 \\
\hline HBW & Used a ride hailing service (Uber / Lyft, etc.) & 16 & 0.025 \\
\hline
\end{tabular}




\begin{tabular}{l|l|r|c}
\hline $\begin{array}{c}\text { Trip } \\
\text { Purpose }\end{array}$ & \multicolumn{1}{|c|}{ Mode } & n & \% \\
\hline HBW & Bicycled - personal bike & 15 & 0.023 \\
\hline HBW & Used a taxi & 7 & 0.011 \\
\hline HBW & Used a carpool/vanpool service & 6 & 0.009 \\
\hline HBW & Used car share (Zipcar, Car2Go, etc.) & 5 & 0.008 \\
\hline HBW & Used a shared ride hailing service (Uber Pool, Lyft Line, etc.) & 3 & 0.005 \\
\hline HBW & Bicycled - bike share & 1 & 0.002 \\
\hline HBW & motorcycle & 1 & 0.002 \\
\hline HBW & Walked & 1 & 0.002 \\
\hline
\end{tabular}

Figure 3.16 and Figure 3.17 show calculated average in-vehicle travel speed by mode for the first and second recalled trip, respectively. As expected, driving a personal car is the fastest mode, followed by riding as a passenger. The speed of ride-hailing services is much slower than driving a personal car. This is possibly because most ride-hailing trips are taken on urban roadways for shorter trips. The shared ride-hailing service requires time for collecting passengers, thus its average speed is even slower than that of the ride-hailing service. The speed of public transit, which includes both rail and bus, is similar to that of the ride-hailing service.

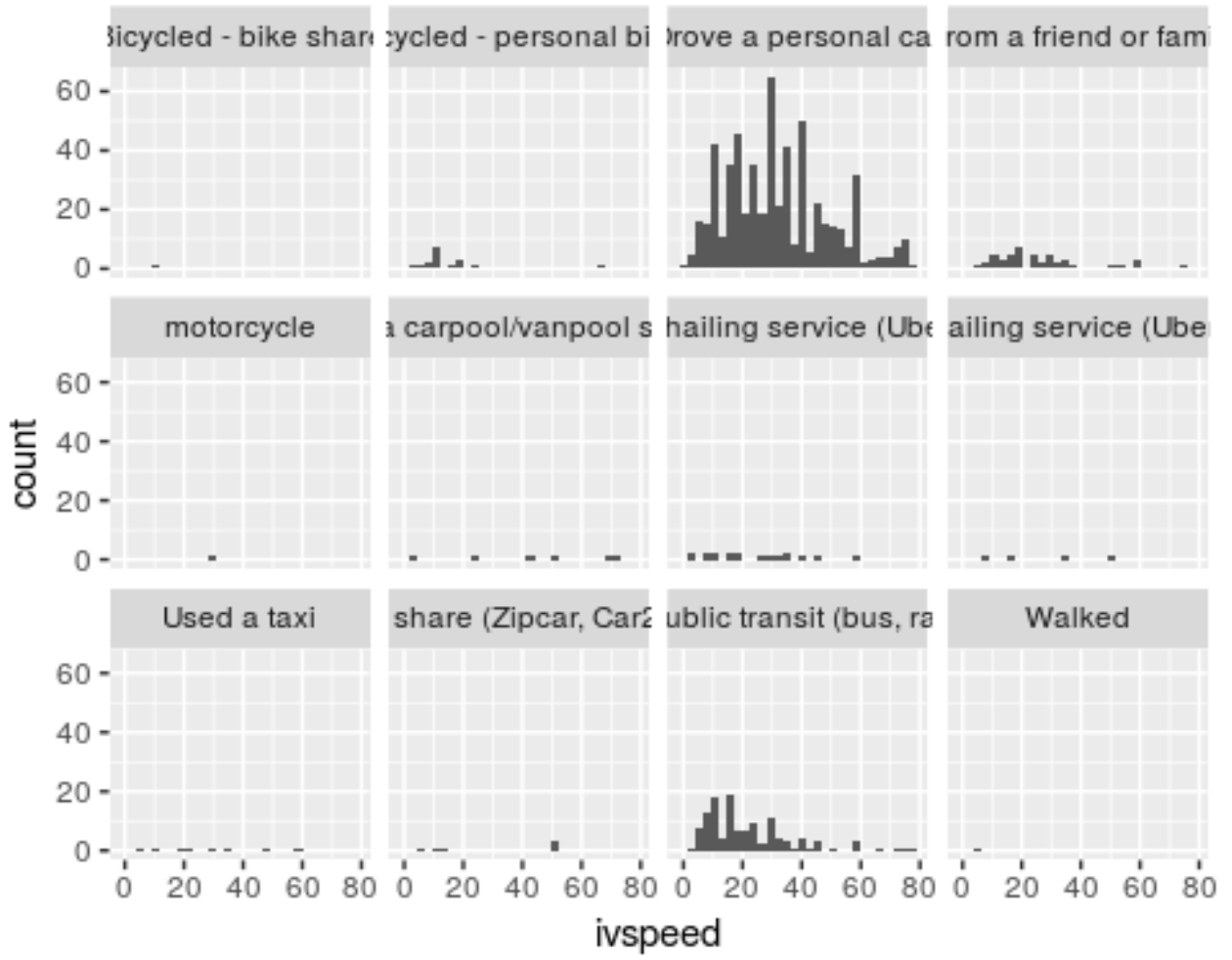

Figure 3.16: Calculated average in-vehicle speed (miles/hour) of the first recalled trip by mode 


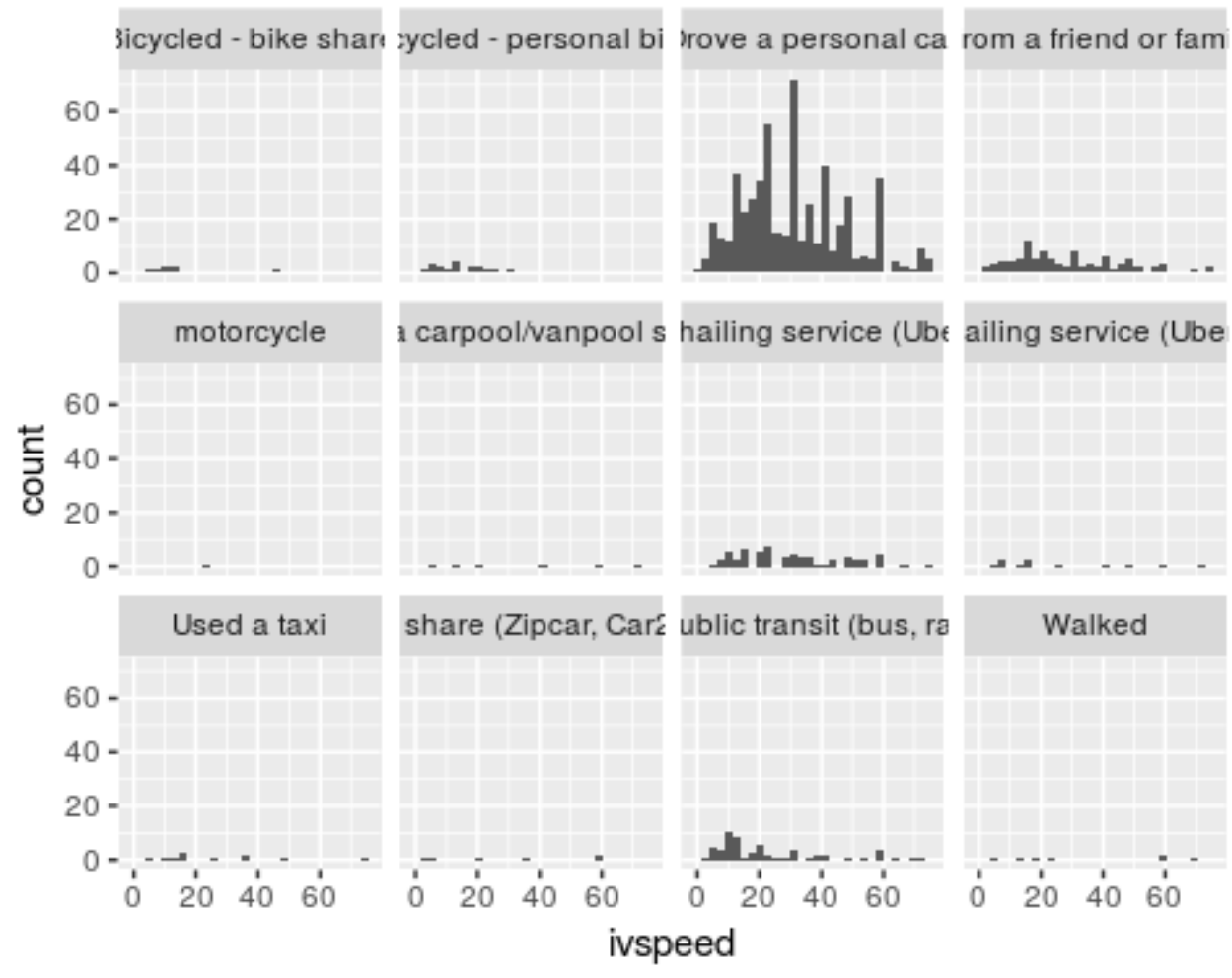

Figure 3.17: Calculated average in-vehicle speed (miles/hour) of the second recalled trip by mode

\subsection{DESCRIPTIVE STATISTICS OF STATED PREFERENCE (SP) CHOICE EXPERIMENTS}

Each of the 1,117 respondents was presented with two sets of five stated choice experiments. Consequently, 8,093 choices were captured after eliminating incomplete data and outliers, from which travelers' preference for attributes of travel options including emerging modes were inferred. Within each experiment, respondents were asked to compare the chosen mode of the recalled trip and its attributes against emerging mode alternatives, including one self-driving (AV) mode and one non-AV alternative. Where the chosen mode overlapped with the emerging mode alternatives, that option was removed as a potential alternative. Overall six modes were available to choose from in the SP experiments:

- $\quad$ Biking using shared bike

- Driving using car sharing vehicle

- $\quad$ Ride-hail service

- $\quad$ Ride-hail service shared with unknown passenger

- $\quad$ Self-driving car

- $\quad$ Self-driving car shared with unknown passenger

Four attributes including out-of-pocket cost and time (walking, waiting, and in-vehicle time when appropriate) of each mode are randomly sampled from pre-specified levels. 
Attribute levels of the emerging mode alternatives were set at random based on a combination of revealed trip characteristics, respondent location, and defined attribute ranges based on our review of estimated costs (self-driving modes) or currently offered services (other modes). Additional details of the experiment choice sets and attribute levels are provided in Section 2.1.1.

Each respondent was asked to indicate the mode they used for their recalled trips. The modes of the recalled trips included (Table 3.3):

- $\quad$ Bicycled - bike share

- $\quad$ Bicycled - personal bike

- Drove a personal car

- Got a ride from a friend or family member

- Used a carpool/vanpool service

- Used a ride hailing service (Uber/Lyft, etc.)

- Used a shared ride hailing service

- Used a taxi

- Used car share (Zipcar, Car2Go, etc.)

- Used public transit (bus, rail, etc.)

- Walked

If respondents used more than one transportation mode, the mode that respondents used for the longest distance on the trip was recorded as the main mode of the trip.

Figure 3.18 shows the share of SP mode by mode actually used for the recalled trips by trip purpose, and Table 3.4 shows the mode share of the SP choice experiments by trip purpose. Even though there were $73.6 \%$ of drivers and $65.1 \%$ of car passengers sticking to these modes, there would be substantial percentages of travelers shifting to use the emerging modes if they are available with the characteristics presented in the experiments. The proportions of drivers and car passengers who chose to use the same modes were higher than those of other modes. It seems drivers and car passengers have the highest inertia and are most likely to stick to their current modes. 


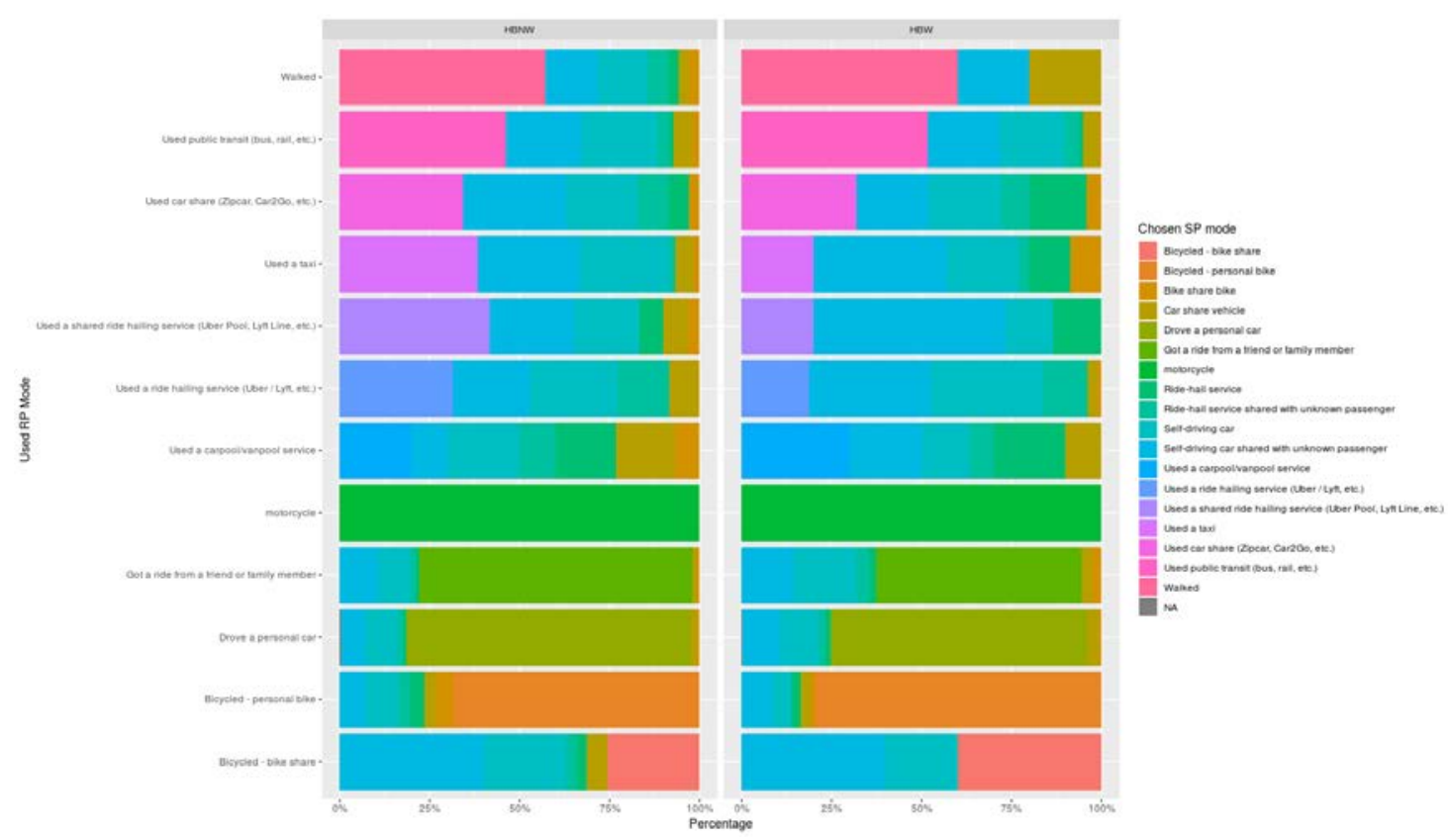

Figure 3.18: Share of SP mode by mode used for the recalled trips by trip purpose

Table 3.4: Mode share of SP choice experiments by trip purpose

\begin{tabular}{l|r|r|r|r}
\hline \multicolumn{1}{c|}{ Mode } & \multicolumn{1}{c|}{ HBNW } & \multicolumn{2}{c}{ HBW } \\
\hline Drove a personal car & \multicolumn{1}{c|}{ n } & \multicolumn{1}{c}{ \% } & \multicolumn{1}{c}{ n } & \multicolumn{1}{c}{$\%$} \\
\hline Self-driving car & 2535 & 52.6 & 1674 & 51.4 \\
\hline Self-driving car shared with unknown passenger & 558 & 11.6 & 436 & 13.4 \\
\hline Got a ride from a friend or family member & 495 & 10.3 & 417 & 12.8 \\
\hline Used public transit (bus, rail, etc.) & 449 & 9.3 & 278 & 8.5 \\
\hline Car share vehicle & 173 & 3.6 & 102 & 3.1 \\
\hline Ride-hail service shared with unknown passenger & 124 & 2.6 & 82 & 2.5 \\
\hline Used a ride hailing service (Uber/Lyft, etc.) & 120 & 2.5 & 63 & 1.9 \\
\hline Bicycled - personal bike & 94 & 1.9 & 61 & 1.9 \\
\hline Ride-hail service & 67 & 1.4 & 58 & 1.8 \\
\hline Bike share bike & 58 & 1.2 & 33 & 1 \\
\hline Used a shared ride hailing service (Uber Pool, Lyft & 50 & 1 & 15 & 0.5 \\
Line, etc.) & 25 & 0.5 & 9 & \\
\hline Used a taxi & 23 & 0.5 & 5 & 0.2 \\
\hline Walked & 20 & 0.4 & 7 & 0.2 \\
\hline Bicycled - bike share & 9 & 0.2 & 8 & 0.2 \\
\hline Used car share (Zipcar, Car2Go, etc.) & 12 & 0.2 & 2 & 0.1 \\
\hline Motorcycle & 5 & 0.1 & 3 & 0.1 \\
\hline Used a carpool/vanpool service & 6 & 0.1 & 3 & 0.1 \\
\hline
\end{tabular}


Overall, 20.2\% of drivers chose self-driving modes, including self-driving car and self-driving car shared with an unknown passenger, and 28.5\% of car passengers chose self-driving modes. Respondents who used ride-hailing service were most likely to select self-driving modes. Overall, 31.1\% and 33.3\% of ride-hailing service users chose self-driving car and self-driving car shared with an unknown passenger, respectively. There were certain proportions of all other modes users chose to use self-driving modes. For example, $40 \%$ of respondents who walked for their reference trip selected self-driving modes in the SP experiments. This implies that selfdriving modes would exert thorough impacts on traffic systems.

Compared to auto modes, only $20 \%$ of ride-hailing users and $40 \%$ of shared ride-hailing users chose to use their current modes. This indicates users of ride-hailing and shared ride-hailing services are more easily attracted to shift to other modes than auto modes users. Respondents who used car share (28.6\%) for their reference trips were most likely to select ride-hailing modes, followed by carpool/vanpool users (22.9\%), and taxi users (13.3\%). In general, the proportion of respondents who chose ride-hailing modes in the SP experiments is lower than self-driving modes. This implies that self-driving modes will be more popular than ride-hailing modes even though self-driving modes are not available yet.

There were $70 \%$ of respondents who used a personal bike for their reference trips and chose to still use a personal bike in the SP experiment, while there were only $40 \%$ of respondents who used bike share for their reference trips and chose to still use bike share in the SP experiment. This implies that bicycle ownership contributes to adoption of bike modes (personal bike and bike share). The proportions of users who stuck to original modes were low for car sharing users (28\%) and carpool/vanpool users (15\%), which means these modes users were likely to shift to other modes. 


\subsection{MODELING THE STATED PREFERENCE CHOICE EXPERIMENTS}

In this chapter, we develop models using the data from the stated preference choice experiments, along with information of the revealed preference recalled trips and socio-demographic characteristics of the survey respondents. The purpose of developing these models are twofolded:

1. Models allow researchers to understand the tradeoffs that survey respondents are making across different attributes (e.g., costs vs. time) when they choose among travel modes;

2. Models enable us to predict mode choices for individuals under different scenarios, which can be further aggregated into share for each available mode.

We use the random utility maximization framework as the theoretical foundation to model how an individual (survey respondent) chooses a choice among discrete modes (McFadden, 1981). The model suggests that individuals choose modes to maximize utility. In other words, individuals choose a mode where the utility associated with the mode exceeds the utility of all the other alternative modes. Utility of an individual $i$ choosing mode $m$ among the choice set of three modes can be represented by

$U_{i m}=V_{i m}+\epsilon_{i m}$ and $V_{i m}=\alpha X_{m}+\beta I_{i} X_{m}^{\prime}$,

where

- $U_{i m}$ is the utility of individual $i$ choosing mode $m$,

- $V_{i m}$ is the deterministic components of $U_{i m}$,

- $\epsilon_{i m}$ is the unobserved errors,

- $\quad \alpha$ and $\beta$ the coefficients to be estimated,

- $\quad X_{m}$ and $X_{m}^{\prime}$ are attributes of mode $m$, and

- $\quad I_{i}$ is socio-demographic characteristics of individual $i$.

Following the specification of a multinomial logit model (MNL) (Ben-Akiva and Lerman, 1987), we assume that the deterministic components $V_{i m}$ of the utility are linear-in-parameters with the attributes of modes.

In this paper, we only use indicator (dummy) variables for $I_{i}$, for example, HBW trip purpose variable indicating whether individual $i$ is making a HBW trip (1) or not (0). The interaction term $I_{i} X_{m}^{\prime}$, along with the estimated coefficient $\beta$, captures the difference in utilities for mode attribute $X_{m}^{\prime}$ between individuals making these two different types of trips. For example, we can capture the relative (dis-)utilities of employed individuals derived from out-of-pocket cost using the interaction term of employed and cost. If the coefficient of the interaction term is positive 
and significant, then employed individuals are more likely than the unemployed to choose modes with higher cost, everything else being the same.

Based on the utility maximization theory, the probability of an individual $i$ choosing a specific mode $k$ is represented by

$\operatorname{Pr}\left(Y_{i}=k\right)=\operatorname{Prob}\left(V_{i k}+\epsilon i k>V_{i m}+\epsilon_{i m}\right)$, for $k, m \in 1,2,3$, and $k \neq m$.

Assuming that the error term $\epsilon_{i m}$ follows an independent and identically distributed type I extreme value distribution, the probability of individual $i$ choosing $m$ is:

$\operatorname{Pr}\left(Y_{i}=k\right)=\frac{\exp \left(V_{i k}\right)}{\sum_{m=1}^{3} \exp \left(V_{i m}\right)}$

The parameters of $\alpha$ and $\beta$ in are estimated by maximizing the log likelihood function of the MNL:

$L L=\sum_{i=1}^{H} \sum_{k=1}^{M} d_{i k} \ln \left(\operatorname{Pr}\left(y_{i}=k\right)\right)$

(4-4)

where LL is the log likelihood function. $d_{i k}$ equals 1 if individual $i$ chooses mode $k$, and it equals 0 otherwise.

\subsection{THE BASE MODEL}

The base model only includes mode attributes in the model specification. $\beta I_{i} X_{m}^{\prime}$ in Equation 4-1 is not included in the base model specification. It is assumed that there is no heterogeneity among individuals in their preference when making mode choice decisions. This may be an unrealistic assumption, but the advantage of the base model is that it is the simplest to apply in predictions because it does not require socio-demographic characteristics or attitudinal information of individuals.

The variables in the model specification of the base model include out-of-pocket cost and travel time components (in-vehicle travel time, waiting time, and walking time), as well as a series of dummy variables for indicating attributes of a mode. The dummy variables include

- $\quad$ ride-hail, whether a mode is a rail-hailing service

- $\quad$ ride-share, whether a mode requires sharing a ride with an unknown passenger

- $\quad$ car-share, whether a mode uses car sharing

- $\quad$ bike-share, whether a mode uses bike sharing

- biking, whether a mode is biking, either using a personal bike or a bike sharing bike

Table 4.1 presents the model specification and estimate coefficients of the base model. All the coefficients are significant with an expected sign. Since in an MNL model the absolute size of each coefficient is not meaningful by itself, we derive and analyze the relative magnitude or ratio 
of the coefficients. Ratio of a coefficient to the cost coefficient are interpreted as the willingness to pay. The ratios of the time coefficients to the cost coefficient is a special type of willingness to pay - value of time (VOT), that is, the amount of money a traveler is willing to pay to save a unit of travel time.

Table 4.1: Model specification of the base model

\begin{tabular}{l|l}
\hline & $\begin{array}{l}\text { Base Model } \\
\text { Coeff (t-stat) }\end{array}$ \\
\hline ivmins & $-0.01(0.00)^{* * *}$ \\
\hline wait & $-0.06(0.00)^{* * *}$ \\
\hline walk & $-0.01(0.00)^{* * *}$ \\
\hline cost & $-0.07(0.00)^{* * *}$ \\
\hline ridehail & $-1.10(0.06)^{* * *}$ \\
\hline rideshare & $-0.77(0.04)^{* * *}$ \\
\hline carshare & $-1.73(0.07)^{* * *}$ \\
\hline biking & $0.64(0.19)^{* * *}$ \\
\hline biking:bikeshare & $-2.46(0.21)^{* * *}$ \\
\hline AIC & 12101.67 \\
\hline Log Likelihood & -6041.83 \\
\hline Num. obs. & 8079 \\
\hline$* * * p$ & $8.001,{ }^{* *} p<0.01,{ }^{*} p<0.05$ \\
\hline
\end{tabular}

Table 4.2 shows the VOT and willingness to pay derived from the base model. In-vehicle travel time (ivtt) has a value of time of $\$ 10.81 /$ hour, while waiting time and walking time have a value of time of $\$ 47.57 /$ hour and $\$ 9.23 /$ hour, respectively. All are in a reasonable range, even though the VOT for walking time is generally expected to be higher than that for ivtt.

The willingness to accept (pay) for using ride hailing, ride-sharing, bike sharing, and car sharing are high in the range of \$11-35. That is, comparing ride hailing services and another mode with the same travel time components, the ride hailing service needs to lower the out-of-pocket cost by $\$ 15.71$ for it to provide the same utility as the other mode. According to the modeling results, for biking mode, the bike sharing program needs to provide a cost savings of $\$ 35$ for it to be competitive as a personal bike, which seems extreme. It should be noted that given the experiment's design, dummy coefficients for emerging modes likely also capture general inertia effects with regard to switching from a current mode. 
Table 4.2: Value of time and willingness to pay derived from the base model

\begin{tabular}{l|r|l}
\hline \multicolumn{1}{c|}{ Type } & WTP & \multicolumn{1}{c}{ Unit } \\
\hline ivtt & 10.81 & $\$$ /hour \\
\hline waiting time & 47.57 & $\$$ /hour \\
\hline walking time & 9.23 & $\$ /$ hour \\
\hline ride hailing & 15.71 & $\$$ \\
\hline ride share & 11.02 & $\$$ \\
\hline bike sharing & 35.17 & $\$$ \\
\hline car sharing & 24.70 & $\$$ \\
\hline
\end{tabular}

\subsection{THE FULL MODEL}

In the full model, $\beta I_{i} X^{\prime}{ }_{m}$ in Equation 4-1 is included in the model specification to reflect heterogeneity among individuals in their preference when making mode choice decisions. Table 4.3 presents the model specification and estimated coefficients of the full model. We tested a number of different socio-demographic dummy variables interacting with mode-specific attributes, but only kept those with at least some significant coefficients for the interaction terms. The coefficients for the interaction term read as the relative difference in utility from the modespecific attribute for the population subgroup identified by the socio-demographic dummy variable. For example, the coefficient for is for the interaction between employed and cost, which is positive and significant $(\mathrm{p}<0.01)$ at 0.18 . The overall population has a cost coefficient of -0.29 , while the cost coefficient for the employed is $-0.11(=-0.29+0.18)$. Table 4.4 shows the VOT and willingness to pay for the overall population, while Table 4.5 presents those for the employed. Note that VOT and willingness to pay for variables whose coefficients are not statistically significant are not calculated.

Table 4.3: Model specification of the full model

\begin{tabular}{l|l}
\hline & $\begin{array}{l}\text { Full Model } \\
\text { Coeff (t-stat) }\end{array}$ \\
\hline ivmins & $0.04(0.02)$ \\
\hline wait & $-0.04(0.01)^{* *}$ \\
\hline walk & $0.00(0.02)$ \\
\hline cost & $-0.29(0.03)^{* * *}$ \\
\hline ridehail & $-0.38(0.28)$ \\
\hline rideshare & $-0.61(0.19)^{* *}$ \\
\hline carshare & $-2.05(0.55)^{* * *}$ \\
\hline biking & $-0.34(0.65)$ \\
\hline biking:bikeshare & $-2.41(0.24)^{* * *}$ \\
\hline ivmins:purpHBW & $0.01(0.01)$ \\
\hline wait:purpHBW & $0.01(0.01)$ \\
\hline walk:purpHBW & $-0.01(0.00)^{*}$ \\
\hline cost:purpHBW & $-0.01(0.00)^{*}$ \\
\hline &
\end{tabular}




\begin{tabular}{|c|c|}
\hline & Full Model Coef \\
\hline ridehail:purpHBW & $0.04(0.12)$ \\
\hline rideshare:purpHBW & $0.22(0.09)^{*}$ \\
\hline carshare:purpHBW & $0.30(0.15)^{*}$ \\
\hline biking:purpHBW & $0.31(0.22)$ \\
\hline ivmins:studentStudent & $0.01(0.01)^{*}$ \\
\hline wait:studentStudent & $0.03(0.01)^{* * *}$ \\
\hline walk:studentStudent & $0.02(0.00)^{* * *}$ \\
\hline cost:studentStudent & $0.10(0.01)^{* * *}$ \\
\hline ridehail:studentStudent & $0.02(0.12)$ \\
\hline rideshare:studentStudent & $0.09(0.09)$ \\
\hline carshare:studentStudent & $0.03(0.15)$ \\
\hline biking:studentStudent & $0.57(0.22)^{* *}$ \\
\hline ivmins:genderFemale & $-0.02(0.01)^{*}$ \\
\hline wait:genderFemale & $-0.00(0.01)$ \\
\hline walk:genderFemale & $-0.02(0.00)^{* * *}$ \\
\hline cost:genderFemale & $-0.02(0.01)^{* * *}$ \\
\hline ridehail:genderFemale & $0.48(0.12)^{* * *}$ \\
\hline rideshare:genderFemale & $-0.13(0.09)$ \\
\hline carshare:genderFemale & $0.28(0.15)$ \\
\hline biking:genderFemale & $-0.17(0.23)$ \\
\hline ivmins:low_income & $0.00(0.01)$ \\
\hline wait:low_income & $0.00(0.01)$ \\
\hline walk:low_income & $-0.01(0.01)$ \\
\hline cost:low_income & $-0.08(0.01)^{* * *}$ \\
\hline ridehail:low_income & $0.66(0.13)^{* * *}$ \\
\hline rideshare:low_income & $0.06(0.10)$ \\
\hline carshare:low_income & $0.21(0.18)$ \\
\hline biking:low_income & $-0.01(0.25)$ \\
\hline ivmins:minority & $-0.01(0.01)$ \\
\hline wait:minority & $-0.01(0.01)$ \\
\hline walk:minority & $-0.01(0.01)^{*}$ \\
\hline cost:minority & $0.00(0.00)$ \\
\hline ridehail:minority & $0.03(0.12)$ \\
\hline rideshare:minority & $0.29(0.09)^{* *}$ \\
\hline carshare:minority & $-0.03(0.16)$ \\
\hline biking:minority & $0.01(0.24)$ \\
\hline ivmins:employed & $-0.05(0.02)^{*}$ \\
\hline wait:employed & $-0.04(0.01)^{*}$ \\
\hline walk:employed & $-0.02(0.01)$ \\
\hline cost:employed & $0.18(0.03)^{* * *}$ \\
\hline ridehail:employed & $-1.07(0.27)^{* * *}$ \\
\hline rideshare:employed & $-0.29(0.18)$ \\
\hline carshare:employed & $0.18(0.54)$ \\
\hline
\end{tabular}




\begin{tabular}{l|l}
\hline & Full Model Coeff \\
\hline biking:employed & $0.66(0.61)$ \\
\hline AIC & 11090.48 \\
\hline Log Likelihood & -5488.24 \\
\hline Num. obs. & 7980 \\
\hline$* * * \boldsymbol{p}<\mathbf{0 . 0 0 1 , * * p}<0.01,{ }^{*} \mathrm{p}<0.05$ \\
\hline
\end{tabular}

Table 4.4: Value of time and willingness to pay derived from the full model

\begin{tabular}{l|r|l}
\hline \multicolumn{1}{c|}{ Type } & WTP & \multicolumn{1}{|c}{ Unit } \\
\hline waiting time & 8.55 & $\$ /$ hour \\
\hline ride share & 2.08 & $\$$ \\
\hline bike sharing & 8.25 & $\$$ \\
\hline car sharing & 7.00 & $\$$ \\
\hline
\end{tabular}

Table 4.5: Value of time and willingness to pay derived from the full model for employed individuals

\begin{tabular}{l|r|r}
\hline \multicolumn{1}{c|}{ Type } & WTP & \multicolumn{1}{c}{ Unit } \\
\hline ivtt & 27.96 & $\$ /$ hour \\
\hline waiting time & 41.82 & $\$ /$ hour \\
\hline ride hailing & 9.71 & $\$$ \\
\hline ride share & 5.53 & $\$$ \\
\hline bike sharing & 21.90 & $\$$ \\
\hline car sharing & 18.59 & $\$$ \\
\hline
\end{tabular}

\subsection{INCORPORATION INTO RSPM TOOLS}

The emerging modes are being incorporated into the VETravelDemand module for RSPM. The code is released as an open-source repository on GitHub:

https://github.com/cities/VETravelDemand. The VETravelDemandMM module is an R package that implements a module for RSPM to simulate multimodal travel demand for individual households. The original motivations of developing the new package includes better policy sensitivities for non-driving modes and taking advantage of newer and better data sources available since the implementation of the RSPM/GreenSTEP model. This project adds the capacity for the module to simulate mode shift with the emerging modes.

\subsection{FUTURE RESEARCH}

There are two modeling tasks left for future research. The first is to incorporate attitudinal information in the MNL models. The survey questionnaire includes various attitudinal information towards travel, various modes, and technology. According to the literature, these attitudinal variables are powerful in explaining the mode choice behavior. We do not include mode specification with attitudinal variables in this chapter because attitudinal variables are difficult to use in prediction applications. The second is to test possible better model structure. 
Since each respondent in the survey completed multiple choice experiments, theoretically the experiments completed by the same respondent are likely to share some characteristics that may be unobserved by the researcher. A better model structure that addresses this is the mixed logit model (MXL). The downside of MXL models is that they are computationally more expensive. 


\subsection{REFERENCES}

Agatz, N. A. H., Erera, A. L., Savelsbergh, M. W. P., \& Wang, X. (2011). Dynamic ride-sharing: A simulation study in metro Atlanta. Transportation Research Part B: Methodological, 45(9), 1450-1464. https://doi.org/10.1016/j.trb.2011.05.017

Akar, G., \& Clifton, K. (2009). Influence of individual perceptions and bicycle infrastructure on decision to bike. Transportation Research Record: Journal of the Transportation Research Board, (2140), 165-172.

Anderson, J. M., Nidhi, K., Stanley, K. D., Sorensen, P., Samaras, C., \& Oluwatola, O. A. (2014). Autonomous Vehicle Technology: A Guide for Policymakers. Rand Corporation.

Bansal, P., \& Kockelman, K. M. (2017). Forecasting Americans’ long-term adoption of connected and autonomous vehicle technologies. Transportation Research Part A: Policy and Practice, 95, 49-63. https://doi.org/10.1016/j.tra.2016.10.013

Bansal, P., \& Kockelman, K. M. (2017). Forecasting Americans’ long-term adoption of connected and autonomous vehicle technologies. Transportation Research Part A: Policy and Practice, 95, 49-63. https://doi.org/10.1016/j.tra.2016.10.013

Ben-Akiva, M., Lerman, S.R., 1987. Discrete Choice Analysis: Theory and Application to Travel Demand. The MIT Press, Cambridge, Massachusetts.

Bialik, C., Flowers, A., Fischer-Baum, R., \& Mehta, D. (2015, August 10). Uber Is Serving New York’s Outer Boroughs More Than Taxis Are. Retrieved August 26, 2017, from https://fivethirtyeight.com/features/uber-is-serving-new-yorks-outer-boroughs-more-than-taxisare/

Bösch, P. M., Becker, F., Becker, H., \& Axhausen, K. W. (2018). Cost-based analysis of autonomous mobility services. Transport Policy, 64, 76-91

Buck, D., Buehler, R., Happ, P., Rawls, B., Chung, P., Borecki, N., 2013. Are Bikeshare Users Different from Regular Cyclists?: A First Look at Short-Term Users, Annual Members, and Area Cyclists in the Washington, D.C., Region. Transportation Research Record: Journal of the Transportation Research Board 2387, 112-119. doi:10.3141/2387-13

Buliung, R. N., Soltys, K., Bui, R., Habel, C., \& Lanyon, R. (2010). Catching a ride on the information super-highway: toward an understanding of internet-based carpool formation and use. Transportation, 37(6), 849-873. 
Burkhardt, J., Millard-Ball, A., 2006. Who Is Attracted to Carsharing? Transportation Research Record: Journal of the Transportation Research Board 1986, 98-105. doi:10.3141/1986-15.

Burns, L. D., W. Jordan and B. Scarborough (2013). Transforming personal mobility, Technical Report, The Earth Institute, Columbia University.

Canning, P. E., Hughes, S. J., Hellawell, E. E., Gatersleben, B. C. M., \& Fairhead, C. J. (2010). Reasons for participating in formal employer-led carpool schemes as perceived by their users. Transportation Planning and Technology, 33(8), 733-745.

Cartenì, A., Cascetta, E., \& de Luca, S. (2016). A random utility model for park \& carsharing services and the pure preference for electric vehicles. Transport Policy, 48, 49-59. https://doi.org/10.1016/j.tranpol.2016.02.012

Chan, N. D., \& Shaheen, S. A. (2012). Ridesharing in North America: Past, Present, and Future. Transport Reviews, 32(1), 93-112. https://doi.org/10.1080/01441647.2011.621557

Charles, K. K., \& Kline, P. (2006). Relational costs and the production of social capital: evidence from carpooling. The Economic Journal, 116(511), 581-604.

Ciari, F., \& Axhausen, K. W. (2012, January). Choosing carpooling or carsharing as a mode: Swiss stated choice experiments. In 91st Annual Meeting of the Transportation Research Board, Washington, DC.

Cline, M., Sparks, C., \& Eschbach, K. (2009). Understanding carpool use by Hispanics in Texas. Transportation Research Record: Journal of the Transportation Research Board, (2118), 39-46.

Concas, S., Winters, P., \& Wambalaba, F. (2005). Fare Pricing Elasticity, Subsidies, and Demand for Vanpool Services. Transportation Research Record: Journal of the Transportation Research Board, 1924, 215-223. https://doi.org/10.3141/1924-27

Correia, G., \& Viegas, J. M. (2011). Carpooling and carpool clubs: Clarifying concepts and assessing value enhancement possibilities through a Stated Preference web survey in Lisbon, Portugal. Transportation Research Part A: Policy and Practice, 45(2), 81-90. https://doi.org/10.1016/j.tra.2010.11.001

Dawes, M. (2016). Perspectives on the Ridesourcing Revolution: surveying individual attitudes toward Uber and Lyft to inform urban transportation policymaking. Massachusetts Institute of Technology.

de Luca, S., \& Di Pace, R. (2015). Modelling users’ behaviour in inter-urban carsharing program: A stated preference approach. Transportation Research Part A: Policy and Practice, 71, 59-76. https://doi.org/10.1016/j.tra.2014.11.001

DeLoach, S. B., \& Tiemann, T. K. (2012). Not driving alone? American commuting in the twenty-first century. Transportation, 39(3), 521-537. 
Eiró, T., and L.M. Martínez, 2014. Analyzing Impacts of New Shared Transport Alternatives in an Urban Mobility System, paper presented at the the Transportation Research Board 93rd Annual Meeting (No. 14-3237).

Eriksson, L., Friman, M., \& Gärling, T. (2008). Stated reasons for reducing work-commute by car. Transportation Research Part F: Traffic Psychology and Behaviour, 11(6), 427-433.

Ewing, R. (1993). TDM, Growth Management and the other 4 out of 5 trips. Transportation Quarterly, 47(3), 343-366.

Fagnant, D. J., \& Kockelman, K. M. (2014). The travel and environmental implications of shared autonomous vehicles, using agent-based model scenarios. Transportation Research Part C: Emerging Technologies, 40, 1-13.

Fagnant, D. J., \& Kockelman, K. (2015). Preparing a nation for autonomous vehicles: opportunities, barriers and policy recommendations. Transportation Research Part A: Policy and Practice, 77, 167-181. https://doi.org/10.1016/j.tra.2015.04.003

Ferguson, E. (1995). Demographics of carpooling. Transportation Research Record, 142-150.

Ferguson, E. (1997). The rise and fall of the American carpool: 1970-1990. Transportation, 24(4), 349-376. https://doi.org/10.1023/A:1004928012320

Fischer-Baum, R., \& Bialik, C. (2015). Uber Is Taking Millions Of Manhattan Rides Away From Taxis. Retrieved August 26, 2017, from https:/fivethirtyeight.com/features/uber-is-takingmillions-of-manhattan-rides-away-from-taxis/

Fishman, E., Washington, S., \& Haworth, N. (2013). Bike share: a synthesis of the literature. Transport reviews, 33(2), 148-165.

Fishman, E. (2016). Bikeshare: A review of recent literature. Transport Reviews, 36(1), 92-113.

Flegenheimer, M., \& Fitzsimmons, E. G. (2015, July 16). City Hall and Uber Clash in Struggle Over New York Streets. The New York Times. Retrieved from https://www.nytimes.com/2015/07/17/nyregion/city-hall-and-uber-clash-in-struggle-over-newyork-streets.html

Fraedrich, E., Heinrichs, D., Bahamonde-Birke, F. J., \& Cyganski, R. (2018). Autonomous driving, the built environment and policy implications. Transportation Research Part A: Policy and Practice. https://doi.org/10.1016/j.tra.2018.02.018

Furuhata, M., Dessouky, M., Ordóñez, F., Brunet, M.-E., Wang, X., \& Koenig, S. (2013). Ridesharing: The state-of-the-art and future directions. Transportation Research Part B: Methodological, 57, 28-46. https://doi.org/10.1016/j.trb.2013.08.012

Gardner, B., \& Abraham, C. (2007). What drives car use? A grounded theory analysis of commuters' reasons for driving. Transportation Research Part F: Traffic Psychology and Behaviour, 10(3), 187-200. https://doi.org/10.1016/j.trf.2006.09.004 
Gärling, T., Gärling, A., \& Johansson, A. (2000). Household choices of car-use reduction measures. Transportation Research Part A: Policy and Practice, 34(5), 309-320.

Giuliano, G., Hall, R., \& Golob, J. (1995). Los Angeles Smart Traveler Field Operational Test Evaluation. Retrieved from http://escholarship.org/uc/item/8xq8558z.pdf

Giuliano, G., Hwang, K., \& Wachs, M. (1993). Employee trip reduction in Southern California: First year results. Transportation Research Part A: Policy and Practice, 27(2), 125-137.

Haustein, S. (2012). Mobility behavior of the elderly: an attitude-based segmentation approach for a heterogeneous target group. Transportation, 39(6), 1079-1103.

Henao, A. (2017). Impacts of Ridesourcing - Lyft and Uber - on Transportation Including VMT, Mode Replacement, Parking, and Travel Behavior (Ph.D.). University of Colorado at Denver, United States -- Colorado. Retrieved from https://search.proquest.com/docview/1899208739/abstract/6E5352991A3C4020PQ/1

Howard, D., \& Dai, D. (2014). Public perceptions of self-driving cars: The case of Berkeley, California. In Transportation Research Board 93rd Annual Meeting (Vol. 14).

Hwang, K., \& Giuliano, G. (1990). The determinants of ridesharing: Literature review. Retrieved from http://escholarship.org/uc/item/3r91r3r4.pdf

J.D. Power. (2015). Automotive Emerging Technologies Study Results.

J.D. Power. (2017, April 17). 2017 U.S. Tech Choice Study [Text]. Retrieved August 16, 2018, from http://www.jdpower.com/business/press-releases/jd-power-2017-us-tech-choice-study

Jacobson, S. H., \& King, D. M. (2009). Fuel saving and ridesharing in the US: Motivations, limitations, and opportunities. Transportation Research Part D: Transport and Environment, 14(1), 14-21.

Johnson, B. (2015). Disruptive mobility, Research Report, Barclays. Accessed at https://www.investmentbank.barclays.com/content/dam/barclaysmicrosites/ibpublic/documents/i nvestment-bank/global-insights/barclays-disruptive-mobility-pdf-120115-459kb.pdf

Johnson, C. and J. Walker. (2016). Peak car ownership, Research Report, Rocky Mountain Institute. Accessed at https://rmi.org/wpcontent/uploads/2017/03/Mobility_PeakCarOwnership_Report2017.pdf

Kopp, J., Gerike, R., \& Axhausen, K. W. (2015). Do sharing people behave differently? An empirical evaluation of the distinctive mobility patterns of free-floating car-sharing members. Transportation, 42(3), 449-469. https://doi.org/10.1007/s11116-015-9606-1 
Kwon, J., \& Varaiya, P. (2008). Effectiveness of California’s High Occupancy Vehicle (HOV) system. Transportation Research Part C: Emerging Technologies, 16(1), 98-115.

https://doi.org/10.1016/j.trc.2007.06.008

Krueger, R., Rashidi, T. H., \& Rose, J. M. (2016). Preferences for shared autonomous vehicles. Transportation Research Part C: Emerging Technologies, 69, 343-355. https://doi.org/10.1016/j.trc.2016.06.015

Kyriakidis, M., Happee, R., \& de Winter, J. C. (2015). Public opinion on automated driving: Results of an international questionnaire among 5000 respondents. Transportation Research Part F: Traffic Psychology and Behaviour, 32, 127-140.

Levine, J., Zellner, M., Shiftan, Y., Arquero de Alarcon, M., \& Diffenderfer, A. (2013). Effects of Automated Transit, Pedestrian, and Bicycling Facilities on Urban Travel Patterns. Retrieved from https://trid.trb.org/view.aspx?id=1361372

Levin, M. W., \& Boyles, S. D. (2015). Effects of autonomous vehicle ownership on trip, mode, and route choice. Transportation Research Record: Journal of the Transportation Research Board, (2493), 29-38.

Litman, T. (2014). Autonomous vehicle implementation predictions. Victoria Transport Policy Institute, 28. Retrieved from http://sh.st/st/787f28ed3e745c14417e4aec27303038/http://www.vtpi.org/avip.pdf

Litman, T. (2017). Autonomous vehicle implementation predictions. Victoria, Canada: Victoria Transport Policy Institute. Accessed at http://www.vtpi.org/avip.pdf

McFadden, D., 1981. Econometric Models of Probabilistic Choice, in: Manski, C., McFadden, D. (Eds.), Structural Analysis of Discrete Data with Econometric Applications. MIT Press, Cambridge, MA, pp. 198-272.

McNeil, N., Dill, J., MacArthur, J., Broach, J., \& Howland, S. (2017). Breaking Barriers to Bike Share: Insights from Residents of Traditionally Underserved Neighborhoods. Accessed at https://pdxscholar.library.pdx.edu/cgi/viewcontent.cgi?article=1140\&context=trec_reports

Menczer, W. B. (2007). Guaranteed ride home programs: A study of program characteristics, utilization, and cost. Journal of Public Transportation, 10(4), 7.

Meyer, M. D. (1999). Demand management as an element of transportation policy: using carrots and sticks to influence travel behavior. Transportation Research Part A: Policy and Practice, 33(7), 575-599. https://doi.org/10.1016/S0965-8564(99)00008-7

Milakis, D., van Arem, B., \& van Wee, B. (2017). Policy and society related implications of automated driving: A review of literature and directions for future research. Journal of Intelligent Transportation Systems, 21(4), 324-348. https://doi.org/10.1080/15472450.2017.1291351 
Morency, C. (2007). The ambivalence of ridesharing. Transportation, 34(2), 239-253.

https://doi.org/10.1007/s11116-006-9101-9

Neoh, J. G., Chipulu, M., \& Marshall, A. (2017). What encourages people to carpool? An evaluation of factors with meta-analysis. Transportation, 44(2), 423-447.

https://doi.org/10.1007/s11116-015-9661-7

Murphy, C. (2016). Shared Mobility and the Transformation of Public Transit. Retrieved from https://trid.trb.org/view.aspx?id=1401765

Ozanne, L., \& Mollenkopf, D. (1999). Understanding consumer intentions to carpool: a test of alternative models. In Proceedings of the 1999 annual meeting of the Australian \& New Zealand Marketing Academy. smib. vuw. ac. nz (Vol. 8081). Retrieved from http://anzmac.org/conference_archive/1999/Site/O/Ozanne.pdf

Pew Research Center, October, 2017, “Automation in Everyday Life.” Accessed at http://assets.pewresearch.org/wpcontent/uploads/sites/14/2017/10/03151500/PI_2017.10.04_Automation_FINAL.pdf

Rayle, L., Dai, D., Chan, N., Cervero, R., \& Shaheen, S. (2016). Just a better taxi? A surveybased comparison of taxis, transit, and ridesourcing services in San Francisco. Transport Policy, 45, 168-178

Rosen, L. D., Whaling, K., Carrier, L. M., Cheever, N. A., \& Rokkum, J. (2013). The media and technology usage and attitudes scale: An empirical investigation. Computers in human behavior, 29(6), 2501-2511.

Schaefers, T. (2013). Exploring carsharing usage motives: A hierarchical means-end chain analysis. Transportation Research Part A: Policy and Practice, 47, 69-77.

https://doi.org/10.1016/j.tra.2012.10.024

Schoettle, B., \& Sivak, M. (2014). A survey of public opinion about autonomous and self-driving vehicles in the US, the UK, and Australia.

Shaheen, S. A., Chan, N. D., \& Micheaux, H. (2015). One-way carsharing's evolution and operator perspectives from the Americas. Transportation, 42(3), 519-536.

Shaheen, S., Chan, N., \& Rayle, L. (2017). Ridesourcing’s Impact and Role in Urban Transportation. Retrieved from http://www.accessmagazine.org/wpcontent/uploads/sites/7/2017/05/Shaheen-Rayle-and-Chan-Access-Spring-2017.pdf

Shirgaokar, M. (2017). Which Barriers Prevent Seniors from Accessing Transportation Network Company (TNC) Services? Identifying Ways Forward for a Gendered Policy Approach. Retrieved from http://docs.trb.org/prp/17-04921.pdf

Shoup, D. C. (1997). Evaluating the effects of cashing out employer-paid parking: Eight case studies. Transport Policy, 4(4), 201-216. https://doi.org/10.1016/S0967-070X(97)00019-X 
Singleton, P. A. (2018). Discussing the "positive utilities" of autonomous vehicles: will travellers really use their time productively? Transport Reviews, 0(0), 1-16.

https://doi.org/10.1080/01441647.2018.1470584

Sommer, K. (2013). Continental mobility study 2011. Continental AG Http://www. ContinentalCorporation.

com/www/download/pressportal_com_en/themes/initiatives/channel_mobility_study_en/ov_mob ility_study2013_en/download_channel/pres_mobility_study_en. Pdf.

Stephens, T., J. Gonder, Y. Chen, Z. Lin, C. Liu and D. Gohlke. (2016). Estimated bounds and important factors for fuel use and consumer costs of connected and automated vehicles, Technical Report, National Renewable Energy Laboratory, U.S. Department of Energy, Golden, CO, Nov. 2016. Accessed at https://www.osti.gov/servlets/purl/1334242

Teal, R. F. (1987). Carpooling: who, how and why. Transportation Research Part A: General, 21(3), 203-214.

Schweizer, J. \& Meggs, J. (n.d.). PRT Mode Share Estimations Using a Direct Demand Stated Preference Method. Urban Public Transportation Systems 2013. https://doi.org/10.1061/9780784413210.001

U.S. Department of Transportation, Federal Highway Administration, 2009 National Household Travel Survey [NHTS 2009]. URL: https://nhts.ornl.gov.

Victoria Transport Policy Institute. (2017). Online TDM Encyclopedia: Ridesharing. Retrieved August 1, 2017, from https://www.vtpi.org/tdm/tdm34.htm

Wambalaba, F. W., Concas, S., \& Chavarria, M. (2004). Price Elasticity of Rideshare:

Commuter Fringe Benefits for Vanpools. Center for Urban Transportation Research at the University of South Florida. Retrieved from http://erepo.usiu.ac.ke/handle/11732/388

Wielinski, G., M. Trepanier and C. Morency, 2015. What About Free-Floating Carsharing? A Look at the Montreal Case. In Transportation Research Board 94th Annual Meeting (No. 153865).

York, B., \& Fabricatore, D. (2003). Puget Sound Vanpool Market Action Plan (Draft). Office of Urban Mobility, WSDOT (www. Wsdot. Wa. gov). [Available at Www. Vtpi. org/VanpoolMAPReport. Pdf].

Zacharias, J., \& Li, X. (2016). Shifting from Metro to Sustainable Surface Modes for ShortDistance Travel. Transportation Research Record: Journal of the Transportation Research Board, (2541), 38-45.

Zmud, J., Sener, I. N., \& Wagner, J. (2016). Self-driving vehicles: Determinants of adoption and conditions of usage. Transportation Research Record: Journal of the Transportation Research Board, (2565), 57-64. 


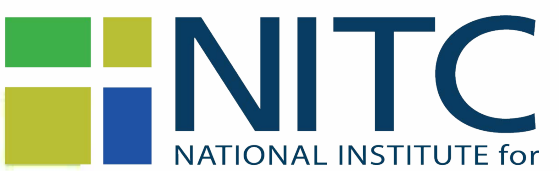

TRANSPORTATION and COMMUNITIES

Transportation Research and Education Center

Portland State University

1900 S.W. Fourth Ave., Suite 175

Portland, OR 97201 